Aus der Klinik für Psychiatrie und Psychotherapie

(Prof. Dr. med. J. Wiltfang)

der Medizinischen Fakultät der Universität Göttingen

\title{
Prävalenz bakterieller Infektionen bei psychiatrischen Erkrankungen - \\ Zusammenhänge mit Alter, Verweildauer und F-Diagnosen
}

\author{
INAUGURAL-DISSERTATION \\ zur Erlangung des Doktorgrades \\ der Medizinischen Fakultät der \\ Georg-August-Universität zu Göttingen
}

vorgelegt von

Nico Sebastian Rehling

aus

Hamburg

Göttingen 2018 
Dekan:

Referent/in:

Ko-Referent/in:

Drittreferent/in:
Prof. Dr. rer. nat. H. K. Kroemer

Prof. Dr. J. Wiltfang

Datum der mündlichen Prüfung: 
Hiermit erkläre ich, die Dissertation mit dem Titel "Prävalenz bakterieller Infektionen bei psychiatrischen Erkrankungen Zusammenhänge mit Alter, Verweildauer und F-Diagnosen" eigenständig angefertigt und keine anderen als die von mir angegebenen Quellen und Hilfsmittel verwendet zu haben.

Göttingen, den 


\section{Inhaltsverzeichnis}

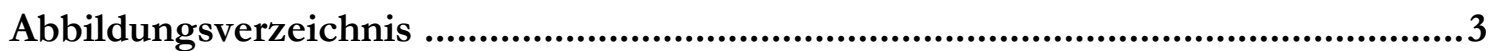

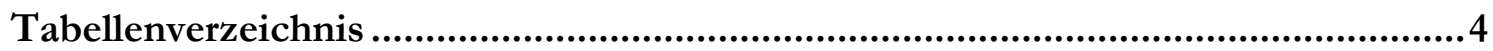

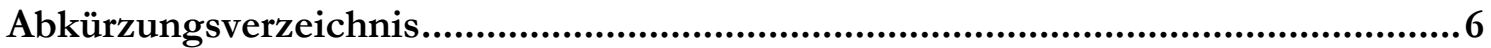

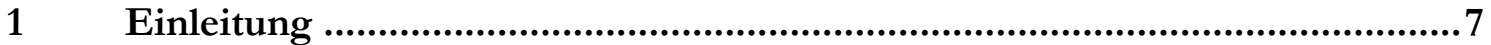

1.1 Durchschnittliche stationäre Verweildauer psychiatrischer Patienten ......................................... 8

1.2 Auswirkungen bakterieller Infektionen auf die Verweildauer und die Kosten .........................9

1.2.1 Entstehung und Verbreitung einer bakteriellen Flora im Krankenhaus ...................................

1.2.2 Prävalenz nosokomialer Infektionen..................................................................................10

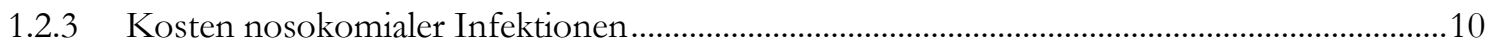

1.2.4 Verweildauer aufgrund nosokomialer Infektionen ..............................................................11

1.3 Die häufigsten nosokomialen Infektionen und ihre Erreger ...................................................12

1.3.1 Anteil der multiresistenten Erreger an nosokomialen Infektionen in Deutschland...............12

1.4 Präventions- und Kontrollmaßnahmen zur Eindämmung von Infektionen............................13

1.5 Auswirkung des Alters auf das Immunsystem und auf die Infektionsanfälligkeit...................14

1.6 Zusammenhänge zwischen psychischen Erkrankungen und Infektionen................................15

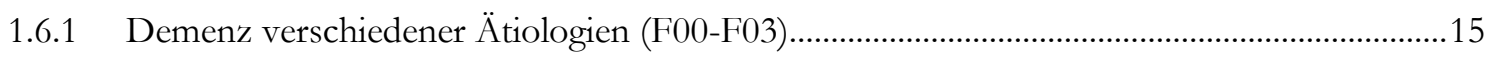

1.6.2 Psychische und Verhaltensstörungen durch Alkohol (F10) ...................................................16

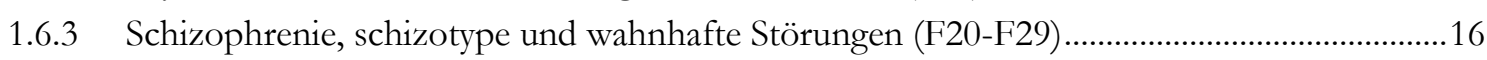

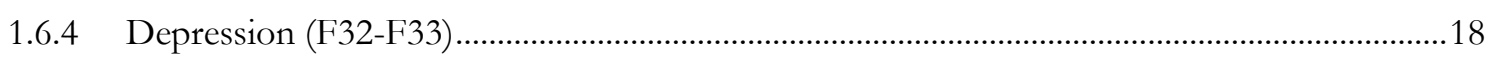

$1.7 \quad$ Fragestellung / Hypothesen ................................................................................................

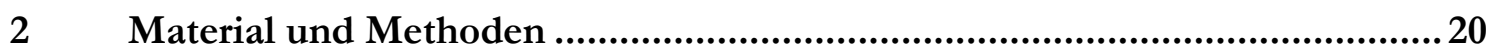

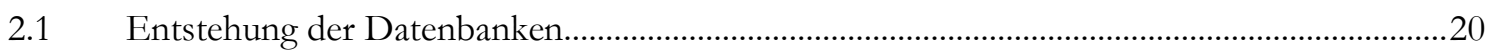

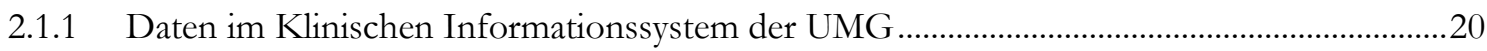

2.1.2 Daten im M/Lab® des Mikrobiologischen Instituts.............................................................20

2.2 Erhebung des Datensatzes (Einschluss/Ausschlusskriterien) ………………………………...21

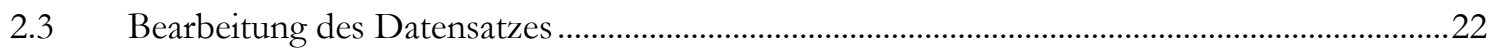

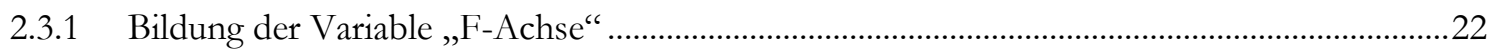

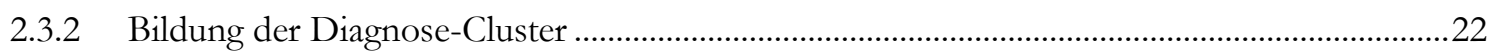

2.3.3 Bildung der Keimfamilien ........................................................................................................2

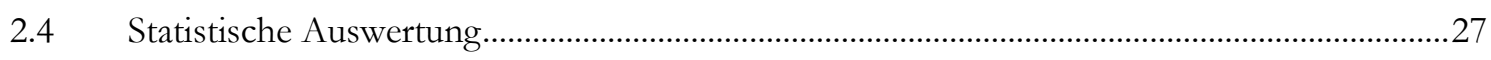

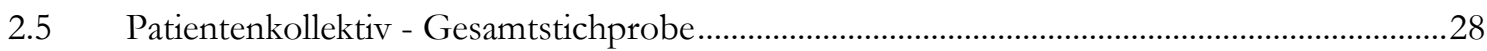

2.5.1 Untergruppe des Patientenkollektivs - positiv getestete Patienten.............................................30

2.5.2 Untergruppe des Patientenkollektivs - negativ getestete Patienten .............................................32

2.5.3 Untergruppe des Patientenkollektivs - nicht getestete Patienten..............................................33

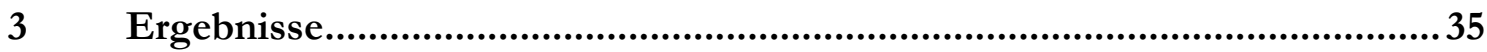

3.1 Mikrobiologische Untersuchung und Verweildauer ....................................................................35

3.1.1 Mikrobiologische Untersuchung und Verweildauer bei positiv, negativ und nicht getesteten Patienten (Hypothese 1)..... 
3.1.2 Mikrobiologische Untersuchung und Verweildauer innerhalb der gebildeten Cluster

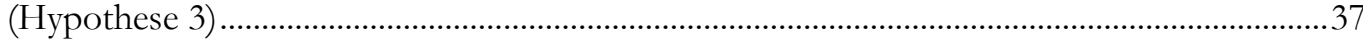

3.2 Mikrobiologische Untersuchung und Alter in Jahren.............................................................39

3.2.1 Mikrobiologische Untersuchung und Alter in Jahren bei positiv, negativ und nicht getesteten Patienten (Hypothese 2) ........................................................................................

3.2.2 Mikrobiologische Untersuchung und Alter in Jahren innerhalb der gebildeten Cluster

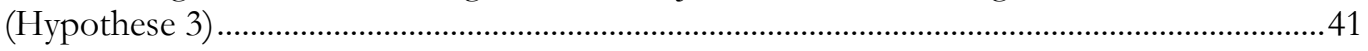

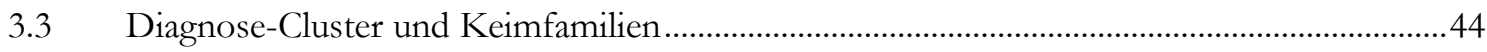

3.4 Quotenverhältnisse für die Diagnose-Cluster innerhalb der Bakterienfamilie

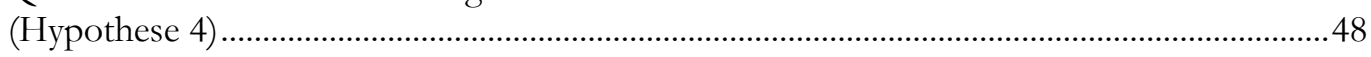

3.4.1 Einfluss von Lebensalter auf das Risiko einer bakteriellen Infektion bei Demenzpatienten

4 Diskussion. 53

4.1 Mikrobiologische Untersuchung und Verweildauer (Hypothese 1)

4.1.1 Mikrobiologische Untersuchung und Verweildauer bei positiv, negativ und nicht getesteten Patienten

4.1.2 Mikrobiologische Untersuchung und Verweildauer innerhalb der Cluster - Vergleich der positiv, negativ und nicht getesteten Patienten (Hypothese 3) ............................................56

4.2 Mikrobiologische Untersuchung und Alter (Hypothese 2) ………………….........................57

4.2.1 Mikrobiologische Untersuchung und Alter bei positiv, negativ und nicht getesteten

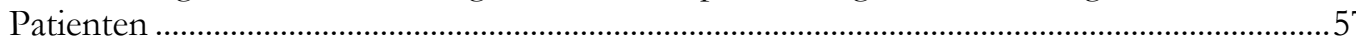

4.2.2 Mikrobiologische Untersuchung und Alter innerhalb der Cluster - Vergleich der positiv, negativ und nicht getestete Patienten (Hypothese 3) ....................................................58

4.3 Diagnose-Cluster und Keimfamilien (Hypothese 4)..................................................................59

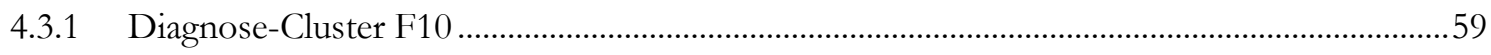

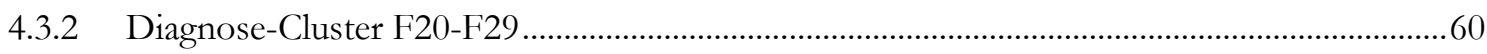

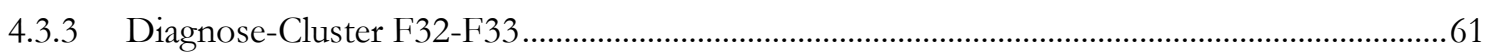

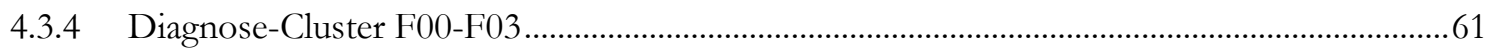

4.3.5 Altersbasierte Vergleichsgruppe zu Diagnose-Cluster F00-F03 ……………..........................62

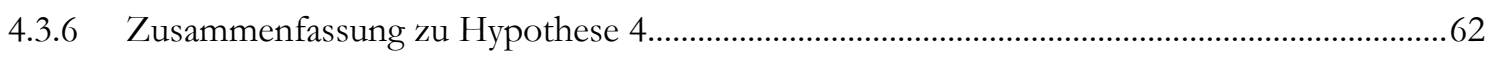

4.3.7 Spezielles Bakterium oder Infektion im Allgemeinen ...............................................................62

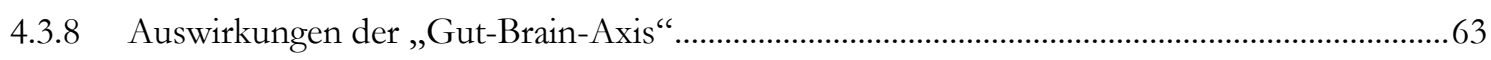

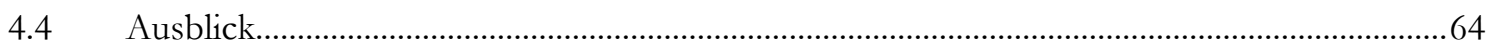

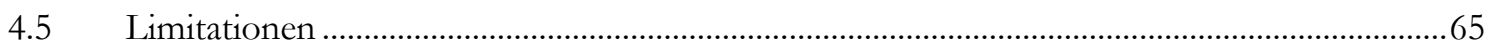

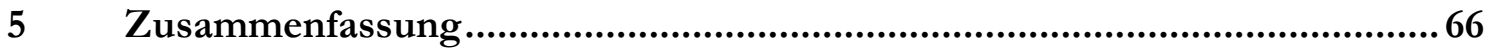

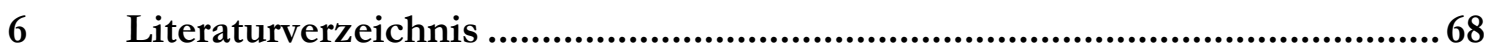

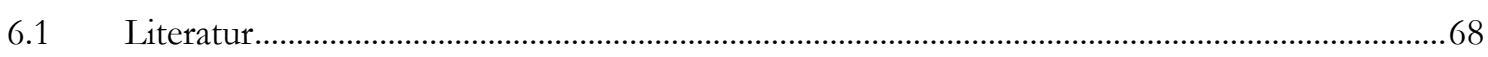

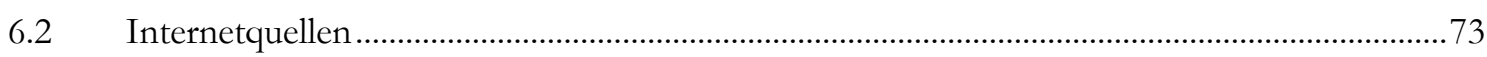




\section{Abbildungsverzeichnis}

Abbildung 1. Anzahl der Diagnosen der Patienten der Gesamtstichprobe, eingeteilt nach F-

Achsen

Abbildung 2. Anzahl der Diagnosen aller positiv getesteten Patienten, eingeteilt nach F-

Achsen

Abbildung 3. Anzahl der Diagnosen aller negativ getesteten Patienten, eingeteilt nach F-

Achsen

Abbildung 4. Anzahl der Diagnosen aller nicht getesteten Patienten, eingeteilt nach F-Achsen........34

Abbildung 5. Mittelwerte (Verweildauer in Tagen) mit 95\%-Konfidenzintervallen und Bonferroni-korrigierten Paarvergleichen, aufgeteilt nach Keimtestung...

Abbildung 6. Mittelwerte der Verweildauer in Tagen für Diagnose-Cluster, aufgeteilt nach

Keimtestung.

Abbildung 7. Mittelwerte (Alter in Jahren) mit 95\%-Konfidenzintervallen und Bonferroni-

korrigierten Paarvergleichen, aufgeteilt nach Keimtestung.

Abbildung 8. Mittelwerte des Alter in Jahren für Diagnose-Cluster, aufgeteilt nach

Keimtestung.

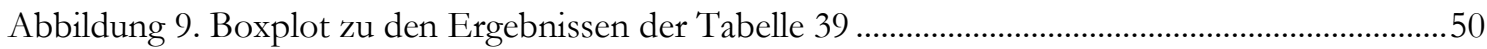

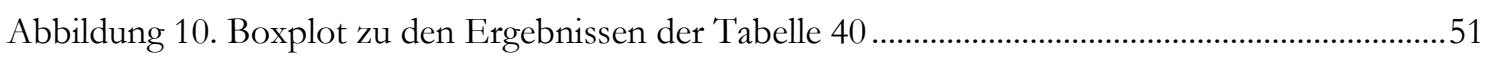




\section{Tabellenverzeichnis}

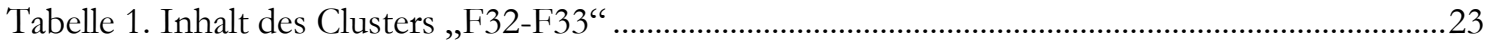

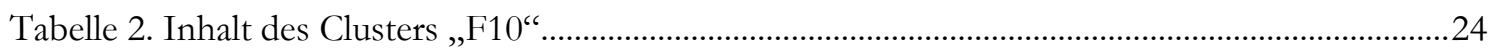

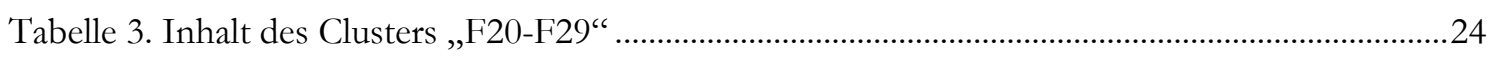

Tabelle 4. Inhalt des Clusters „F00-F03“ (inkl. ausgewählter G-Diagnosen).........................................25

Tabelle 5. Zusammensetzung der Familie der Enterobacteriaceae ........................................................26

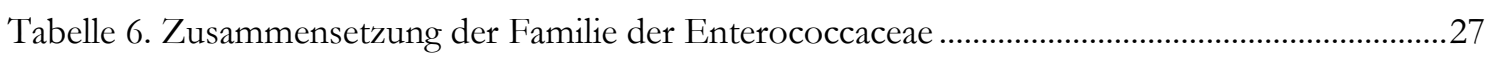

Tabelle 7. Zusammensetzung der Familie der Corynebacteriaceae.........................................................27

Tabelle 8. Zusammensetzung der Familie der Staphylococcaceae .......................................................27

Tabelle 9. Deskriptive Daten der Gesamtstichprobe und der drei Subgruppen...................................29

Tabelle 10. Die fünf häufigsten Diagnosen der Gesamtstichprobe ........................................................29

Tabelle 11. Aufteilung der Diagnosen der Gesamtstichprobe nach F-Achsen .......................................30

Tabelle 12. Die fünf häufigsten Diagnosen aller positiv getesteten Patienten........................................31

Tabelle 13. Aufteilung aller Diagnosen der positiv getesteten Patienten nach F-Achsen .....................31

Tabelle 14. Die fünf häufigsten Diagnosen aller negativ getesteten Patienten.......................................32

Tabelle 15. Aufteilung aller Diagnosen der negativ getesteten Patienten nach F-Achsen.....................32

Tabelle 16. Die fünf häufigsten Diagnosen aller nicht getesteten Patienten ..........................................33

Tabelle 17. Aufteilung aller Diagnosen der nicht getesteten Patienten nach F-Achsen ........................34

Tabelle 18. Ergebnis der Zwischensubjekteffekte mit Verweildauer als abhängiger Variable.............35

Tabelle 19. Mittelwerte der Verweildauer in Tagen, Standardabweichung der Verweildauer und Anzahl der Fälle der positiv, negativ und nicht getesteten Patienten..................................35

Tabelle 20. Ergebnisse des Bonferroni-korrigierten Post-Hoc-Tests zwischen den positiv, negativ und nicht getesteten Patienten in Bezug auf die mittlere Verweildauer.......................36

Tabelle 21. Mittelwerte der Verweildauer in Tagen, Standardabweichung der Verweildauer und Anzahl der Fälle für die Diagnose-Cluster aller Patienten ........................................................37

Tabelle 22. Ergebnisse des Bonferroni-korrigierten Post-Hoc-Tests zwischen den DiagnoseClustern in Bezug auf die mittlere Verweildauer ........................................................................37

Tabelle 23. Mittelwerte der Verweildauer in Tagen, Standardabweichung der Verweildauer und Anzahl der Fälle für die Diagnose-Cluster..............................................................................38

Tabelle 24. Ergebnis der Zwischensubjekteffekte mit Alter in Jahren als abhängiger Variable ..........40

Tabelle 25. Mittelwerte des Lebensalters in Jahren, Standardabweichung des Lebensalters und Anzahl der Fälle der Gesamtstichprobe.

Tabelle 26. Ergebnisse der Bonferroni-korrigierten Paarvergleiche zwischen den positiv, negativ und nicht getesteten Patienten in Bezug auf das mittlere Lebensalter.

Tabelle 27. Mittelwerte des Lebensalters in Jahren, Standardabweichung des Lebensalters und Anzahl der Fälle für die Diagnose-Cluster aller Patienten

Tabelle 28. Ergebnisse des Bonferroni-korrigierten Post-Hoc-Tests zwischen den DiagnoseClustern in Bezug auf den Mittelwert des Lebensalters in Jahren .............................................42

Tabelle 29. Mittelwerte des Lebensalters in Jahren, Standardabweichung des Lebensalters und Anzahl der Fälle für die Diagnose-Cluster..

Tabelle 30. Erwartete Anzahl an Nachweisen der Bakterienfamilie Enterobacteriacea pro Diagnose-Cluster...

Tabelle 31. Ergebnis des Chi-Quadrat-Tests für die 5×2-Felder-Matrix der Enterobacteriacea ........45

Tabelle 32. Erwartete Anzahl an Nachweisen der Bakterienfamilie Enterococcaceae pro

Diagnose-Cluster.

Tabelle 33. Ergebnis des Chi-Quadrat-Tests für die 5×2-Felder-Matrix der Enterococcaceae ..........46

Tabelle 34. Erwartete Anzahl an Nachweisen der Bakterienfamilie Corynebacteriaceae pro

Diagnose-Cluster.. 
Tabelle 35. Ergebnis des Chi-Quadrat-Tests für die 5×2-Felder-Matrix der Corynebacteriaceae .....46

Tabelle 36. Erwartete Anzahl an Nachweisen der Bakterienfamilie Staphylococcaceae pro Diagnose-Cluster.. .46

Tabelle 37. Ergebnis des Chi-Quadrat-Tests für die $5 \times 2$-Felder-Matrix der Staphylococcaceae .......47

Tabelle 38. Anzahl der nachgewiesenen Anzahl an Bakterienfamilien und Quotenverhältnisse innerhalb der einzelnen Cluster pro Bakterienfamilie

Tabelle 39. Gegenüberstellung des F00-F03-Clusters (inkl. G-Diagnosen) zu restlichen Diagnosen

Tabelle 40. Gegenüberstellung des F00-F03-Clusters (inkl. G-Diagnosen) zur altersangepassten Vergleichsgruppe .

Tabelle 41. Ergebnisse der Quotenverhältnisse und Chi-Quadrat-Tests zwischen altersangepasster Vergleichsgruppe und F00-F03-Cluster

Tabelle 42. Vergleich der Verweildauer der Cluster dieser Arbeit und der Verweildauer ähnlicher Krankheitsgruppierungen aus Internetquellen

Tabelle 43. Zusammenfassung der Ergebnisse der Chi-Quadrat-Testungen und Signifikanzwerte zwischen Diagnose-Clustern und Bakterienfamilien 


\section{Abkürzungsverzeichnis}

\begin{tabular}{|c|c|c|}
\hline BPtK & - & Bundespsychotherapeutenkammer \\
\hline COX & - & Cyclooxygenase \\
\hline GBE & - & Gesundheitsberichterstattung des Bundes \\
\hline HIV & - & Human Immundefizienz-Virus \\
\hline ICD-10-GM & - & $\begin{array}{l}\text { International Statistical Classification of Diseases and Related Health } \\
\text { Problems - } 10 \text { - German Modification }\end{array}$ \\
\hline IL-6 & - & Interleukin-6 \\
\hline IS-H® & - & Industrial Solution-Hospital \\
\hline KHEntgG & - & Krankenhausentgeltgesetz \\
\hline KIS & - & klinisches Informationssystem \\
\hline KRINKO & - & Kommission für Krankenhaushygiene und Infektionsprävention \\
\hline MRSA & - & Methicillin-resistenter Staphylococcus aureus \\
\hline NRZ & - & $\begin{array}{l}\text { Nationales Referenzzentrum für Surveillance von Nosokomialen } \\
\text { Infektionen }\end{array}$ \\
\hline OPS & - & Operationen- und Prozeduren-Schlüssel \\
\hline PEPP & - & Pauschalierendes Entgeltsystem Psychiatrie und Psychosomatik \\
\hline RKI & - & Robert Koch-Institut \\
\hline TNF & - & Tumornekrosefaktor \\
\hline UMG & - & Universitätsmedizin Göttingen \\
\hline
\end{tabular}




\section{$1 \quad$ Einleitung}

Diese Dissertation untersucht einen Datensatz, bestehend aus mikrobiologischen und krankenhausstatistischen Daten der Klinik für Psychiatrie und Psychotherapie der Universitätsmedizin Göttingen (UMG) hinsichtlich verschiedener Fragestellungen. Zum einen wird untersucht, ob sich Infektionen auf die Aufenthaltsdauer von Patienten auswirken und ob sie vermehrt im höheren Lebensalter auftreten. Zum anderen wird analysiert, ob es eine Unter- oder Überrepräsentation von Erregern bei bestimmten psychiatrischen Erkrankungen gibt. Untersucht werden die Jahre 2004 bis 2015.

Es wurden in dem Zeitraum alle Patienten mit Erstkontakt zu der Klinik für Psychiatrie und Psychotherapie in einer Datenbank zusammengefasst. Aus dieser Gesamtmenge wurden 3 Gruppen gebildet: (1) Patienten, denen keine mikrobiologische Probe entnommen wurde, (2) Patienten, denen eine mikrobiologische Probe entnommen wurde, die einen positiven Bakteriennachweis aufwies und (3) Patienten, denen eine Probe entnommen wurde, die sich als negativ herausstellte. Die häufigsten psychiatrischen Erkrankungen wurden in Diagnose-Cluster zusammengefasst: „F00-F03“ - demenzielle Erkrankungen, „F10“ - Verhaltensstörungen durch Alkohol, „F20-F29“ - Schizophrenie, schizotype und wahnhafte Störungen und „F32-F33“ - Unipolare Depressionen.

Die Auswertung des aufbereiteten Datensatzes erfolgte anhand der anonymisierten patientenbezogenen Stammdaten (Alter, Geschlecht), Aufnahme- und Entlassungsdatum, Art und Datum des mikrobiologischen Keimnachweises und der Hauptdiagnose. Die Auswertung untergliederte sich in zwei Teile.

Der erste Teil untersuchte statistisch, welche Unterschiede es innerhalb der drei Gruppen bezüglich der Aufenthaltsdauer und des Alters gibt und ob sich diese Unterschiede auch in den vier Clustern der Abhängigkeitserkrankungen, demenziellen Erkrankungen, psychotischen Störungen und affektiven Erkrankungen wiederfinden. Der zweite Teil untersuchte, ob signifikante Assoziationen zwischen den Diagnose-Clustern und den Bakterienfamilien zu finden sind.

Es existiert eine Vielzahl von Modellen und Hypothesen über die Ursachen psychiatrischer Erkrankungen. In der Literatur finden sich darüber hinaus zahlreiche Arbeiten zu möglichen Zusammenhängen von psychiatrischen Erkrankungen und Infektionen. Eine Zielsetzung der vorliegenden Arbeit ist es, durch die Auswertung dieses Routinedatensatzes Erkenntnisse bezüglich der Assoziation zwischen bakteriellen Infektionen und 
psychiatrischen Erkrankungen $\mathrm{zu}$ erlangen, welche Grundlage für weitere Forschungsprojekte sein können.

Im Rahmen der Einleitung der vorliegenden Arbeit soll im Folgenden zunächst die durchschnittliche Verweildauer psychiatrischer Patienten im Krankenhaus dargestellt werden. Im Anschluss werden Studienergebnisse zur Entstehung und Prävalenz von nosokomialen Infektionen und deren Auswirkung auf die Verweildauer von Patienten und auf die entstehenden Zusatzkosten berichtet. Weiterhin werden Veröffentlichungen über die Auswirkung des Lebensalters auf die Infektanfälligkeit und die Möglichkeiten zur Eindämmung von Infektionen wiedergegeben. Ebenfalls werden Studienergebnisse zu bereits bekannten Assoziationen zwischen psychischen Erkrankungen und Infektionen berichtet. Abschließend werden die Fragestellungen/Hypothesen der vorliegenden Arbeit abgeleitet.

\subsection{Durchschnittliche stationäre Verweildauer psychiatrischer Patienten}

Laut der Gesundheitsberichterstattung des Bundes beträgt die durchschnittliche Verweildauer eines Patienten mit F-Diagnose (F00-F99 Psychische und Verhaltensstörungen) im Jahr 2015 24,7 Tage und variiert zwischen den einzelnen Diagnosen.

Patienten der Diagnose „F10 - Psychische und Verhaltensstörungen durch Alkohol“ verblieben im Durchschnitt 12,9 Tage, Patienten mit der Diagnose „F00-F03 - Demenz“ blieben 13,4 Tage und Patienten mit der Diagnose „F30-F39 - Affektive Störungen“ blieben 35,3 Tage in stationärer Behandlung (Gesundheitsberichterstattung des Bundes Durchschnittliche Verweildauer ausgewählter Diagnosen 2017).

Laut der Bundespsychotherapeutenkammer (BPtK) verbrachten an einer Schizophrenie erkrankte Patienten durchschnittlich 32 Tage in vollstationärer Behandlung (Bundespsychotherapeutenkammer - Studie zur stationären Versorgung psychisch kranker Menschen 2014).

Diese Zahlen decken sich mit den Zahlen des Bremer Krankenhausspiegels. Patienten mit einer Demenzerkrankungen, z. B. M. Alzheimer, blieben je nach behandelndem Krankenhaus 8,7 bis 23,8 Tage ( $M=13,98$ Tage). Patienten mit einer Suchterkrankung, $z$. B. Drogen- oder Alkoholsucht, blieben 7,5 bis 12,4 Tage ( $M=9,7$ Tage). Patienten mit einer schizophrenen Erkrankung, z. B. Wahnvorstellungen, blieben 23,2 bis 31,6 Tage ( $M$ 
$=27,53$ Tage). Patienten mit einer affektive Störung, z. B. Depression, blieben 22,6 bis 37,3 Tage $(M=28,4$ Tage)(Bremer Krankenhausspiegel - Verweildauer je Erkrankung 2016).

\subsection{Auswirkungen bakterieller Infektionen auf die Verweildauer und die Kosten}

Bakterielle Infektionen im Krankenhaus erhöhen den Leidensdruck eines jeden Patienten und sind deshalb ungünstige Einflussgrößen für den Krankheitsverlauf. Sie bedeuten eine Verlängerung des Aufenthaltes, eine Ausdehnung der Diagnostik, eine Eskalation der Therapie und einen erhöhten pflegerischen Aufwand. In der Konsequenz führen sie zu höheren Kosten und stellen unter ökonomischen Gesichtspunkten ein bedeutsames wirtschaftliches Risiko für das Krankenhaus dar. Die volkswirtschaftlichen Kosten durch den verlängerten Arbeitsausfall des Patienten fließen noch zusätzlich in die Rechnung mit ein.

Die Entgelt-Abrechnung in der Psychiatrie erfolgt nach dem „Pauschalierendem Entgeltsystem Psychiatrie und Psychosomatik“ (PEPP). Dieses sieht eine tagesgenaue Abrechnung der Entgeltbeträge vor, abhängig von der Hauptdiagnose, Aufenthaltsdauer und komplizierenden Konstellationen, z. B. ausgesuchte Infektionen. Somit hat eine verlängerte Aufenthaltsdauer des Patienten in einer psychiatrischen Einrichtung direkte Auswirkung auf die entstehenden Kosten für das Gesundheitssystem (PsychiatrieEntgelt.de - PEPP-System 2015; Spitzenverband Bund der Krankenkassen - PEPP 2015).

Von versorgungswissenschaftlichem Interesse ist es, Aufschlüsse darüber zu bekommen, ob sich Infektionen auf die Aufenthaltsdauer eines psychiatrischer Patienten auswirken oder nicht.

\subsubsection{Entstehung und Verbreitung einer bakteriellen Flora im Krankenhaus}

Jeder Mensch besitzt eine bakterielle Flora, die bei einem intakten Immunsystem nicht zwingend pathogen ist. Das bedeutet auch, dass jeder Patient, jeder Pfleger, jeder Arzt und jeder Besucher, der ein Krankenhaus betritt, diese bakterielle Flora mit sich bringt und dort hinterlässt. In den USA wurde bei Bezug eines Klinikneubaues untersucht, inwieweit Bakterien einen neuen Lebensraum erobern und man stellte fest, dass sich innerhalb kürzester Zeit Bakterien wie Corynebakterien, Staphylokokken und Streptokokken in den neuen Räumen verbreiteten (Aerztezeitung.de - Hygiene: Wie Mikroben ein neues Krankenhaus besiedeln 2017). 
Sind die Bakterien erst einmal innerhalb des Krankenhauses, gibt es verschiedene Wege der Übertragung zwischen den anwesenden Menschen. Es wird zwischen endogenen und exogenen Übertragungswegen unterschieden. Unter exogener Infektion wird die Keimübertragung mit darauffolgender Infektion durch direkten Kontakt mit Personen (z. B. durch Hände), durch Berührung von Gegenständen (Betten, Stethoskope etc.) und die Übertragung durch Luft und Wasser verstanden. Endogene Infektionen unterteilt man in primär und sekundär. Die primär endogene nosokomiale Infektion bezeichnet eine Infektion des Patienten mit seiner eigenen biologischen Flora, z. B. während eines Zeitraumes, in dem das Immunsystem geschwächt ist. Um eine sekundäre endogene Infektion handelt es sich, wenn der Patient während seines Krankenhausaufenthaltes einen neuen Keim zu seiner biologischen Flora hinzubekommt und dieser dann eine Infektion nach sich zieht (Gesundheitsberichterstattung des Bundes - Themenheft 8 „Nosokomiale Infektionen“ 2002).

\subsubsection{Prävalenz nosokomialer Infektionen}

Im Jahr 2016 ergab die Punkt-Prävalenz-Studie des Nationalen Referenzzentrums für Surveillance von Nosokomialen Infektionen (NRZ), dass die Raten der nosokomialen Infektionen in der Psychiatrie mit 0,71\% gering, die Raten in der Geriatrie mit 7,8\% jedoch hoch ausfallen (Nationales Referenzzentrum - Abschlussbericht der Deutschen Nationalen Punkt-Prävalenzstudie zu nosokomialen Infektionen und Antibiotika-Anwendung 2017).

Dies richtet die Aufmerksamkeit auf das Alter als Parameter für erhöhte Infektanfälligkeit.

\subsubsection{Kosten nosokomialer Infektionen}

Die zusätzlich entstehenden Kosten pro Patient bei einer nosokomialen Infektion variieren zwischen 5.000 und 9.000 Euro/Fall. Sie hängen von dem verursachenden Bakterium und den daraus folgenden Isolationstagen und Therapieanpassungen ab (Fleßa und Hübner 2016). Eine europaweit durchgeführte Studie kam zu dem Ergebnis, dass nosokomiale Infektionen sieben Milliarden Euro Mehrkosten pro Jahr verursachen (European Centre for Desease Prevention and Control - Annual epidemiological report on communicable diseases in Europe 2008).

Als direkte Kosten werden am häufigsten der gesteigerte Hygieneaufwand (Pflege und Material), die Laborkosten, die Opportunitätskosten (Erlösausfälle während der Isolation durch Bettenausfall und die verlängerte Verweildauer), zusätzliche Medikamente und erweiterte Diagnostik angegeben. Indirekte Kosten entstehen durch den Arbeitsausfall und 
mögliche Rehabilitationsmaßnahmen. Intangible Kosten (Lebensqualitätsverlust, erhöhte Morbidität/Mortalität, psychische Folgen) kommen noch hinzu (Robert Koch-Institut Medizinische Wirksamkeit und Kosten-Effektivität von Präventions- und Kontrollmaßnahmen gegen Methicillin-resistente Staphylococcus aureus (MRSA)Infektionen im Krankenhaus 2010).

\subsubsection{Verweildauer aufgrund nosokomialer Infektionen}

Infektionen im Allgemeinen und nosokomiale Infektionen im Speziellen erhöhen die Verweildauer von Patienten im Krankenhaus. Zu diesem Ergebnis kommen mehrere Studien bei verschiedenen Patienten und Keimen.

Infektionen mit dem Bakterium Clostridium difficile wurden wiederholt untersucht, immer mit dem Ergebnis eines verlängerten Krankenhausaufenthaltes. Je nach Studie, Patientenkollektiv, Land und Untersucher verblieben die Patienten 4-16 Tage länger im Krankenhaus als die jeweilige Vergleichsgruppe (Vonberg et al. 2008; Rodrigues et al. 2010; Forster et al. 2012; Eckmann et al. 2013; Monge et al. 2013).

Nosokomiale Infektionen wurden in der genannten Literatur im Allgemeinen untersucht, ohne sich auf einen spezifischen Keim festzulegen. Auch hier verlängerte sich die Aufenthaltsdauer der Patienten im Mittel um 8 Tage (Arefian et al. 2016) oder um 7,3 Tage in einer belgischen Studie (Vrijens et al. 2012). Bei Intensiv-Patienten verlängerte sich die Aufenthaltsdauer um 18,2 Tage im Durchschnitt (Chen et al. 2005).

Eine laborbestätigte Sepsis verlängerte den Aufenthalt um 15 Tage, Harnwegsinfektionen im Speziellen verlängerten den Aufenthalt nicht, Infektionen der untere Atemwege um 2,58 Tage und andere Arten von Infektionen um 2,61 Tage (Orsi et al. 2002; Graves et al. 2007). Im Gesundheitsbericht des Bundes in Zusammenarbeit mit dem Robert Koch-Institut (RKI) im Jahr 2008 wurden für die nosokomiale Pneumonie eine verlängerte Verweildauer von 4,7-25 Tagen und für die postoperative Wundinfektion eine verlängerte Verweildauer von 5,7-23,7 Tagen angegeben (Gesundheitsberichterstattung des Bundes - Themenheft 8 „Nosokomiale Infektionen“ 2002).

13 Tage länger blieben Patienten im Schnitt bei einer katheterassoziierten Sepsis, 10 Tage länger für beatmungsassoziierte Pneumonie und 5 Tage länger für eine katheterassoziierte Urogenitalinfektion (Rosenthal et al. 2003).

Eine MRSA-Infektion verlängerte die Behandlungsdauer der Patienten um 11,5-15,3 Tage (Macedo-Viñas et al. 2013). 
Man fand heraus, dass viele Patienten mit einer Demenzerkrankung bei Aufnahme unter einer Infektion litten und dass sich die Aufenthaltsdauer durch frühe antibiotische Behandlung deutlich reduzieren ließ (Malyuk et al. 2012).

$\mathrm{Ob}$ sich eine bakterielle Infektion auch auf die Aufenthaltsdauer von anderweitig psychiatrisch Erkrankten auswirkt, wurde unter anderem in der vorliegenden Arbeit untersucht.

Zusammenfassend lassen die berichteten Studien darauf schließen, dass bakterielle Infektionen in den meisten Fällen sowohl die Verweildauer verlängern als auch die Kosten erhöhen.

\subsection{Die häufigsten nosokomialen Infektionen und ihre Erreger}

Die im Jahr 2016 am häufigsten dokumentierten nosokomialen Infektionen waren die Infektion der unteren Atemwege (24,0\% Anteil), die postoperativen Wundinfektionen $(22,4 \%)$, die Harnweginfektionen (21,6\%), die Clostridium difficile-Infektionen (10,0\%), die primäre Sepsis $(5,1 \%)$ und andere gastrointestinale Infektionen $(3,4 \%)$.

Die häufigsten Erreger sind je nach Infektionsart unterschiedlich. Insgesamt können bei nosokomialen Infektionen am häufigsten Escherichia coli (16,6\%), Clostridium difficile (13,3\%), Staphylococcus aureus (12,0\%) und Enterococcus faecalis (6,9\%) nachgewiesen werden (Nationales Referenzzentrum - Abschlussbericht der Deutschen Nationalen Punkt-Prävalenzstudie zu nosokomialen Infektionen und Antibiotika-Anwendung 2017).

\subsubsection{Anteil der multiresistenten Erreger an nosokomialen Infektionen in Deutschland}

Ein besonderes Augenmerk ist auf die multiresistenten Erreger zu richten. Der Anteil mit Methicillin-Resistenz an allen Staphylococcus aureus-Isolaten betrug 18,8\%, der Anteil mit Glycopeptid-Resistenz aller Enterococcus faecium-Isolaten lag bei 23,1\%. Von den Escherichia coli-Erregern waren 16,8\% resistent gegen die 3. Generation der Cephalosporine. Von den Pseudomonas aeruginosa waren $18,9 \%$ resistent gegen Carbapeneme (Nationales Referenzzentrum - Abschlussbericht der Deutschen Nationalen Punkt-Prävalenzstudie zu nosokomialen Infektionen und Antibiotika-Anwendung 2017). Laut dem RKI werden ca. 6\% aller nosokomialen Infektionen pro Jahr durch einen multiresistenten Erreger verursacht. Bei 400.000-600.000 nosokomialen Infektionen sind das ca. 30.000-35.000 Infektionen mit multiresistenten Bakterien pro Jahr (Robert Koch-Institut Antibiotikaresistenz und Nosokomiale Infektionen (FAQ) 2017). 


\subsection{Präventions- und Kontrollmaßnahmen zur Eindämmung von Infektionen}

Im Jahr 2004 wurden die Richtlinien der Kommission für Krankenhaushygiene und Infektionsprävention (KRINKO) des RKI veröffentlicht. Diese beinhalten Maßnahmen zur Prävention nosokomialer Infektionen, Aufgaben des Hygienemanagements, die Aufforderung zur Erfassung und Bewertung nosokomialer Infektionen und Vorschriften zur Verhütung der Übertragung von Infektionen durch Personal auf Patienten.

Darüber hinaus wurden Maßnahmen zur Verhinderung der Weiterverbreitung übertragbarer Krankheiten vorgestellt. Diese beinhalten unter anderem „Empfehlungen zur Prävention und Kontrolle von Methicillin-resistenten Staphylococcus aureus-Stämmen (MRSA) in medizinischen und pflegerischen Einrichtungen“ und „Hygienemaßnahmen bei Infektion oder Besiedlung mit multiresistenten gramnegativen Stäbchen“ (Robert KochInstitut - Empfehlungen der Kommission für Krankenhaushygiene und Infektionsprävention 2004). Parallel zu dem Vorgehen bei einer bekannten Infektion mit genannten Erregern (Hygienemaßnahmen, ggf. Patienten-Isolation, Schutzkleidung etc.), werden auch risikobasierte Reihenuntersuchungen ohne vorhandene klinische Symptome (sog. Screening) diskutiert.

Z. B. hat die KRINKO mehrere Faktoren für eine erhöhte Wahrscheinlichkeit der MRSABesiedlung herausgearbeitet. Dazu zählen unter anderem eine bekannte MRSA-Anamnese, ein Aufenthalt in einer Region oder Einrichtung mit bekannt hohem MRSA-Vorkommen, ein stationärer Krankenhausaufenthalt länger als drei Tage in den letzten zwölf Monaten und das Vorhandensein von zwei oder mehr Risikofaktoren, wie z. B. ein liegender Katheter oder chronische Pflegebedürftigkeit. Die KRINKO empfiehlt, auf Grundlage der Risikofaktoren eine ärztliche Bewertung durchzuführen und anhand dieser ein Screening zu initiieren (Ruscher 2014).

Ohne ein Screening werden 69-85\% der MRSA-besiedelten Patienten bei Aufnahme in ein Krankenhaus nicht erkannt (Salgado und Farr 2006; Vos et al. 2009).

Die Niederlande verfolgen seit den 1980er Jahren die sogenannte search-and-destroyStrategie im Kampf gegen den MRSA. Ein MRSA-Risiko-Patient wird bei Aufnahme in ein Krankenhaus isoliert, auf MRSA untersucht (search) und erst aus der Isolation entlassen, wenn der Abstrich auf MRSA negativ ist. Ist der Abstrich positiv, wird der Keim mit den geeigneten Maßnahmen beseitigt (destroy) (MRSA-net.nl - Was bedeutet search-anddestroy Politik? 2005). 
Dies führt dazu, dass die Anzahl an resistenten Arten aller Stapyblococcus aureus-Isolaten in den Niederlanden im Jahr 2015 bei 1,2\% lag. (Uni-Muenster.de - Niederlande als Vorbild im Kampf gegen Krankenhauskeime 2015). Im Vergleich dazu liegt der Wert in Deutschland wie bereits erwähnt bei 18,8\%.

\subsection{Auswirkung des Alters auf das Immunsystem und auf die Infektionsanfälligkeit}

Das Immunsystem verändert sich mit zunehmendem Alter und wird schwächer. Dieser Vorgang wird als Immunoseneszenz bezeichnet. Die Veränderungen betreffen auf zellulärer und hormoneller Ebene sowohl das angeborene als auch das erworbene Immunsystem (Castle 2000). Daraus resultieren eine erhöhte Anfälligkeit alter Menschen auf Krankheitserreger und ein herabgesetztes Ansprechen des Immunsystems auf Impfungen (Ginaldi et al. 1999; Weiskopf et al. 2009).

Es werden folgende Gründe für eine erhöhte Infektanfälligkeit im Alter beschrieben: (1) geschwächte zelluläre und humorale Immunabwehr, (2) beeinträchtigte physiologische Funktion, z. B. Hustenreflex, Schluckakt, Durchblutung, nervale Innervation und eine herabgesetzte Wundheilung, (3) Harnblasenkatheter und intravenöse Zugänge, (4) erhöhte Prävalenz chronischer Erkrankungen, die die Immunabwehr beeinträchtigen, z. B. Diabetes mellitus, (5) Einnahme von Arzneimitteln, die die Immunabwehr beeinträchtigen, z. B. Immunsuppressiva, Protonenpumpeninhibitoren und H2-Blocker, (6) Hygieneprobleme und nosokomiale Infektionen (Pflegeeinrichtung, Klinik) und (7) Unter- oder Mangelernährung (Allgemeinarzt-online.de - Infektionen im Alter - Was macht sie so gefährlich? 2015).

So sind z. B. über 60\% der an einer nosokomialen Pneumonie erkrankten Patienten älter als 70 Jahre (Ewig et al. 2009) und knapp 50\% aller Patienten mit ambulant erworbenen Clostridium-difficile-Infektionen über 75 Jahre alt (Murphy et al. 2012).

Ein höheres Lebensalter geht mit einer erhöhten Anfälligkeit für Infektionen einher. In dieser Arbeit wird untersucht, ob positiv getestete Patienten mit einer psychischen Erkrankung ein höheres Durchschnittsalter als negativ getestete Patienten und nicht getestete Patienten haben. 


\subsection{Zusammenhänge zwischen psychischen Erkrankungen und Infektionen}

Die allgemein angenommenen Ursachen und Auslöser der hier untersuchten psychiatrischen Erkrankungen werden als bekannt vorausgesetzt und im Rahmen der Einleitung dieser Dissertation nicht erneut erörtert. Die Recherche in wissenschaftlichen Veröffentlichungen bezieht sich auf diskutierte Erreger als Auslöser, Verstärker oder Begleitinfektion der vorgegebenen psychiatrischen Erkrankungen.

\subsubsection{Demenz verschiedener Ätiologien (F00-F03)}

Es werden mehrere Formen der Demenz unterschieden. Nach der ICD-10-GM-2017Klassifikation (International Statistical Classification of Diseases and Related Health Problems - German Modification) werden die Demenz bei Alzheimer-Krankheit (F00), die vaskuläre Demenz (F01), die Demenz aufgrund anderenorts klassifizierten Krankheiten (F02) und die nicht näher bezeichnete Demenz (F03) unterschieden. Zu den anderenorts klassifizierten Krankheiten, die eine Demenz nach sich ziehen können, gehören unter anderen die Pick-Krankheit, die Creutzfeldt-Jakob-Krankheit, Chorea Huntington, das primäre Parkinson-Syndrom, die eine Erkrankung an dem Human Immundefizienz-Virus (HIV), die Lewy-Körper-Krankheit und ein Vitamin-B12-Mangel (F02.1 - F02.8) (ICD-10GM-2017 - F00-F09 Organische, einschließlich symptomatischer psychischer Störungen, S. $10)$.

Die Erforschung der Pathomechanismen demenzieller Erkrankungen ist außerordentlich komplex und in sehr vielen Aspekten noch nicht geklärt. Die vorliegende Arbeit legt einen Fokus auf komorbide Keimbesiedlungen bei demenziellen Erkrankungen und die Identifizierung möglicher Assoziationen.

So besteht ein statistischer Zusammenhang zwischen der Alzheimer-Krankheit und dem Vorhandensein von Spirochäten und Chlamydophilia pneumoniae (Shima et al. 2010; Maheshwari und Eslick 2015). Die Spirochäten wurden genauer untersucht, und es zeigte sich, dass bei Patienten mit M. Alzheimer im Mund befindliche Treponema-Arten ( $T$. pectinovorum, T. amylovorum, T. lecithinolyticum, T. maltophilum, T. medium, T. socranskir) und Borrelia burgdorferi erhöht waren (Miklossy 2011). Generell stehen Infektionen im Mundraum im Verdacht, die Alzheimer-Krankheit auslösen zu können (Olsen und Singhrao 2015). Neben dem HI-Virus ist auch das Herpes-simplex-Virus als möglicher Auslöser eines M. Alzheimer entdeckt worden (Lövheim et al. 2015; Steel und Eslick 2015). 
Die Blut-Hirn-Schranke schützt das Gehirn vor dem Übertritt von pathogenen Krankheitserregern. Manche Erreger sind dazu in der Lage, diese Barriere zu überwinden. Dabei muss es nicht der komplette Erreger sein, es reichen Proteinfragmente aus, die bei der Vermehrung von pathogenen Keimen entstehen. Diese Moleküle werden von den Immunzellen erkannt, die daraufhin Entzündungsmediatoren ausschütten. Eine chronische Erhöhung dieser Entzündungsmediatoren kann für die Ansammlung von $\alpha \beta$-Amyloid bei der Demenz verantwortlich sein und die kognitiven Einschränkungen verstärken (Bibi et al. 2014; Barichello et al. 2015). Für diese These spricht auch, dass sich bei AlzheimerPatienten erhöhte Werte des Entzündungsmarkers Interleukin-6 (IL-6) im Plasma finden lassen (Wu et al. 2015). Periphere Entzündungen können das Risiko für eine AlzheimerKrankheit ebenfalls erhöhen (Eikelenboom et al. 2012).

Bei vaskulärer Demenz steht eine Helicobacter-pylori-Infektion im Verdacht, die Denkleistung zu verschlechtern. Vermutet wird ein Zusammenhang mit der erhöhten Ausschüttung von Entzündungsmediatoren wie Interleukinen und dem Tumornekrose-Faktor- $\alpha(\mathrm{TNF}-\alpha)(\mathrm{Xu}$ et al. 2016).

\subsubsection{Psychische und Verhaltensstörungen durch Alkohol (F10)}

In den jüngsten Veröffentlichungen beschreiben die Autoren überwiegend Infektionen, die durch chronischen Alkoholkonsum begünstigt werden. Diskutierte Infektionen oder Erreger als Auslöser von Suchterkrankungen im Allgemeinen konnten nicht gefunden werden.

Im Mundraum alkoholkranker Patienten zeigte sich eine erhöhte Anzahl folgender Bakterienarten: T. forsythia, $P$. gingivalis, $A$. actinomycetemcomitans, $T$. denticola, $F$ nucleatum, $P$. intermedia, E. corrodens (Sender-Janeczek und Ziętek 2016).

Chronischer Alkoholkonsum kann aber auch zu einer Verringerung bestimmter Bakterienarten führen. Es wurde die Zusammensetzung der Magen-Darm-Flora alkoholabhängiger Patienten untersucht und festgestellt, dass die Anzahl der Bacteroidetes und Lachnosspiraceae dezimiert war (Chen et al. 2011).

\subsubsection{Schizophrenie, schizotype und wahnhafte Störungen (F20-F29)}

Die allgemeinen Annahmen für die Ursachen und Entstehung von Schizophrenie sind multifaktoriell. In Betracht kommen biologische, toxische, hormonelle, immunologische, und psychosoziale Faktoren. $\mathrm{Zu}$ den biologischen Faktoren gehören unter anderem genetische Voraussetzungen, Anomalien von anatomischen Gehirnstrukturen, 
biochemische Veränderungen im Gehirn und bakterielle oder virale Infektionen (Aerzteblatt.de - Infektion und Psychose 2008; Neurologen-und-Psychiater-im-Netz.org Schizophrenie: Ursachen 2015; Bundespsychotherapeutenkammer - Schizophrenie Ursachen, Symptome, Diagnostik, Therapie 2018).

Im Fokus stehen zurzeit pränatale Infektionen der Mutter und fetale Infektionen als Auslöser späterer psychiatrischer Erkrankungen im Erwachsenenalter, Infektionen mit Toxoplasma gondii, Infektionen mit dem Herpes-simplex-Virus Typ I und Entzündungen im Allgemeinen. Es wurde ein Zusammenhang zwischen einem erhöhten Spiegel des Entzündungsmarkers IL-6 und späteren psychischen Erkrankungen gefunden (Khandaker et al. 2014a).

Bei den pränatalen Entzündungen konnten über mehrere Jahrzehnte viele verschiedene Entzündungsauslöser zu unterschiedlichen Schwangerschaftsmonaten identifiziert werden. Unter anderem Diphterie, Pneumonie, Influenza (Watson et al. 1984), Masern, Varizella Zoster (Torrey 1988) und das Poliovirus (Suvisaari et al. 1999). In dem Review über Zusammenhänge zwischen pränatalen Infektionen und Schizophrenie von Khandaker wurde zusammengefasst, dass in drei von fünf Studien ein erhöhtes Risiko bei pränataler Infektion mit dem Herpes-simplex-Virus Typ I, in fünf Studien ein erhöhtes Risiko nach einer pränatalen Toxoplasma gondii-Infektion und in einer Studie ein erhöhtes Risiko nach Influenza-Infektion nachgewiesen worden ist (Khandaker et al. 2013).

Bei der Schizophrenieentstehung finden sich Hinweise auf Assoziationen zwischen Infektionen und Ausbruch der Erkrankung sowohl in der pränatalen Phase als auch in der Kindheitsphase. Es gibt einen Zusammenhang zwischen Infektionen mit dem EpsteinBarr-Virus (Khandaker et al. 2014b), viralen ZNS-Infektionen im Allgemeinen (Rantakallio et al. 1997; Koponen et al. 2004; Dalman et al. 2008; Khandaker et al. 2012), oder einer Meningitis im Kindesalter (Abrahao et al. 2005) und einer Schizophrenieentwicklung im Erwachsenenalter.

Es steht eine ganze Reihe von Erregern im Verdacht im Erwachsenenalter psychotische Episoden oder Schizophrenien auszulösen. Unter anderem Erreger aus der Familie der Borrelien (Cevizci et al. 2015); ebenso Viren wie Herpes-simplex, Epstein-Barr-Virus, Cytomegalievirus, Grippe-Virus, Masern, Rubella-Virus, Mumps, Polio, Enteroviren (z. B. Coxsackie B4), Arboviren, Retroviren wie der HI-Virus oder Borna-Viren (Yolken und Torrey 2008). Hinzu kommen noch Einzeller wie das Protozoon Toxoplasma gondii (Yolken et al. 2009; Torrey et al. 2012). 


\subsubsection{Depression (F32-F33)}

Bei der Depression sind Assoziationen mit Infektionen beschrieben. Eine Infektion mit HIV geht mit erhöhter Suizidalität und erhöhter Depressionsrate einher (Nanni et al. 2015; Serafini et al. 2015), ebenso Toxoplasma gondii (Hsu et al. 2014), Tuberkulose (Shen et al. 2014), eine Herpes Zoster-Infektion (Chen et al. 2014) und eine Influenza-Erkrankung (Bornand et al. 2016).

Eine computerbasierte Literaturanalyse zusammengestellt aus diversen Datenbanken ergab eine Verbindung zwischen Depression und Infektionen mit dem Borna-Virus, Herpessimplex-Virus Typ I, Varizella-Zoster-Virus, Epstein-Barr-Virus und Chlamydophila trachomatis (Wang et al. 2014). Die Frage, warum manche Erreger eine Depression nach sich ziehen und welche diese sind, ist weiterhin offen.

Es müssen nicht zwingend pathogene Krankheitserreger sein, die eine Depression auslösen, auch Patienten mit chronischer Osteomyelitis haben ein erhöhtes Risiko, an einer Depression zu erkranken (Tseng et al. 2014).

Es gibt daher die Vermutung, dass nicht der pathogene Krankheitserreger per se die Depression verursacht, sondern das Resultat der körpereigenen Entzündungsreaktion hierfür verantwortlich ist. Es wurde nachgewiesen, dass es einen Zusammenhang zwischen Entzündungsprozessen und der Entwicklung und Entstehung von Depressionen gibt. Es wurden erhöhte Zytokinwerte bei an einer Depression erkrankten Patienten gefunden (Dantzer et al. 2008; Young et al. 2014; Kudlow et al. 2016).

Die beschriebenen und diskutierten Erreger, die in Assoziation zu den erwähnten psychiatrischen Erkrankungen stehen, sind vielfältig, folgen auf dem ersten Blick keiner einheitlichen Struktur und sind vermutlich noch nicht in voller Gänze erfasst. Es ist von wissenschaftlichem Interesse, weitere Assoziationen zwischen Bakterienfamilien und psychiatrischen Erkrankungen zu finden oder gegebenenfalls bereits identifizierte Assoziationen zu bestätigen.

\subsection{Fragestellung / Hypothesen}

Wegen der deutlich knapper werdenden monetären Ressourcen im Gesundheitswesen ist eine Untersuchung der Auswirkung einer Infektion auf die Hospitalisierungsdauer eines Patienten von Bedeutung. Aufgrund der dargestellten Studien und theoretischen Überlegungen zu erhöhter Verweildauer bei bakterieller Infektion werden die folgenden Hypothesen abgeleitet: 


\section{Hypothese 1 - Verweildauer:}

- H1.1: Patienten mit einem positiven mikrobiologischen Keimnachweis haben im Durchschnitt eine längere Verweildauer als negativ getestete und nicht getestete Patienten.

- H1.2: Patienten ohne Keimnachweis haben aufgrund mangelnder Infektionssymptome im Durchschnitt die geringste Verweildauer.

Inwieweit sich das Lebensalter auf das Risiko, an einer Infektion zu erkranken, auswirkt, ist in Anbetracht der stetig steigenden Lebenserwartung und zunehmenden Überalterung der Gesellschaft in Deutschland von zunehmender Relevanz. Die recherchierten Studien legen eine erhöhte Anfälligkeit für bakterielle Infektionen mit ansteigendem Lebensalter nahe. Es wird die folgende Hypothese abgeleitet:

\section{Hypothese 2 - Alter:}

- H2: Positiv getestete Patienten haben ein höheres Durchschnittsalter als negativ getestete und nicht getestete Patienten.

Zusätzlich soll überprüft werden, ob sich die gefundenen Unterschiede zwischen positiv, negativ sowie nicht getesteten Patienten bezüglich Verweildauer und Alter auch in den gebildeten Diagnose-Clustern darstellten. Die folgende Hypothese wird abgeleitet:

\section{Hypothese 3 - Cluster:}

- H3: Die Vorhersagen der Hypothesen 1 und 2 spiegeln sich auch in den gebildeten Clustern („F00-F03“ Demenz, „F10“ Alkohol, „F20-F29“ Schizophrenie, „F33F32“ Depression) wider.

Die hier dargestellten Studien zeigen des Weiteren, dass bei einer großen Anzahl an Erregern Assoziationen $\mathrm{zu}$ psychiatrischen Erkrankungen bestehen. Aufgrund der Heterogenität der vorliegenden Studien werden keine konkreten Vorhersagen zur Häufung einzelner Erreger in den gebildeten Diagnose-Clustern gemacht, sondern es wird die folgende explorative Hypothese abgeleitet:

\section{Hypothese 4 - Assoziationen:}

- H4: Es besteht eine Assoziation zwischen in der klinischen Routine bei Erstkontakt des Patienten an der UMG (Universitätsmedizin Göttingen) erhobenen mikrobiologischen Befunden und psychischen Erkrankungen. 


\section{$2 \quad$ Material und Methoden}

\subsection{Entstehung der Datenbanken}

\subsubsection{Daten im Klinischen Informationssystem der UMG}

Jeder Patient, der in der Klinik für Psychiatrie und Psychotherapie der UMG behandelt wird, erhält bei Erstkontakt eine Patientennummer und für den Zeitraum der Behandlung eine Fallnummer. Falls derselbe Patient erneut vorstellig wird, behält er seine Patientennummer, die Fallnummer wird bei erneutem Kontakt geändert.

Unter der Patientennummer werden von allen behandelnden Berufsgruppen die jeweils am Patienten erbrachten Leistungen in das System „ID-Scorer ${ }^{\circledR}$ “ eingetragen. Das System „ID-Scorer ${ }^{\circledR}$ “ wandelt die erbrachten Leistungen in OPS (Operationen- und ProzedurenSchlüssel) um und übermittelt diese an das KIS (Klinisches Informationssystem) der Firma SAP, das mit dem Modul IS-H® (Industrial Solution - Hospital) arbeitet. In diesem System werden die abrechnungsrelevanten Daten - gemäß Datenlieferung $\$ 21$ KHEntgG (Krankenhausentgeltgesetz) - gesammelt.

\subsubsection{Daten im M/Lab® des Mikrobiologischen Instituts}

Wenn ein Patient durch Infektionszeichen auffällig wird, stellt ein Arzt z. B. die Indikation einer mikrobiologischen Untersuchung. Bevor der Arzt das zu untersuchende Material entnimmt, erstellt er über das hausinterne Netzwerk eine Anforderung zur Bearbeitung der Probe. Daraufhin druckt der anfordernde Arzt einen Barcode aus, der im System über die Patientennummer und eine Probenfallnummer dem richtigen Patienten zugeordnet werden kann, versieht die Probe mit diesem Barcode und schickt sie per Rohrpost in das Institut für Medizinische Mikrobiologie der UMG. Hier wird die Anforderung bereits im hauseigenen System „M/Lab®“ der Firma Dorner geführt, nachdem der Arzt auf Station die Untersuchung der Probe angefordert hat.

Je nach Anforderung und Probenart wird das entnommene Material im Institut für Medizinische Mikrobiologie aufgearbeitet und ausgewertet. Sobald eine Diagnose gestellt werden kann, wird diese der Patientennummer zugehörig in das Programm „M/Lab®“ eingetragen. Die Probe wird als „aktiv“ und „identifiziert“ angegeben. 
Solange eine Probe noch nicht diagnostiziert, also identifiziert worden ist, steht sie im „M/Lab®“ unter „Beobachtung“. Es kommt vor, dass in einer Anzucht zwei Keime heranwachsen, die sich optisch unterschiedlich darstellen. Beide stehen dann im „M/Lab®“ unter „Beobachtung“ und „aktiv“. Wenn sich bei der Identifikation herausstellt, dass es sich bei beiden Anzüchten um denselben Keim handelt, wird die eine Anzucht der Probe im System als ,inaktiv“ geführt, die andere weiterhin als „aktiv“ und als „identifiziert“. Dieses Vorgehen ist notwendig, um den Umfang der erhobenen Diagnosen und eine Mehrfachnennung von Keimen zu vermeiden.

\subsection{Erhebung des Datensatzes (Einschluss/Ausschlusskriterien)}

Mit einem SQL-Skript wurde der mikrobiologische Datensatz aus dem „M/Lab®“ extrahiert. Dieser enthielt die Stationsnummer, Fallnummer, die Art der Probe (Abstrich etc.), die Tagebuchnummer, die Patientennummer, das Datum der letzten Änderung an der M/Lab®-Datei, Lokalisation der Probenentnahme und die Beschreibung des Befundes.

Es wurden alle Einträge erfasst, die seit Beginn der digitalen Datenerfassung im Jahr 2004 im „M/Lab®“ erstellt worden sind. Als Filter wurden die Stationen '4090', '4091', '4092', '4093', '4094', '4095', '4096', '4099', '4190' und '4199' angegeben. Es wurden nur Keime in den Datensatz aufgenommen, die identifiziert und im System als „aktiv“ gekennzeichnet waren.

Der Datensatz wurde durch die Abteilung „Zentrales Datenmanagement“ der UMG mit Daten aus dem SAP-System der UMG und dem „ID-Scorer ${ }^{\circledR}$ der Psychiatrie vervollständigt. Es wurden mittels SQL-Skript den jeweiligen Patientennummern die Fallnummer aus der Gesamtdatei, das Aufnahmejahr, die Aufnahmestation, das Entlassungsjahr, die Entlassungsstation, die Verweildauer in Tagen, das Alter, das Geschlecht, die Hauptdiagnose, die Nebendiagnosen, die OPS, das Gesamtentgelt, die Fallart (ob voll- oder teilstationär) und die Krankenkasse hinzugefügt.

Die Patientennummern wurden durch die SQL-Funktion „newid $\left({ }^{\text {“ }}\right.$ pseudonymisiert, damit keine Rückschlüsse auf den jeweiligen Patienten gezogen werden können und die Auswertung anonym erfolgen kann.

Nicht in den Datensatz aufgenommen wurden Patienten der Psychosomatischen Abteilung, Angehörige, die als Besucher im Datensatz erschienen, Patienten, die sich zum Erhebungszeitpunkt in Behandlung befanden und kein Entlassungsdatum hatten, 
unvollständige Patientendaten und Patienten, die nicht von der Psychiatrie aufgenommen oder entlassen worden sind.

\subsection{Bearbeitung des Datensatzes}

Der vorliegende Datensatz beinhaltete 20.894 Datenpunkte. Um zwischen positivem, negativem und keinem Testergebnis unterscheiden zu können, wurde die Variable „pos_neg_Testergebnis“ erstellt. Jeder diagnostizierte Keim (Bakterium, Virus oder Pilz) wurde zu den positiven Testungen gezählt. Alle mikrobiologischen Datenpunkte mit negativem Keimnachweis, den Diagnosen „Standortflora“ und „physiologische Flora“ wurden zu den negativen Testungen gezählt. Alle anderen Datenpunkte wurden zu der Gruppe „nicht getestet““ zusammengefasst.

Die Gefahr einer Infektion steigt generell mit fortschreitender Aufenthaltsdauer auf einer Station an. Um diese zeitliche Konfundierung in der vorliegenden Studie zu reduzieren sowie Überrepräsentationen einzelner Patienten im Datensatz zu vermeiden, wurde von jedem Patienten nur der jeweils erste Aufenthalt in der Klinik für Psychiatrie und Psychologie der UMG und bei mehrfach erfolgter Testung während des ersten Aufenthaltes der erste erhobenen Befund in die Auswertung aufgenommen $(N=8.545)$. Für die Auswertung der Hypothesen zu Zusammenhängen zwischen Verweildauer, Lebensalter und bakteriellen Infektionen (H1.1, H1.2, H2 und H3) wurde auf die Variablen positives/negatives Testergebnis, Verweildauer, Alter, Geschlecht, Hauptdiagnose und Teil-/Vollstationär zugegriffen.

Für die Auswertung der Hypothese zu Assoziationen zwischen Bakterienfamilien und Diagnose-Clustern (H4) wurden die Variablen „F-Achse“, „Diagnose-Cluster“ und „KeimFamilie" erstellt.

\subsubsection{Bildung der Variable „F-Achse“}

Um einen Eindruck von der Gesamtverteilung aller Hauptdiagnosen zu bekommen, wurde die Variable „F-Achse“ erstellt. Diese sortiert jede Hauptdiagnose ihrer übergeordneten Diagnosen-Familie nach ICD-10-GM-2017 zu (s. Tabelle 11).

\subsubsection{Bildung der Diagnose-Cluster}

Aus insgesamt 314 vergebenen unterschiedlichen Hauptdiagnosen in der vorliegenden Stichprobe wurden zur Analyse vier Diagnose-Cluster gebildet. Basierend auf dem ICD-10- 
GM-2017-Diagnose-Katalog wurden die laut Statistischem Bundesamt häufigsten Hauptdiagnosen (Statistisches Bundesamt - Die 10 häufigsten psychischen und Verhaltensstörungen 2015) nach klinischer Erscheinung und Behandlungsform sinngemäß zusammengefasst und zusätzlich ähnliche Störungsbilder hinzugefügt. Es ergaben sich folgende Cluster: (1) Unipolare Depressionen („F32-F33“, $n=2.553,29,9 \%$ ); (2) Psychische und Verhaltensstörungen durch Alkohol („F10“, $n=1.200,14,0 \%$ ); (3) Schizophrenie, schizotype und wahnhafte Störungen („F20-F29“, $n=1.016,11,9 \%$ ). Aufgrund der hohen zu erwartenden Keimbelastung bei höherem Lebensalter wurde trotz geringerer Fallzahlen zusätzlich das Cluster (4) Demenzen („F00-F03“ und G-Diagnosen, n $=342,4,0 \%$ ) erstellt, da prognostisch die Anzahl an Demenzerkrankten auf ca. 3 Millionen ansteigen wird (Alzheimer-Europe.org - Prevalence of dementia in Europe 2013). Aufgrund der Kreuz-Stern-Verschlüsselung im Bereich der Demenzen wurden dem Demenz-Cluster als G-Diagnose verschlüsselte Demenzpatienten ${ }^{1}$ hinzugefügt. Die übrigen Fälle wurden als Referenzgruppe (5) „Andere Diagnosen“ ( $n=3434,40,2 \%$ ) zusammengefasst. Für die Häufigkeit der einzelnen Hauptdiagnosen in dem jeweiligen Cluster s. Tabelle 1, Tabelle 2, Tabelle 3 und Tabelle 4.

Tabelle 1. Inhalt des Clusters „F32-F33“

\begin{tabular}{lccc}
\hline Diagnose & $n$ & Anteil Cluster (\%) & Anteil Gesamt (\%) \\
\hline F33.2 & 788 & $31,0 \%$ & $9,2 \%$ \\
F32.2 & 744 & $29,3 \%$ & $8,7 \%$ \\
F32.1 & 387 & $15,2 \%$ & $4,5 \%$ \\
F33.1 & 304 & $12,0 \%$ & $3,6 \%$ \\
F32.3 & 127 & $5,0 \%$ & $1,5 \%$ \\
F33.3 & 119 & $4,7 \%$ & $1,4 \%$ \\
F32.9 & 34 & $1,3 \%$ & $0,4 \%$ \\
F32.0 & 25 & $1,0 \%$ & $0,3 \%$ \\
F33.0 & 11 & $0,4 \%$ & $0,1 \%$ \\
\hline Anmerkung: $n_{\mathrm{F} 32-\mathrm{F} 33}=2553$. & &
\end{tabular}

$1+$ G30.0 (Alzheimer-Krankheit mit frühem Beginn; F00.0*), +G30.1 (Alzheimer-Krankheit mit spätem Beginn; F00.1*), +G30.8 (Sonstige Alzheimer-Krankheit; F00.2*), +G30.9 (Alzheimer-Krankheit, nicht näher bezeichnet; F00.9*) und +G31.82 (LewyKörper-Krankheit; F02.8*) 
Tabelle 2. Inhalt des Clusters „F10“

\begin{tabular}{lccc}
\hline \multicolumn{1}{c}{ Diagnose } & $n$ & Anteil Cluster (\%) & Anteil Gesamt (\%) \\
\hline F10.2 & 929 & $77,4 \%$ & $10,9 \%$ \\
F10.0 & 140 & $11,7 \%$ & $1,6 \%$ \\
F10.1 & 38 & $3,2 \%$ & $0,4 \%$ \\
F10.3 & 38 & $3,2 \%$ & $0,4 \%$ \\
F10.4 & 27 & $2,3 \%$ & $0,3 \%$ \\
F10.6 & 17 & $1,4 \%$ & $0,2 \%$ \\
F10.5 & 5 & $0,4 \%$ & $0,1 \%$ \\
F10.7 & 3 & $0,3 \%$ & $<0,1 \%$ \\
F10.8 & 2 & $0,2 \%$ & $<0,1 \%$ \\
F10.9 & 1 & $0,1 \%$ & $<0,1 \%$ \\
\hline Anm
\end{tabular}

Anmerkung: $n_{\mathrm{F} 10}=1200$.

Tabelle 3. Inhalt des Clusters „F20-F29“

\begin{tabular}{lccc}
\hline \multicolumn{1}{c}{ Diagnose } & $n$ & Anteil Cluster (\%) & Anteil Gesamt (\%) \\
\hline F20.0 & 556 & $54,7 \%$ & $6,5 \%$ \\
F25.1 & 90 & $8,9 \%$ & $1,1 \%$ \\
F22.0 & 72 & $7,1 \%$ & $0,8 \%$ \\
F25.0 & 70 & $6,9 \%$ & $0,8 \%$ \\
F23.0 & 20 & $2,0 \%$ & $0,2 \%$ \\
F32.1 & 20 & $2,0 \%$ & $0,2 \%$ \\
F25.2 & 20 & $2,0 \%$ & $0,2 \%$ \\
F25.9 & 17 & $1,7 \%$ & $0,2 \%$ \\
F29 & 16 & $1,6 \%$ & $0,2 \%$ \\
F23.2 & 14 & $1,4 \%$ & $0,2 \%$ \\
F20.1 & 13 & $1,3 \%$ & $0,2 \%$ \\
F20.2 & 13 & $1,3 \%$ & $0,2 \%$ \\
F20.5 & 13 & $1,3 \%$ & $0,2 \%$ \\
F20.9 & 13 & $1,3 \%$ & $0,2 \%$ \\
F20.8 & 10 & $1,0 \%$ & $0,1 \%$ \\
F21 & 10 & $1,0 \%$ & $0,1 \%$ \\
F28 & 9 & $0,9 \%$ & $0,1 \%$ \\
F23.9 & 8 & $0,8 \%$ & $0,1 \%$ \\
F20.3 & 7 & $0,7 \%$ & $0,1 \%$ \\
F23.8 & 7 & $0,7 \%$ & $0,1 \%$ \\
F23.3 & 5 & $0,5 \%$ & $0,1 \%$ \\
F22.9 & 4 & $0,4 \%$ & $<0,1 \%$ \\
F25.8 & 4 & $0,4 \%$ & $<0,1 \%$ \\
F20.6 & 3 & $0,3 \%$ & $<0,1 \%$ \\
F22.8 & 1 & $0,1 \%$ & $<0,1 \%$ \\
F24 & 1 & $0,1 \%$ & $<0,1 \%$ \\
\hline Anm $\%$ \\
\hline
\end{tabular}

Anmerkung: $n_{\mathrm{F} 20-\mathrm{F} 29}=1016$. 
Tabelle 4. Inhalt des Clusters „F00-F03“ (inkl. ausgewählter G-Diagnosen)

\begin{tabular}{lccc}
\hline \multicolumn{1}{c}{ Diagnose } & $n$ & Anteil Cluster (\%) & Anteil Gesamt (\%) \\
\hline F03 & 165 & $48,2 \%$ & $1,9 \%$ \\
F01.9 & 11 & $3,2 \%$ & $0,1 \%$ \\
F01.3 & 9 & $2,6 \%$ & $0,1 \%$ \\
F01.2 & 7 & $2,0 \%$ & $0,1 \%$ \\
F01.0 & 6 & $1,8 \%$ & $0,1 \%$ \\
F01.1 & 6 & $1,8 \%$ & $0,1 \%$ \\
F00.1 & 4 & $1,2 \%$ & $0,1 \%$ \\
F01.8 & 3 & $0,9 \%$ & $0,1 \%$ \\
F00.2 & 1 & $0,3 \%$ & $<0,1 \%$ \\
F02.0 & 1 & $0,3 \%$ & $<0,1 \%$ \\
F02.3 & 1 & $0,3 \%$ & $<0,1 \%$ \\
& & & \\
\hline G30.1 & 68 & $19,9 \%$ & $1,9 \%$ \\
G30.0 & 24 & $7,0 \%$ & $0,3 \%$ \\
G31.82 & 16 & $4,7 \%$ & $0,2 \%$ \\
G30.8 & 10 & $2,9 \%$ & $0,1 \%$ \\
G30.9 & 10 & $2,9 \%$ & $0,1 \%$ \\
\hline Anmerkung: $n_{\text {F00 }} \% 30$ &
\end{tabular}

Anmerkung: $n_{\mathrm{F} 00-\mathrm{F} 03 \text { (inkl. G-Dia.) }}=342$.

\subsubsection{Bildung der Keimfamilien}

Bei $n=376$ teils mehrfach positiv getesteten Patienten sind zum jeweils ersten Messungszeitpunkt 56 verschiedene Bakterienarten nachgewiesen worden. Um eine Auswertung vornehmen zu können, wurden die Bakterienarten ihrer hierarchischen Rangstufe „Familie“ zu geordnet. Hierzu wurde die Taxonomie der LPSN verwendet (Parte 2014). Es ergaben sich die vier häufigsten biologischen Familien in absteigender Reihenfolge: (1) Enterobacteriaceae ( $n=169,44,9 \%)$, (2) Staphylococcaceae $(n=149,39,6 \%),(3)$ Enterococcaceae $(n=91,24,2 \%)$ und (4) Corynebacteriaceae $(n=46,12,2 \%)$.

Wenn ein Patient bei der ersten Messung einen mehrfach positiven Befund mit Bakterienarten verschiedener Bakterienfamilien hatte, wurden beide Bakterienfamilien in die Auswertung aufgenommen (mehrfach-positiv). Wenn beide Bakterienarten zur selben Familie zählten, wurde dieser Befund einmal mit in die Auswertung aufgenommen (einfach-positiv).

\subsubsection{Globale Übersicht der Bakterienarten pro Bakterienfamilie}

Aufgrund einbezogener mehrfach-positiver Befunde ergeben sich bei den einbezogenen Patienten Überschneidungen zwischen den einzelnen Bakterienfamilien. Dementsprechend werden die Bakterienarten pro Bakterienfamilie bei den positiv getesteten Patienten mit Erstkontakt zur Klinik der Psychiatrie und Psychosomatik der UMG nicht separat 
aufgelistet. Um einen Überblick über das Keimspektrum innerhalb der Bakterienfamilien zu ermöglichen, werden im Folgenden die Bakterienarten pro Bakterienfamilie des globalen Datensatzes aufgelistet (s. Tabelle 5, Tabelle 6, Tabelle 7 und Tabelle 8). Dadurch werden zeitlich aufeinanderfolgende Mehrfachbestimmungen eines Keimes pro Patient mit einbezogen.

Tabelle 5. Zusammensetzung der Familie der Enterobacteriaceae

\begin{tabular}{lccc}
\hline \multicolumn{1}{c}{ Bakterienart } & $n$ & $\%$ & kumulierte $\%$ \\
\hline Escherichia coli (B96.2!) & 288 & 48,4 & 48,4 \\
Escherichia coli (U80.4!) & 56 & 9,4 & 57,8 \\
Proteus mirabilis & 33 & 5,5 & 63,4 \\
Klebsiella pneumoniae & 30 & 5,0 & 68,4 \\
Proteus species & 27 & 4,5 & 72,9 \\
coliforme Stäbchen & 23 & 3,9 & 76,8 \\
Klebsiella oxytoca & 17 & 2,9 & 79,7 \\
Enterobacter cloacae & 15 & 2,5 & 82,2 \\
Serratia marcescens & 15 & 2,5 & 84,7 \\
Citrobacter freundii & 11 & 1,8 & 86,6 \\
Citrobacter koseri & 9 & 1,5 & 88,1 \\
Enterobacter cloacae-Komplex & 9 & 1,5 & 89,6 \\
Morganella morganii & 9 & 1,5 & 91,1 \\
Enterobacter aerogenes & 8 & 1,3 & 92,4 \\
Klebsiella pneumoniae & 6 & 1,0 & 93,4 \\
Proteus vulgaris & 6 & 1,0 & 94,5 \\
Salmonella infantis & 6 & 1,0 & 95,5 \\
Citrobacter koseri-Komplex & 4 & 0,7 & 96,1 \\
Enterobacter species & 4 & 0,7 & 96,8 \\
Hafnia alvei & 2 & 0,3 & 97,1 \\
Pantoea species & 2 & 0,3 & 97,5 \\
Salmonella-Gruppe C & 2 & 0,3 & 97,8 \\
Citrobacter amalonaticus & 1 & 0,2 & 98,0 \\
Citrobacter freundii-Komplex & 1 & 0,2 & 98,2 \\
Enterobacter cloacae-Komplex & 1 & 0,2 & 98,3 \\
Klebsiella oxytoca & 1 & 0,2 & 98,5 \\
Pantoea agglomerans & 1 & 0,2 & 98,7 \\
Proteus mirabilis & 1 & 0,2 & 98,8 \\
Providencia stuartii & 1 & 0,2 & 99,0 \\
Raoultella ornithinolytica & 1 & 0,2 & 99,2 \\
Raoultella ornithinolytica & 1 & 0,2 & 99,3 \\
Raoultella planticola & 0,2 & 99,5 \\
Salmonella agona & 0,2 & 99,7 \\
Salmonella species & 0,2 & 99,8 \\
Serratia odorifera & 0,2 & 100,0 \\
\hline Anmerkung: Summe ale Bakteris \\
\hline
\end{tabular}

Anmerkung: Summe aller Bakterienarten innerhalb der Familie der Enterobacteriaceae, unter Einbezug mehrfach-positiver Werte aller Patienten $\left(\sum=595\right.$ Nachweise im globalen Datensatz). 
Tabelle 6. Zusammensetzung der Familie der Enterococcaceae

\begin{tabular}{lccc}
\hline \multicolumn{1}{c}{ Bakterienart } & $n$ & $\%$ & kumulierte $\%$ \\
\hline Enterococcus faecalis (B95.2!) & 160 & 57,1 & 57,1 \\
Enterococcus species & 73 & 26,1 & 83,2 \\
Enterococcus faecalis (U80.21!) & 29 & 10,4 & 93,6 \\
Enterococcus faecium (B95.2!) & 13 & 4,6 & 98,2 \\
Enterococcus casseliflavus & 2 & 0,7 & 98,9 \\
Enterococcus avium & 1 & 0,4 & 99,3 \\
Enterococcus faecium (U80.31!) & 1 & 0,4 & 99,6 \\
Enterococcus raffinosus & 1 & 0,4 & 100,0 \\
\hline
\end{tabular}

Anmerkung: Summe aller Bakterienarten innerhalb der Familie der Enterococcaceae, unter Einbezug mehrfach-positiver Werte aller Patienten $(\Sigma=280$ Nachweise im globalen Datensatz).

Tabelle 7. Zusammensetzung der Familie der Corynebacteriaceae

\begin{tabular}{lccc}
\hline \multicolumn{1}{c}{ Bakterienart } & $n$ & $\%$ & kumulierte \% \\
\hline Corynebacterium species & 116 & 93,5 & 93,5 \\
Corynebacterium striatum & 5 & 4,0 & 97,6 \\
Corynebacterium amycolatum & 1 & 0,8 & 98,4 \\
Corynebacterium-Gruppe F & 1 & 0,8 & 99,2 \\
Corynebacterium propinquum & 1 & 0,8 & 100,0 \\
\hline
\end{tabular}

Anmerkung: Summe aller Bakterienarten innerhalb der Familie der Corynebacteriaceae, unter Einbezug mehrfach-positiver Werte aller Patienten $\left(\sum=124\right.$ Nachweise im globalen Datensatz).

Tabelle 8. Zusammensetzung der Familie der Staphylococcaceae

\begin{tabular}{lccc}
\hline \multicolumn{1}{c}{ Bakterienart } & $n$ & $\%$ & kumulierte $\%$ \\
\hline Staphylococcus epidermidis & 218 & 43,2 & 43,2 \\
Koagulase-negative Staphylokokeken & 109 & 21,6 & 64,8 \\
Staphylococcus aureus (B95.6!) & 104 & 20,6 & 85,3 \\
Staphylococcus aureus /MRS A (U80.01!) & 47 & 9,3 & 94,7 \\
Staphylococcus epidermidis-Gruppe & 9 & 1,8 & 96,4 \\
Staphylococcus hominis & 4 & 0,8 & 97,2 \\
Staphylococcus simulans & 3 & 0,6 & 97,8 \\
Staphylococcus warneri & 3 & 0,6 & 98,4 \\
Staphylococcus aureus (U80.01!) & 2 & 0,4 & 98,8 \\
Staphylococcus haemolyticus & 2 & 0,4 & 99,2 \\
Staphylococcus lugdunensis & 2 & 0,4 & 99,6 \\
Staphylococcus saprophyticus & 1 & 0,2 & 99,8 \\
Staphylococcus sciuri & 1 & 0,2 & 100,0 \\
\hline Anmerkung: Summe all
\end{tabular}

Anmerkung: Summe aller Bakterienarten innerhalb der Familie der Staphylococcaceae, unter Einbezug mehrfach-positiver Werte aller Patienten $\left(\sum=505\right.$ Nachweise im globalen Datensatz).

\subsection{Statistische Auswertung}

Zur Auswertung der Daten wurde die Statistiksoftware SPSS in der Version 24 verwendet.

Für den deskriptiven Teil dieser Dissertation wurden Mittelwerte $(M)$ und Standardabweichungen $(S D)$ ermittelt. 
Um zu überprüfen, ob generelle Unterschiede zwischen den positiv, negativ und nicht getesteten Patienten bezüglich der Verweildauer und des Alters auftraten, wurden Varianzanalysen (UNIANOVA) mit dreistufigem Zwischensubjektfaktor (positiv, negativ, nicht getestet) berechnet. Zudem wurden Post-Hoc Bonferroni-korrigierte Paarvergleiche und die jeweilige Signifikanz zwischen den Faktorstufen berechnet. Zusätzlich wurden die Diagnose-Cluster als zweiter Zwischensubjektfaktor in das jeweilige Modell integriert und zugehörige Bonferroni-korrigierte Paarvergleiche und die jeweilige Signifikanz berechnet.

Zur Überprüfung, ob es Häufungen oder Unterrepräsentationen von Bakterienfamilien innerhalb der Diagnose-Cluster gab, wurden zudem vier Chi-Quadrat-Tests (jeweils $5 \times 2$ Felder-Matrix) und Quotenverhältnisse innerhalb der jeweiligen Matrizen (Quot. = Odds Ratio) berechnet. Gleiches wurde für das Cluster „F00-F03“ und eine altersangepasste Vergleichsgruppe durchgeführt.

Alle Signifikanzen werden auf zweiseitigem Niveau berichtet. Alle $p$-Werte wurden aufgrund der $\alpha$-Fehler-Inflation nach der Bonferroni-Methode für die Anzahl statistischer Tests sowie innerhalb der UNIANOVAs korrigiert.

\subsection{Patientenkollektiv - Gesamtstichprobe}

In die Auswertung der Arbeit wurden retrospektiv Patienten mit eingeschlossen, die in dem Zeitraum vom 01.01.2004 bis zum 31.12.2015 erstmalig Kontakt zu der Klinik für Psychiatrie und Psychotherapie der UMG hatten.

Dieses Patientenkollektiv bestand aus $N=8.545$ Patienten, davon 50,3\% Frauen $(n=$ 4.296) und 49,7\% Männer $(n=4.249)$. Hiervon wurden $11,4 \%(n=978)$ Patienten teilstationär behandelt, $88,6 \%$ vollstationär $(n=7.567)$. Das mittlere Alter war $M=45,905$ Jahre $(S D=17,519)$, die mittlere Verweildauer betrug $M=28,228$ Tage $(S D=32,498)$. Insgesamt wurden $n=7.818$ (91,5\%) Patienten nicht auf Keime getestet, $n=351$ (4,1\%) negativ sowie $n=376(4,4 \%)$ positiv (s. Tabelle 9). 
Tabelle 9. Deskriptive Daten der Gesamtstichprobe und der drei Subgruppen

\begin{tabular}{|c|c|c|c|c|c|c|c|}
\hline & $\sum$ Pat. & $\sum$ weiblich & $\sum$ männlich & $\sum$ vollstat. & $\sum$ teilstat. & $\begin{array}{c}\text { Alter } \\
(M \pm S D)\end{array}$ & $\begin{array}{c}\text { VWD } \\
(M \pm S D)\end{array}$ \\
\hline Gesamt & $N=8.545$ & $\begin{array}{c}4.296 \\
(50,3 \%)\end{array}$ & $\begin{array}{c}4.249 \\
(49,7 \%)\end{array}$ & $\begin{array}{c}7.567 \\
(88,6 \%)\end{array}$ & $\begin{array}{c}978 \\
(11,4 \%)\end{array}$ & $45,91 \pm 17,519$ & $28,23 \pm 32,498$ \\
\hline positiv & $n=376$ & $\begin{array}{c}260 \\
(69,1 \%)\end{array}$ & $\begin{array}{c}116 \\
(30,9 \%)\end{array}$ & $\begin{array}{c}361 \\
(96,0 \%)\end{array}$ & $\begin{array}{c}15 \\
(4,0 \%)\end{array}$ & $57,80 \pm 19,165$ & $46,92 \pm 38,753$ \\
\hline negativ & $n=351$ & $\begin{array}{c}183 \\
(52,1 \%)\end{array}$ & $\begin{array}{c}168 \\
(47,9 \%)\end{array}$ & $\begin{array}{c}333 \\
(94,9 \%)\end{array}$ & $\begin{array}{c}18 \\
(5,1 \%)\end{array}$ & $51,02 \pm 18,328$ & $51,92 \pm 50,602$ \\
\hline k. T. & $n=7.818$ & $\begin{array}{c}3.853 \\
(49,3 \%)\end{array}$ & $\begin{array}{c}3.965 \\
(50,7 \%)\end{array}$ & $\begin{array}{c}6.873 \\
(87,9 \%)\end{array}$ & $\begin{array}{c}945 \\
(12,1 \%)\end{array}$ & $45,10 \pm 17,151$ & $26,27 \pm 30,361$ \\
\hline
\end{tabular}

Anmerkung: positiv $=$ positiv getestete Patienten, negativ $=$ negativ getestete Patienten, $k . T .=$ nicht getestete Patienten; $\sum_{\text {vollstat. }}=$ vollstationäre Patienten, $\sum_{\text {teilstat. }}=$ teilstationäre Patienten.

Insgesamt wurden 314 unterschiedliche Hauptdiagnosen vergeben. 95,3\% der Patienten erhielten eine F-Diagnose $(n=8.142)$ als Hauptdiagnose. Die fünf häufigsten Diagnosen der Gesamtstichprobe sind in Tabelle 10 zusammengefasst.

Tabelle 10. Die fünf häufigsten Diagnosen der Gesamtstichprobe

\begin{tabular}{lccc}
\hline \multicolumn{1}{c}{ Diagnose } & $n$ & $\%$ & kumulierte $\%$ \\
\hline F10.2 & 929 & 10,9 & 10,9 \\
F33.2 & 788 & 9,2 & 20,1 \\
F32.2 & 744 & 8,7 & 28,8 \\
F20.0 & 556 & 6,5 & 35,3 \\
F43.2 & 396 & 4,6 & 39,9 \\
\hline
\end{tabular}


Für die Aufteilung der $n=8.142$ Hauptdiagnosen nach den zehn F-Achsen der ICD-10GM-2017-Diagnosen s. Tabelle 11 und Abbildung 1.

Tabelle 11. Aufteilung der Diagnosen der Gesamtstichprobe nach F-Achsen

\begin{tabular}{cccc}
\hline F-Achse & $n$ & $\%$ & kumulierte $\%$ \\
\hline 3 & 2.938 & 36,1 & 36,1 \\
1 & 1.642 & 20,2 & 56,3 \\
4 & 1.397 & 17,2 & 73,4 \\
2 & 1.016 & 12,5 & 85,9 \\
0 & 498 & 6,1 & 92,0 \\
6 & 321 & 3,9 & 95,9 \\
5 & 275 & 3,4 & 99,3 \\
9 & 37 & 0,5 & 99,8 \\
8 & 10 & 0,1 & 99,9 \\
7 & 8 & 0,1 & 100,0 \\
\hline Gesamt & 8.142 & 100,0 & \\
\hline
\end{tabular}

Anmerkung: keine F-Diagnose $n=403 ; N=8.545$

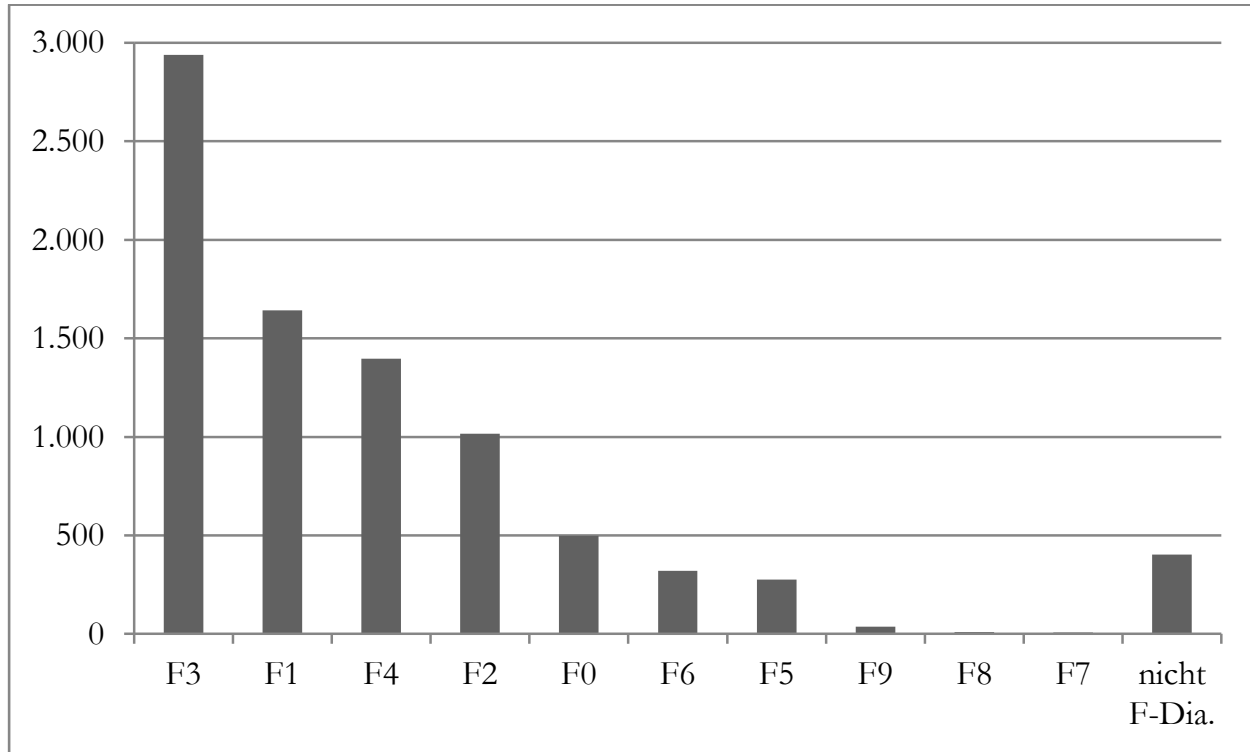

Abbildung 1. Anzahl der Diagnosen der Patienten der Gesamtstichprobe, eingeteilt nach F-Achsen

\subsubsection{Untergruppe des Patientenkollektivs - positiv getestete Patienten}

Diese Untergruppe des Patientenkollektivs bestand aus $n=376$ Patienten, davon 69,1\% Frauen $(n=260)$ und 30,9\% Männer $(n=116)$. Hiervon wurden 4\% der Patienten $(n=15)$ teilstationär behandelt, $96 \%$ der Patienten $(n=361)$ vollstationär. Das mittlere Alter war $M=57,80$ Jahre $(S D=19,165)$, die mittlere Verweildauer betrug $M=46,92$ Tage $(S D=$ 38,753) (s. Tabelle 9). 
Insgesamt wurden 86 unterschiedliche Hauptdiagnosen vergeben. 93,1\% der Patienten erhielten eine F-Diagnose $(n=350)$ als Hauptdiagnose. Für die fünf häufigsten Diagnosen s. Tabelle 12.

Tabelle 12. Die fünf häufigsten Diagnosen aller positiv getesteten Patienten

\begin{tabular}{lccc}
\hline \multicolumn{1}{c}{ Diagnose } & $n$ & $\%$ & kumulierte $\%$ \\
\hline F32.2 & 42 & 11,2 & 11,2 \\
F33.2 & 35 & 9,3 & 20,5 \\
F10.2 & 26 & 6,9 & 27,4 \\
F20.0 & 25 & 6,6 & 34,0 \\
F03 & 23 & 6,1 & 40,2 \\
\hline
\end{tabular}

Für die Aufteilung der $n=350$ Hauptdiagnosen nach den zehn F-Achsen der ICD-10-GM2017-Diagnosen s. Tabelle 13 und Abbildung 2.

Tabelle 13. Aufteilung aller Diagnosen der positiv getesteten Patienten nach F-Achsen

\begin{tabular}{cccc}
\hline F-Achse & $n$ & $\%$ & kumulierte $\%$ \\
\hline 3 & 149 & 42,6 & 42,6 \\
1 & 60 & 17,1 & 59,7 \\
2 & 52 & 14,9 & 74,6 \\
0 & 51 & 14,6 & 89,1 \\
4 & 30 & 8,6 & 97,7 \\
6 & 7 & 2,0 & 99,7 \\
5 & 1 & 0,3 & 100,0 \\
\hline Gesamt & 350 & 100,0 & \\
\hline
\end{tabular}

Anmerkung: keine F-Diagnose $n=26 ; N=376$

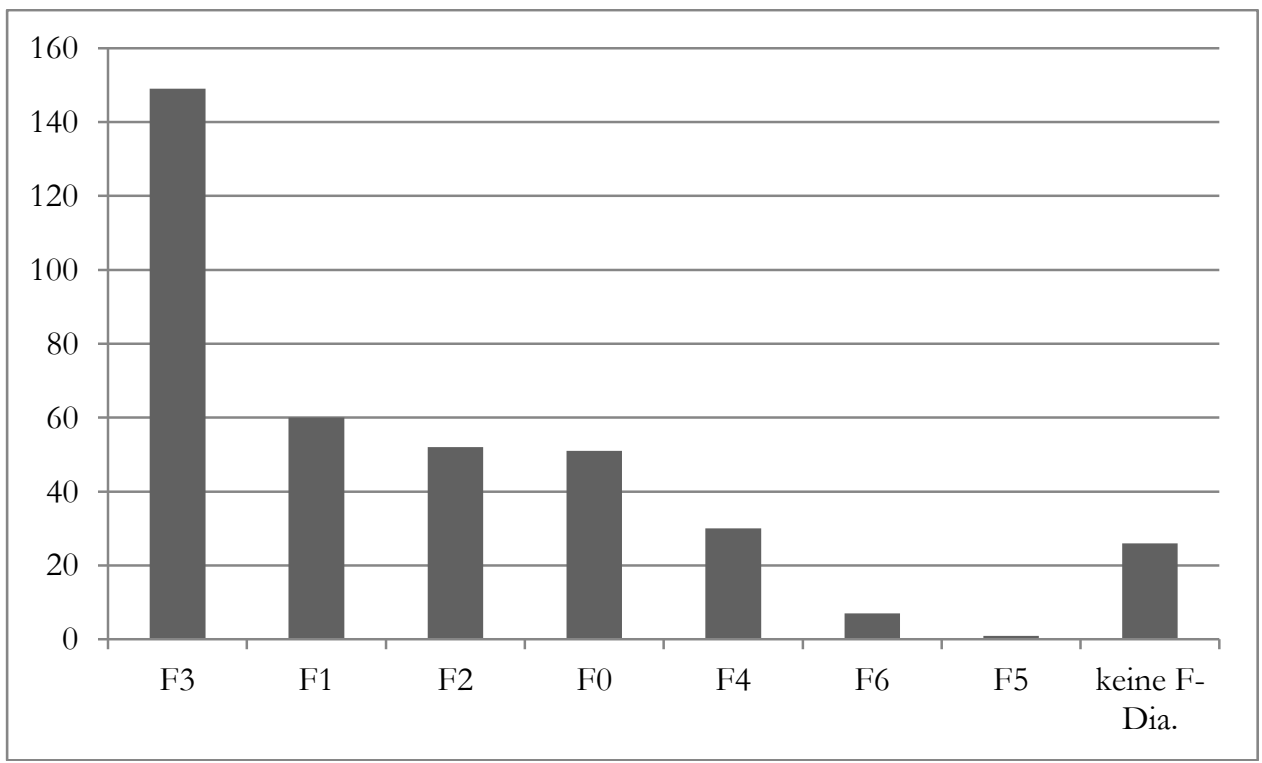

Abbildung 2. Anzahl der Diagnosen aller positiv getesteten Patienten, eingeteilt nach F-Achsen 


\subsubsection{Untergruppe des Patientenkollektivs - negativ getestete Patienten}

Diese Untergruppe des Patientenkollektivs bestand aus $n=531$ Patienten, davon 52,1\% Frauen $(n=183)$ und $47,9 \%$ Männer $(n=168)$. Hiervon wurden $5,1 \%$ der Patienten $(n=$ 18) teilstationär behandelt, $94,9 \%$ der Patienten $(n=333)$ vollstationär. Das mittlere Alter war $M=51,002$ Jahre $(S D=18,328)$, die mittlere Verweildauer betrug $M=51,920$ Tage $(S D=50,602)($ s. Tabelle 9$)$.

Insgesamt wurden 73 unterschiedliche Hauptdiagnosen vergeben. 97,7\% der Patienten erhielten eine F-Diagnose $(n=343)$ als Hauptdiagnose. Für die fünf häufigsten Diagnosen s. Tabelle 14.

Tabelle 14. Die fünf häufigsten Diagnosen aller negativ getesteten Patienten

\begin{tabular}{lccc}
\hline \multicolumn{1}{c}{ Diagnose } & $n$ & $\%$ & kumulierte $\%$ \\
\hline F32.2 & 43 & 12,3 & 12,3 \\
F33.2 & 41 & 11,7 & 23,9 \\
F10.2 & 34 & 9,7 & 33,6 \\
F20.0 & 27 & 7,7 & 41,3 \\
F03 & 16 & 4,6 & 45,9 \\
\hline
\end{tabular}

Für die Aufteilung der $n=343$ Hauptdiagnosen nach den zehn F-Achsen der ICD-10-GM2017-Diagnosen s. Tabelle 15 und Abbildung 3.

Tabelle 15. Aufteilung aller Diagnosen der negativ getesteten Patienten nach F-Achsen

\begin{tabular}{cccc}
\hline F-Achse & $n$ & $\%$ & kumulierte $\%$ \\
\hline 3 & 151 & 44,0 & 44,0 \\
1 & 62 & 18,1 & 62,1 \\
2 & 48 & 14,0 & 76,1 \\
0 & 41 & 12,0 & 88,0 \\
4 & 28 & 8,2 & 96,2 \\
6 & 9 & 2,6 & 98,8 \\
5 & 2 & 0,6 & 99,4 \\
9 & 2 & 0,6 & 100,0 \\
\hline Gesamt & 343 & 100,0 & \\
\hline
\end{tabular}

Anmerkung: keine F-Diagnose $n=8 ; N=351$ 


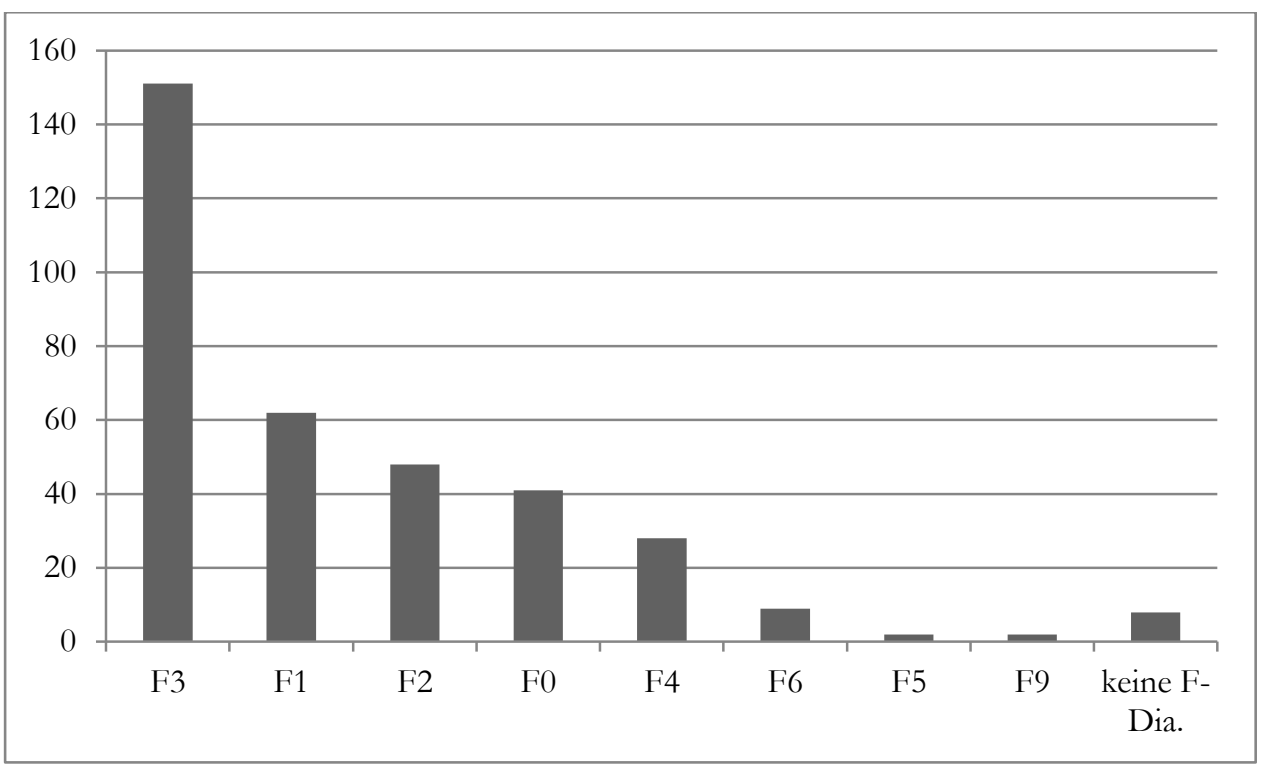

Abbildung 3. Anzahl der Diagnosen aller negativ getesteten Patienten, eingeteilt nach F-Achsen

\subsubsection{Untergruppe des Patientenkollektivs - nicht getestete Patienten}

Diese Untergruppe des Patientenkollektivs bestand aus $n=7.818$ Patienten, davon 49,3\% Frauen $(n=3.853)$ und 50,7\% Männer $(n=3.965)$. Hiervon wurden $12,1 \%$ der Patienten $(n$ $=945)$ teilstationär behandelt, $87,9 \%$ der Patienten $(n=6.873)$ vollstationär. Das mittlere Alter war $M=45,103$ Jahre $(S D=17,151)$, die mittlere Verweildauer betrug $M=26,265$ Tage $(S D=30,361)($ s. Tabelle 9).

Insgesamt wurden 305 unterschiedliche Hauptdiagnosen vergeben. 95,3\% der Patienten erhielten eine F-Diagnose $(n=7.449)$ als Hauptdiagnose. Für die fünf häufigsten Diagnosen s. Tabelle 16.

Tabelle 16. Die fünf häufigsten Diagnosen aller nicht getesteten Patienten

\begin{tabular}{lccc}
\hline \multicolumn{1}{c}{ Diagnose } & $n$ & $\%$ & kumulierte $\%$ \\
\hline F10.2 & 869 & 11,1 & 11,1 \\
F33.2 & 712 & 9,1 & 20,2 \\
F32.2 & 659 & 8,4 & 28,7 \\
F20.0 & 504 & 6,4 & 35,1 \\
F43.2 & 377 & 4,8 & 39,9 \\
\hline
\end{tabular}


Für die Aufteilung der $n=7.449$ Hauptdiagnosen nach den zehn F-Achsen der ICD-10GM-2017-Diagnosen s. Tabelle 17 und Abbildung 4.

Tabelle 17. Aufteilung aller Diagnosen der nicht getesteten Patienten nach F-Achsen

\begin{tabular}{cccc}
\hline F-Achse & $n$ & $\%$ & kumulierte $\%$ \\
\hline 3 & 2.638 & 33,7 & 35,4 \\
1 & 1.520 & 19,4 & 55,8 \\
4 & 1.339 & 17,1 & 73,8 \\
2 & 916 & 11,7 & 86,1 \\
0 & 406 & 5,2 & 91,5 \\
6 & 305 & 3,9 & 95,6 \\
5 & 272 & 3,5 & 99,3 \\
9 & 35 & 0,4 & 99,8 \\
8 & 10 & 0,1 & 99,9 \\
7 & 8 & 0,1 & 100,0 \\
\hline Gesamt & 7.449 & 100,0 & \\
\hline
\end{tabular}

Anmerkung: keine F-Diagnose $n=369 ; N=7.818$

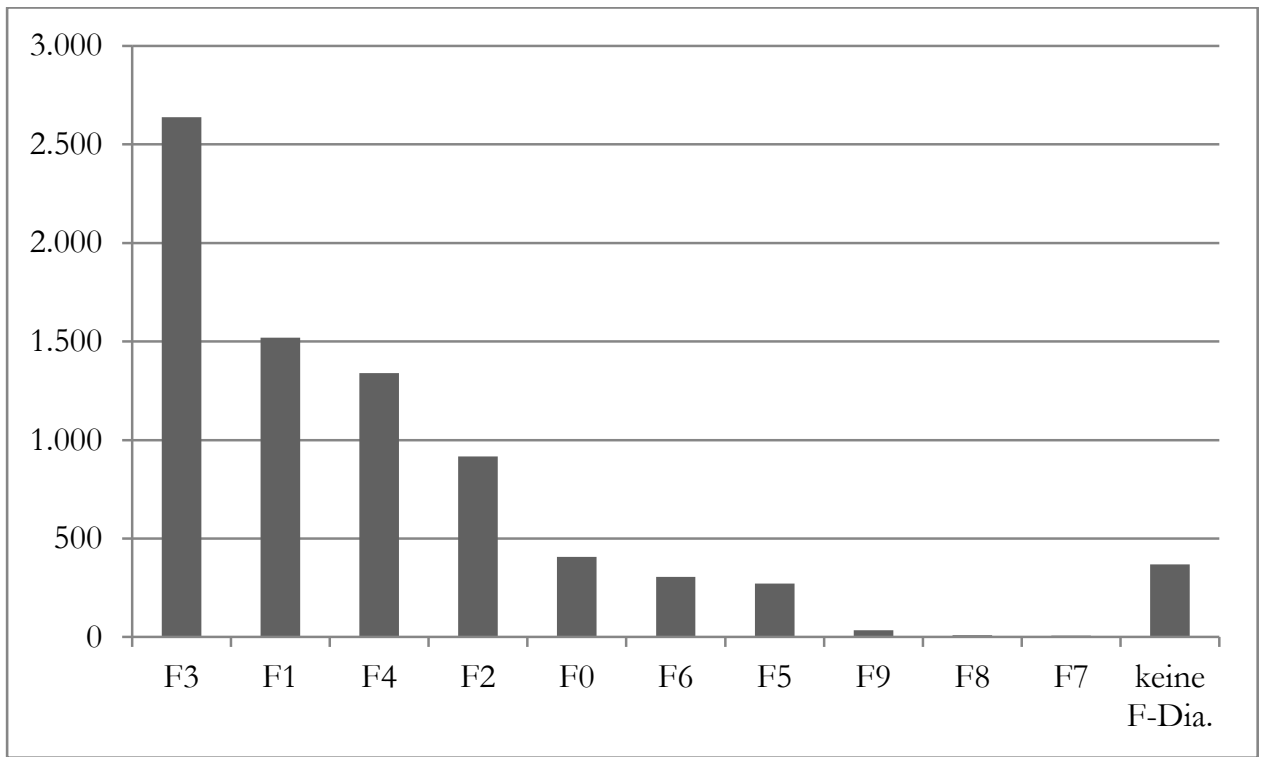

Abbildung 4. Anzahl der Diagnosen aller nicht getesteten Patienten, eingeteilt nach F-Achsen 


\section{Ergebnisse}

\subsection{Mikrobiologische Untersuchung und Verweildauer}

\subsubsection{Mikrobiologische Untersuchung und Verweildauer bei positiv, negativ und nicht getesteten Patienten (Hypothese 1)}

Das Ergebnis der Zwischensubjekteffekte der UNIANOVA lieferte einen Hinweis auf Abweichungen der Variable „Verweildauer in Tagen“ zwischen den Gruppen der positiv, negativ und nicht getesteten Patienten $(F(2,8530)=106,473, p<, 001 ;$ s. Tabelle 18).

Tabelle 18. Ergebnis der Zwischensubjekteffekte mit Verweildauer als abhängiger Variable

\begin{tabular}{lccccc}
\hline \multicolumn{1}{c}{ Quelle } & $\begin{array}{c}\text { Quadratsumme } \\
\text { vom Typ III }\end{array}$ & $d f$ & $\begin{array}{c}\text { Mittel der } \\
\text { Quadrate }\end{array}$ & $F$ & $p$ \\
\hline Korrigiertes Modell & 951102,939 & 14 & $67.935,924$ & 71,786 & 0,000 \\
\hline Konstanter Term & $1.816 .437,896$ & 1 & $1.816 .437,896$ & $1.919,383$ & 0,000 \\
\hline pos_neg_Testergebnis & $201.525,341$ & 2 & $100.762,670$ & 106,473 & 0,000 \\
\hline Hauptdiagnose_Familie & $131.545,664$ & 4 & $32.886,416$ & 34,750 & 0,000 \\
\hline $\begin{array}{l}\text { pos_neg_Testergebnis } \\
* \text { Hauptdiagnose_Familie }\end{array}$ & $25.973,428$ & 8 & $3.246,678$ & 3,431 & 0,001 \\
\hline Fehler & $8.072 .497,151$ & 8.530 & 946,365 & & \\
\hline Gesamt & $15.832 .638,000$ & 8.545 & & & \\
\hline Korrigierte Gesamtvariation & $9.023 .600,090$ & 8.544 & & & \\
\hline Antrant
\end{tabular}

Anmerkung: $d f=$ Freiheitsgrade; $F=$ F-Wert; $p=$ Signifikanz

Zur Überprüfung der durchschnittlichen Verweildauer wurden Mittelwerte und Standardabweichungen der Gruppen der positiv, negativ und nicht getesteten Patienten ermittelt (s. Tabelle 19).

Tabelle 19. Mittelwerte der Verweildauer in Tagen, Standardabweichung der Verweildauer und Anzahl der Fälle der positiv, negativ und nicht getesteten Patienten

\begin{tabular}{lcc}
\hline \multicolumn{1}{c}{ Testergebnis } & $(M \pm S D)$ & $n$ \\
\hline positiv & $46,92 \pm 38,753$ & 376 \\
negativ & $51,92 \pm 50,602$ & 351 \\
nicht getestet & $26,27 \pm 30,361$ & 7.818 \\
\hline
\end{tabular}

Anmerkung: $M=$ Mittelwert; $S D=$ Standardabweichung; $n=$ Anzahl der Fälle 
Zur Überprüfung, ob sich die gefundenen Mittelwerte signifikant unterscheiden, wurden

Bonferroni-korrigierte Paarvergleiche durchgeführt und zur Veranschaulichung ein Säulendiagramm erstellt (s. Tabelle 20 und Abbildung 5).

Tabelle 20. Ergebnisse des Bonferroni-korrigierten Post-Hoc-Tests zwischen den positiv, negativ und nicht getesteten Patienten in Bezug auf die mittlere Verweildauer

\begin{tabular}{llccccc}
\hline & & & & & \multicolumn{2}{c}{$95 \%$ Konfidenzintervall } \\
\cline { 6 - 7 } Testergebnis & Testergebnis & $M_{\text {Diff }}$ & $S E$ & $p$ & Obergrenze & Untergrenze \\
\hline \multirow{2}{*}{ positiv } & negativ & $-5,00$ & 2,283 & 0,086 & $-10,46$ & 0,47 \\
& nicht getestet & $20,66\left(^{*}\right)$ & 1,624 & 0,000 & 16,77 & 24,55 \\
\hline negativ & nicht getestet & $25,65\left(^{*}\right)$ & 1,678 & 0,000 & 21,64 & 29,67 \\
\hline Annnyyy
\end{tabular}

Anmerkung: $(*)=$ signifikant $(p<, 001) ; M_{\text {Diff }}=$ Mittlere Differenz; SE = Standardfehler; $p=$ Signifikanz

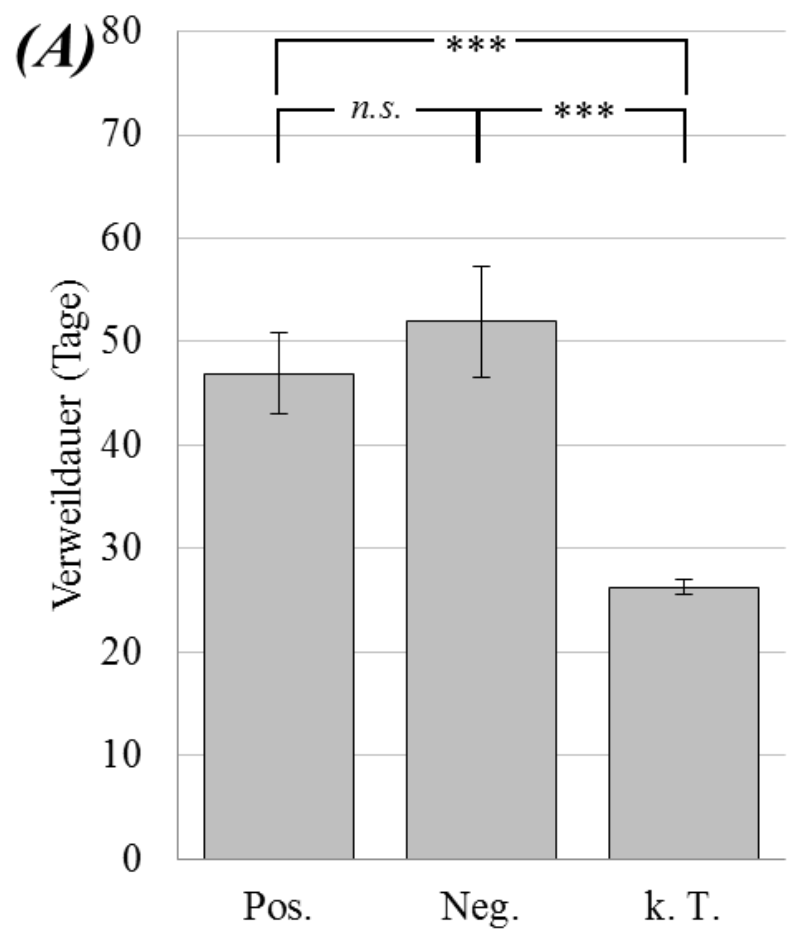

Abbildung 5. Mittelwerte (Verweildauer in Tagen) mit 95\%-Konfidenzintervallen und Bonferroni-korrigierten Paarvergleichen, aufgeteilt nach Keimtestung. $* * *=p<, 001$. Pos. (positiv getestet, $n=376$ ), Neg. (negativ getestet, $n=351$ ), k. T. (kein Test, $n=7818$ ).

Es zeigte sich, dass die negativ getesteten Patienten die höchste Verweildauer aufwiesen, gefolgt von den positiv getesteten Patienten sowie den Patienten ohne Keimtestung. Der Unterschied zwischen positiv und negativ getesteten Patienten wurde nicht signifikant. Somit wird die Hypothese, dass positiv getestete Patienten die längste Verweildauer haben (H1.1) verworfen: positiv getestete Patienten wiesen nicht die höchste Verweildauer auf. Nicht getestete Patienten wiesen die signifikant geringste Verweildauer im Vergleich zu 
positiv und negativ getesteten Patienten auf - die Hypothese, dass nicht getestete Patienten die kürzeste Verweildauer haben (H1.2) kann somit angenommen werden.

\subsubsection{Mikrobiologische Untersuchung und Verweildauer innerhalb der gebildeten Cluster (Hypothese 3)}

Das Ergebnis der Zwischensubjekteffekte der UNIANOVA lieferte einen Hinweis auf Abweichungen der abhängigen Variablen „Verweildauer in Tagen“ zwischen den Clustern. Die Variable „Verweildauer in Tagen“ variierte signifikant zwischen den Diagnose-Clustern $(F(4,8530)=34,750, p<, 001 ;$ s. Tabelle 18).

Zunächst wurden die Mittelwerte der Verweildauer und Standardabweichungen aller Patienten für die jeweiligen Diagnose-Cluster ermittelt und im Anschluss Bonferronikorrigierte Paarvergleiche zur Signifikanzermittlung durchgeführt (s. Tabelle 21 und Tabelle 22).

Tabelle 21. Mittelwerte der Verweildauer in Tagen, Standardabweichung der Verweildauer und Anzahl der Fälle für die Diagnose-Cluster aller Patienten

\begin{tabular}{lcc}
\hline \multicolumn{1}{c}{ Cluster } & $(M \pm S D)$ & $n$ \\
\hline Andere Diagnose & $21,52 \pm 28,902$ & 3.434 \\
F00-F03 & $22,50 \pm 19,234$ & 342 \\
F10 & $19,70 \pm 22,043$ & 1.200 \\
F20-F29 & $37,46 \pm 37,333$ & 1.016 \\
F32-F33 & $38,35 \pm 36,670$ & 2.553 \\
\hline Gesamt & $28,23 \pm 32,498$ & 8.545 \\
\hline
\end{tabular}

Anmerkung: $M=$ Mittelwert; $S D=$ Standardabweichung; $n=$ Anzahl der Fälle

Tabelle 22. Ergebnisse des Bonferroni-korrigierten Post-Hoc-Tests zwischen den Diagnose-Clustern in Bezug auf die mittlere Verweildauer

\begin{tabular}{llccccc}
\hline \multirow{2}{*}{ Cluster } & & & & & \multicolumn{2}{c}{$95 \%$ Konfidenzintervall } \\
\cline { 5 - 7 } Andere & \multicolumn{1}{c}{ Cluster } & $M_{\text {Diff }}$ & $S E$ & & Obergrenze & Untergrenze \\
& F00-F03 & $-0,98$ & 1,744 & 1,000 & $-5,88$ & 3,92 \\
& F10 & 1,82 & 1,032 & 0,780 & $-1,08$ & 4,71 \\
& F20-F29 & $-15,94\left(^{*}\right)$ & 1,099 & 0,000 & $-19,02$ & $-12,85$ \\
& F32-F33 & $-16,83\left(^{*}\right)$ & 0,804 & 0,000 & $-19,08$ & $-14,57$ \\
\hline F00-F03 & F10 & 2,80 & 1,886 & 1,000 & $-2,50$ & 8,09 \\
& F20-F29 & $-14,96\left(^{*}\right)$ & 1,923 & 0,000 & $-20,36$ & $-9,56$ \\
& F32-F33 & $-15,85\left(^{*}\right)$ & 1,771 & 0,000 & $-20,82$ & $-10,88$ \\
\hline F10 & F20-F29 & $-17,75\left(^{*}\right)$ & 1,312 & 0,000 & $-21,44$ & $-14,07$ \\
& F32-F33 & $-18,65\left(^{*}\right)$ & 1,077 & 0,000 & $-21,67$ & $-15,62$ \\
\hline F20-F29 & F32-F33 & $-0,89$ & 1,141 & 1,000 & $-4,09$ & 2,31 \\
\hline
\end{tabular}

Anmerkung: $(*)=$ Signifikant $(p<, 001) ; M_{D i f f}=$ Mittlere Differenz; SE = Standardfehler; $p=$ Signifikanz 
In sechs von zehn korrigierten Paarvergleichen unterschieden sich die Diagnose-Cluster bezüglich der Verweildauer signifikant. Die Diagnose-Cluster „F20-F29“ und „F32-F33“ wiesen im Vergleich zu den anderen drei Clustern eine signifikant längere Verweildauer auf. Im Vergleich untereinander wurde die Signifikanz verfehlt. Ebenso verfehlten alle Paarvergleiche der Cluster „F00-F03“, „F10“ und „Andere Diagnose“ die Signifikanz untereinander bezüglich der unterschiedlichen Verweildauer.

Zur Überprüfung der durchschnittlichen Verweildauer, aufgeteilt nach Diagnose-Clustern sowie positiv, negativ und nicht getesteten Patienten (H3), wurden Mittelwerte und Standardabweichungen der positiv, negativ und nicht getesteten Patienten innerhalb der Cluster ermittelt und zur Veranschaulichung ein Linien-Diagramm erstellt (s. Tabelle 23 und Abbildung 6).

Tabelle 23. Mittelwerte der Verweildauer in Tagen, Standardabweichung der Verweildauer und Anzahl der Fälle für die Diagnose-Cluster

\begin{tabular}{|c|c|c|}
\hline Cluster & $(M \pm S D)$ & $n$ \\
\hline \multicolumn{3}{|c|}{ positiv } \\
\hline Andere Diagnose & $47,00 \pm 38,361$ & 119 \\
\hline F00-F03 & $31,18 \pm 21,373$ & 44 \\
\hline F10 & $32,56 \pm 26,373$ & 36 \\
\hline F20-F29 & $58,94 \pm 54,051$ & 52 \\
\hline F32-F33 & $51,53 \pm 36,812$ & 125 \\
\hline Gesamt & $46,92 \pm 38,753$ & 376 \\
\hline \multicolumn{3}{|c|}{ negativ } \\
\hline Andere Diagnose & $43,39 \pm 37,941$ & 117 \\
\hline F00-F03 & $30,24 \pm 22,720$ & 25 \\
\hline F10 & $40,89 \pm 45,850$ & 38 \\
\hline F20-F29 & $71,69 \pm 60,948$ & 48 \\
\hline F32-F33 & $60,13 \pm 58,151$ & 123 \\
\hline Gesamt & $51,92 \pm 50,602$ & 351 \\
\hline \multicolumn{3}{|c|}{ nicht getestet } \\
\hline Andere Diagnose & $19,77 \pm 27,308$ & 3.198 \\
\hline F00-F03 & $20,39 \pm 17,996$ & 273 \\
\hline F10 & $18,58 \pm 20,134$ & 1.126 \\
\hline F20-F29 & $34,45 \pm 33,101$ & 916 \\
\hline F32-F33 & $36,47 \pm 34,629$ & 2.305 \\
\hline Gesamt & $26,27 \pm 30,361$ & 7.818 \\
\hline
\end{tabular}

Anmerkung: $M=$ Mittelwert; $S D=$ Standardabweichung; $n=$ Anzahl der Fälle 


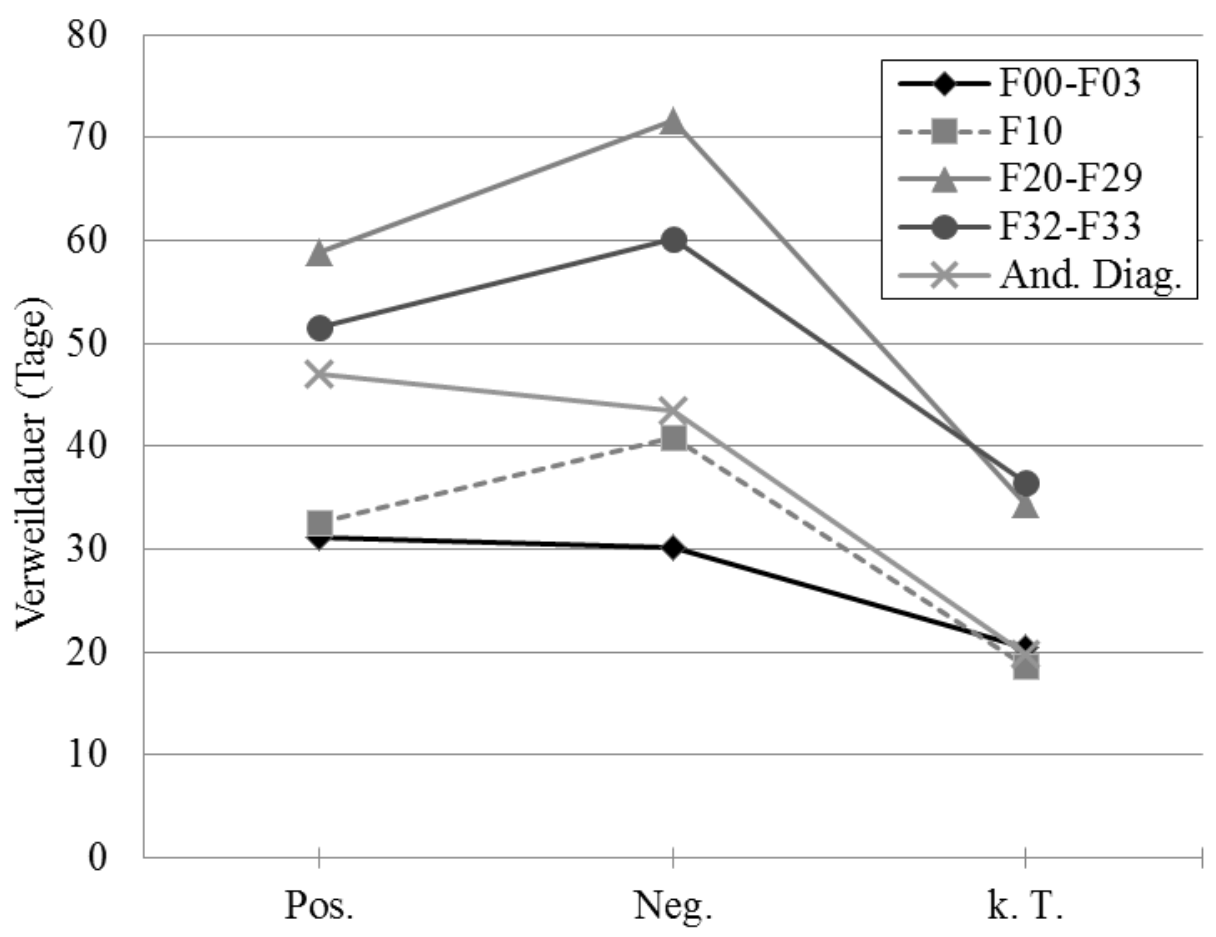

Abbildung 6. Mittelwerte der Verweildauer in Tagen für Diagnose-Cluster, aufgeteilt nach Keimtestung.

Pos. (positiv getestet), Neg. (negativ getestet), k. T. (kein Test), $N=8.545$.

Bei den Clustern „F20-F29“, „F32-F33“ und „F10“ zeigte sich ein ähnliches Muster wie in der Gesamtstichprobe: negativ getestete Patienten wiesen die höchste Verweildauer auf, gefolgt von positiv und nicht getesteten Patienten. Bei den Clustern „F00-F03“ und „Andere Diagnose“ verblieben die positiv getesteten Patienten tendenziell länger als die negativ getesteten. In allen Clustern wiesen die nicht getesteten Patienten die kürzeste Verweildauer auf. Die Hypothese, dass sich in den Clustern das gleiche Bild wie in der Gesamtstichprobe (H3) zeigt, kann somit teilweise angenommen werden: Die in H1.2 gemachte Aussage, dass nicht getestete Patienten die kürzeste Verweildauer aufwiesen, konnte auch für die einzelnen Diagnose-Cluster nachgewiesen werden.

\subsection{Mikrobiologische Untersuchung und Alter in Jahren}

\subsubsection{Mikrobiologische Untersuchung und Alter in Jahren bei positiv, negativ und nicht getesteten Patienten (Hypothese 2)}

Das Ergebnis der Zwischensubjekteffekte der UNIANOVA zeigte Abweichungen der abhängigen Variable „Alter in Jahren“ zwischen den Gruppen der positiv, negativ und nicht auf Keime getesteten Patienten $(F(2,8530)=42,812, p<, 001 ;$ s. Tabelle 24). 
Tabelle 24. Ergebnis der Zwischensubjekteffekte mit Alter in Jahren als abhängiger Variable

\begin{tabular}{lccccc}
\hline \multicolumn{1}{c}{ Quelle } & $\begin{array}{c}\text { Quadratsumme } \\
\text { vom Typ III }\end{array}$ & $d f$ & $\begin{array}{c}\text { Mittel der } \\
\text { Quadrate }\end{array}$ & $F$ & $p$ \\
\hline Korrigiertes Modell & 411872,743 & 14 & $29.419,482$ & 113,535 & 0,000 \\
\hline Konstanter Term & $3.322 .314,699$ & 1 & $3.322 .314,699$ & $12.821,443$ & 0,000 \\
\hline pos_neg_Testergebnis & $22.186,835$ & 2 & $11.093,417$ & 42,812 & 0,000 \\
\hline Hauptdiagnose_Familie & $112.171,359$ & 4 & $28.042,840$ & 108,223 & 0,000 \\
\hline $\begin{array}{l}\text { pos_neg_Testergebnis } \\
* \text { Hauptdiagnose_Familie }\end{array}$ & $6.598,836$ & 8 & 824,855 & 3,183 & 0,001 \\
\hline Fehler & $2.210 .308,475$ & 8.530 & 259,122 & & \\
\hline Gesamt & $20.628 .958,000$ & 8.545 & & & \\
\hline Korrigierte Gesamtvariation & $2.622 .181,218$ & 8.544 & & & \\
\hline Anmerkung: & F Frit & & & & \\
\hline
\end{tabular}

Anmerkung: $d f=$ Freiheitsgrade; $F=$ F-Wert; $p=$ Signifikanz

Zur Überprüfung des durchschnittlichen Alters wurden Mittelwerte und Standardabweichungen der positiv, negativ und nicht getesteten Patienten ermittelt (s. Tabelle 25).

Tabelle 25. Mittelwerte des Lebensalters in Jahren, Standardabweichung des Lebensalters und Anzahl der Fälle der Gesamtstichprobe

\begin{tabular}{lll}
\hline \multicolumn{1}{c}{ Testergebnis } & $(M \pm S D)$ & $n$ \\
\hline positiv & $57,80 \pm 19,165$ & 376 \\
negativ & $51,02 \pm 18,328$ & 351 \\
nicht getestet & $45,10 \pm 17,151$ & 7.818 \\
\hline $\begin{array}{l}\text { Anmerkung: } M=\text { Mittelwert; } S D=\text { Standardabweichung; } \\
n=\text { Anzahl der Fälle }\end{array}$
\end{tabular}

Die Überprüfung auf Unterschiede erfolgte mittels Bonferroni-korrigierter Paarvergleiche. Zur Veranschaulichung wurde ein Säulendiagramm erstellt (s. Tabelle 26 und Abbildung 7).

Tabelle 26. Ergebnisse der Bonferroni-korrigierten Paarvergleiche zwischen den positiv, negativ und nicht getesteten Patienten in Bezug auf das mittlere Lebensalter

\begin{tabular}{llccccc}
\hline & & & & & \multicolumn{2}{c}{$95 \%$ Konfidenzintervall } \\
\cline { 6 - 7 } Testergebnis & Testergebnis & $M_{\text {Diff }}$ & $S E$ & $p$ & Obergrenze & Untergrenze \\
\hline \multirow{2}{*}{ positiv } & negativ & $6,78\left(^{*}\right)$ & 1,195 & 0,000 & 3,92 & 9,64 \\
& nicht getestet & $12,70\left(^{*}\right)$ & 0,850 & 0,000 & 10,66 & 14,73 \\
\hline negativ & nicht getestet & $5,92\left(^{*}\right)$ & 0,878 & 0,000 & 3,82 & 8,02 \\
\hline Annnyyy
\end{tabular}

Anmerkung: $\left({ }^{*}\right)=$ Signifikant $(p<, 001) ; M_{D i f f}=$ Mittlere Differenz; SE = Standardfehler; $p=$ Signifikanz 


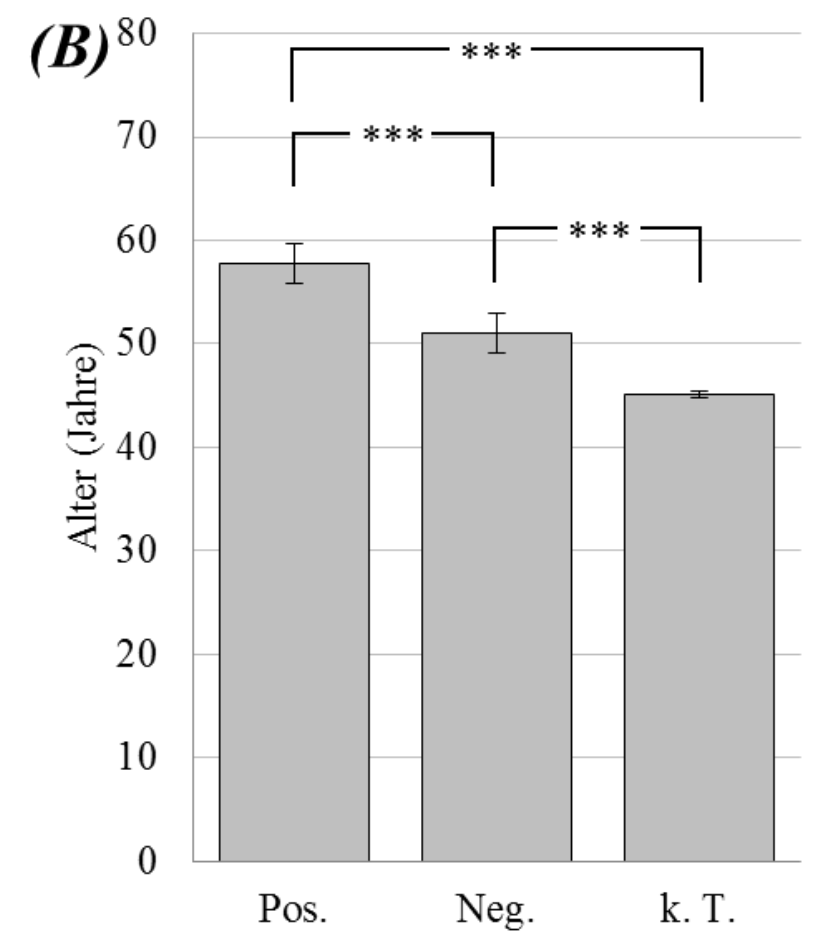

Abbildung 7. Mittelwerte (Alter in Jahren) mit 95\%-Konfidenzintervallen und Bonferroni-korrigierten Paarvergleichen, aufgeteilt nach Keimtestung.

*** $p<$,001. Pos. (positiv getestet, $n=376$ ), Neg. (negativ getestet, $n=351$ ), k. T. (kein Test, $n=7818)$.

Es zeigte sich, dass positiv getestete Patienten das höchste Alter aufwiesen, gefolgt von negativ und nicht getesteten Patienten. Die Hypothese, dass nicht getestete Patienten das geringste Lebensalter aufweisen (H2) kann somit angenommen werden, da nicht getestete Patienten das signifikant geringste Alter aufwiesen.

\subsubsection{Mikrobiologische Untersuchung und Alter in Jahren innerhalb der gebildeten Cluster (Hypothese 3)}

Das Ergebnis der Zwischensubjekteffekte der UNIANOVA zeigte signifikante Abweichungen der Variable „Alter in Jahren“ zwischen den Diagnose-Clustern ( $F(4,8530)$ $=108,223, p<, 001 ; \mathrm{s}$. Tabelle 24).

Zunächst wurden die Mittelwerte des Alters und die Standardabweichungen aller Patienten für die jeweiligen Diagnose-Cluster ermittelt und im Anschluss Bonferroni-korrigierte Paarvergleiche zur Signifikanzermittlung durchgeführt, um generelle Unterschiede zwischen den Diagnose-Clustern bezüglich des Alters zu ermitteln (s. Tabelle 27 und Tabelle 28). 
Tabelle 27. Mittelwerte des Lebensalters in Jahren, Standardabweichung des Lebensalters und Anzahl der Fälle für die Diagnose-Cluster aller Patienten

\begin{tabular}{lcc}
\hline \multicolumn{1}{c}{ Cluster } & $(M \pm S D)$ & $n$ \\
\hline Andere Diagnose & $42,29 \pm 17,761$ & 3.434 \\
F00-F03 & $73,51 \pm 10,196$ & 342 \\
F10 & $47,47 \pm 12,367$ & 1.200 \\
F20-F29 & $40,12 \pm 15,027$ & 1.016 \\
F32-F33 & $48,64 \pm 16,909$ & 2.553 \\
\hline Gesamt & $45,91 \pm 17,519$ & 8.545 \\
\hline
\end{tabular}

Anmerkung: $M=$ Mittelwert; $S D=$ Standardabweichung; $n=$ Anzahl der Fälle

Tabelle 28. Ergebnisse des Bonferroni-korrigierten Post-Hoc-Tests zwischen den Diagnose-Clustern in Bezug auf den Mittelwert des Lebensalters in Jahren

\begin{tabular}{llccccc}
\hline \multirow{2}{*}{ Cluster } & & & & & \multicolumn{2}{c}{$95 \%$ Konfidenzintervall } \\
\cline { 6 - 7 } Andere & \multicolumn{1}{c}{ Cluster } & $M_{\text {Diff }}$ & $S E$ & & Obergrenze & Untergrenze \\
& F00-F03 & $-31,22\left(^{*}\right)$ & 0,913 & 0,000 & $-33,79$ & $-28,66$ \\
& F10 & $-5,18\left(^{*}\right)$ & 0,540 & 0,000 & $-6,70$ & $-3,66$ \\
& F20-F29 & $2,17\left(^{*}\right)$ & 0,575 & 0,002 & 0,55 & 3,78 \\
& F32-F33 & $-6,35\left(^{*}\right)$ & 0,421 & 0,000 & $-7,53$ & $-5,17$ \\
\hline F00-F03 & F10 & $26,04\left(^{*}\right)$ & 0,987 & 0,000 & 23,27 & 28,81 \\
& F20-F29 & $33,39\left(^{*}\right)$ & 1,006 & 0,000 & 30,57 & 36,22 \\
& F32-F33 & $24,87\left(^{*}\right)$ & 0,927 & 0,000 & 22,27 & 27,47 \\
\hline F10 & F20-F29 & $7,35\left(^{*}\right)$ & 0,686 & 0,000 & 5,42 & 9,27 \\
& F32-F33 & $-1,17$ & 0,563 & 0,373 & $-2,76$ & 0,41 \\
\hline F20-F29 & F32-F33 & $-8,52\left(^{*}\right)$ & 0,597 & 0,000 & $-10,20$ & $-6,84$ \\
\hline
\end{tabular}

Anmerkung: $(*)=$ Signifikant $(p<, 001) ; M_{D i f f}=$ Mittlere Differenz; SE = Standardfehler; $p=$ Signifikanz

Die Unterschiede bezüglich des durchschnittlichen Lebensalters zwischen den DiagnoseClustern waren in neun von zehn korrigierten paarweisen Vergleichen signifikant. Nur der Paarvergleich des durchschnittlichen Lebensalters zwischen den Diagnose-Clustern „F10“ und „F32-F33“ verfehlte die Signifikanz, da die jeweiligen Mittelwerte („F32-F33“ $M=$ 48,64 und „F10“ $M=47,47)$ einander fast gleichen. Das höchste Lebensalter wies das Cluster „F00-F03“ $(M=73,51)$ auf, gefolgt von den Clustern „F32-F33“ $(M=48,64)$ und „F10“ $(M=47,47)$. Die Patienten des Clusters „F20-F29“ $(M=40,12)$ hatten im Durchschnitt das geringste Lebensalter (s. Tabelle 27).

Zur Überprüfung des durchschnittlichen Altes, aufgeteilt nach Diagnose-Clustern sowie positiv, negativ und nicht getesteten Patienten (H3), wurden Mittelwerte und Standardabweichungen der positiv, negativ und nicht getesteten Patienten innerhalb der Cluster ermittelt und zur Veranschaulichung ein Linien-Diagramm erstellt (s. Tabelle 29 und Abbildung 8). 
Tabelle 29. Mittelwerte des Lebensalters in Jahren, Standardabweichung des Lebensalters und Anzahl der Fälle für die Diagnose-Cluster

\begin{tabular}{|c|c|c|}
\hline Cluster & $(M \pm S D)$ & $n$ \\
\hline \multicolumn{3}{|c|}{ positiv } \\
\hline Andere Diagnose & $54,79 \pm 19,809$ & 119 \\
\hline F00-F03 & $77,14 \pm 9,095$ & 44 \\
\hline F10 & $54,89 \pm 13,808$ & 36 \\
\hline F20-F29 & $45,67 \pm 17,583$ & 52 \\
\hline F32-F33 & $59,74 \pm 17,842$ & 125 \\
\hline Gesamt & $57,80 \pm 19,165$ & 376 \\
\hline \multicolumn{3}{|c|}{ negativ } \\
\hline Andere Diagnose & $47,90 \pm 18,456$ & 117 \\
\hline $\mathrm{F} 00-\mathrm{F} 03$ & $78,28 \pm 9,002$ & 25 \\
\hline F10 & $46,53 \pm 10,832$ & 38 \\
\hline F20-F29 & $39,44 \pm 15,614$ & 48 \\
\hline F32-F33 & $54,37 \pm 16,198$ & 123 \\
\hline Gesamt & $51,02 \pm 18,328$ & 351 \\
\hline \multicolumn{3}{|c|}{ nicht getestet } \\
\hline Andere Diagnose & $41,62 \pm 17,449$ & 3.198 \\
\hline F00-F03 & $72,49 \pm 10,239$ & 273 \\
\hline F10 & $47,26 \pm 12,304$ & 1.126 \\
\hline F20-F29 & $39,84 \pm 14,794$ & 916 \\
\hline F32-F33 & $47,73 \pm 16,625$ & 2.305 \\
\hline Gesamt & $45,10 \pm 17,151$ & 7.818 \\
\hline
\end{tabular}

Anmerkung: $M=$ Mittelwert; $S D=$ Standardabweichung; $n=$ Anzahl der Fälle 


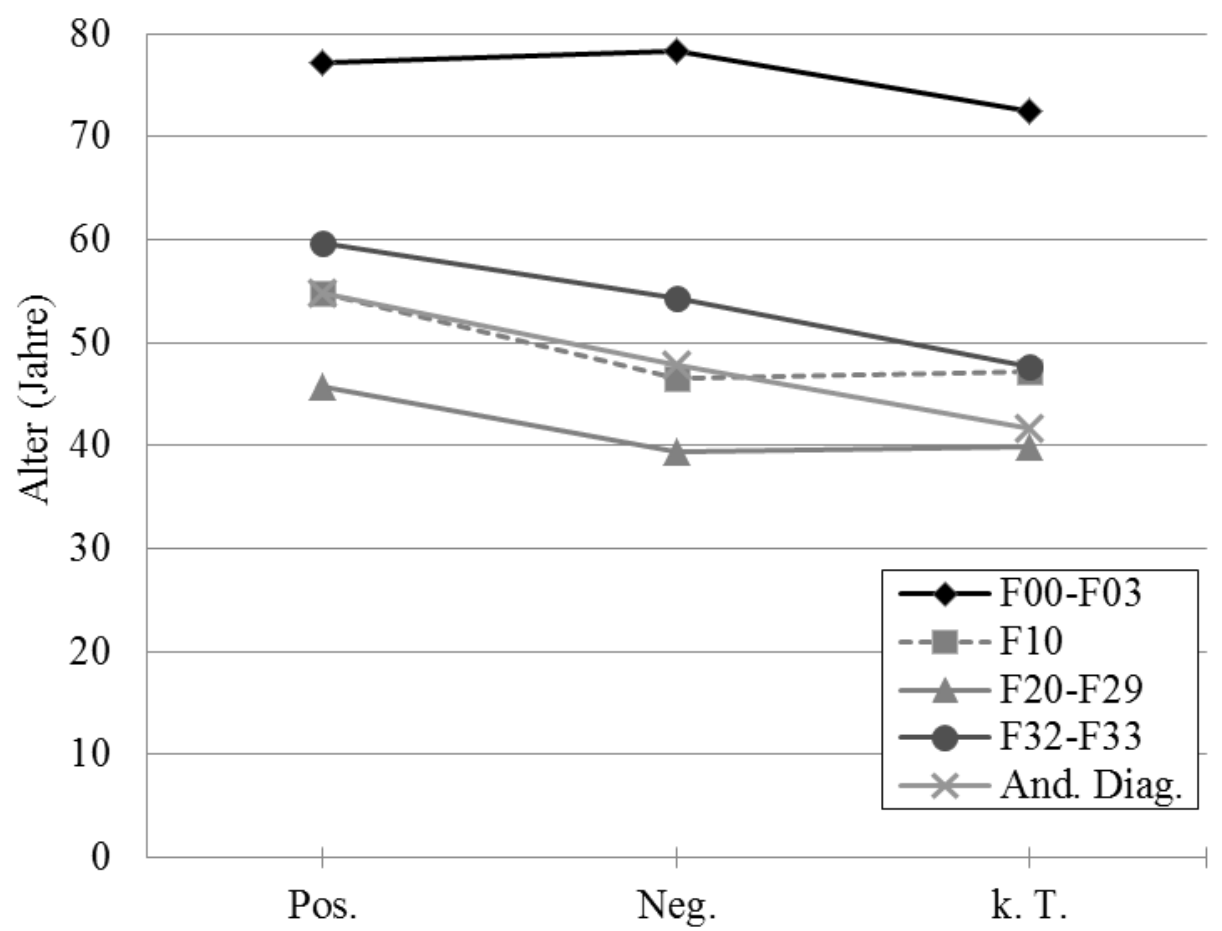

Abbildung 8. Mittelwerte des Alters in Jahren für Diagnose-Cluster, aufgeteilt nach Keimtestung. Pos. (positiv getestet), Neg. (negativ getestet), k. T. (kein Test), $N=8545$.

Die Cluster zeigten teilweise abweichende Muster im Vergleich zu der Gesamtstichprobe. In vier von fünf Fällen („,F32-F33“, „F20-F29“, „F10“ und „Andere Diagnose“) waren die positiv getesteten Patienten am ältesten, im Cluster „F00-F03“ wiesen die negativ getesteten Patienten das höchste Lebensalter auf. In drei von fünf Fällen („F00-F03“, „F32-F33“ und „Andere Diagnose“) sind die nicht getesteten Patienten jünger als die negativ getesteten Patienten, in den Clustern „F20-F29“ und „F10“ sind die negativ getesteten Patienten jünger als die nicht getesteten Patienten. Bei allen Clustern zeigt sich einheitlich, dass die nicht getesteten Patienten jünger sind als die positiv getesteten Patienten. Insgesamt kann somit die Hypothese, dass sich in den Cluster das gleiche Bild wie in der Gesamtstichprobe zeigt (H3), eingeschränkt angenommen werden: tendenziell bildete sich auch in den Diagnose-Clustern ab, dass positiv getestete Patienten ein höheres Lebensalter aufwiesen als negativ oder nicht getestete Patienten.

\subsection{Diagnose-Cluster und Keimfamilien}

Zur Überprüfung, ob es zwischen den Diagnose-Clustern Unterschiede in der Häufigkeit des Auftretens der jeweiligen Bakterienfamilie gibt, wurde zunächst für jede der vier Bakterienfamilien die zu erwartende Anzahl an Nachweisen pro Diagnose-Cluster berechnet (s. Tabelle 30, Tabelle 32, Tabelle 34 und Tabelle 36) und im Anschluss in Bezug 
auf die jeweilige $5 \times 2$-Felder-Matrix ein Chi-Quadrat-Test durchgeführt (s. Tabelle 31, Tabelle 33, Tabelle 35 und Tabelle 37).

Die Ergebnisse der Chi-Quadrat-Tests für die jeweilige $5 \times 2$-Felder-Matrix wichen für alle vier Bakterienfamilien in Bezug auf die Diagnose-Cluster signifikant ab: Es existieren somit allgemeine Assoziationen zwischen einzelnen Keimfamilien und Diagnose-Clustern, die im Folgenden detailliert erläutert werden.

Tabelle 30. Erwartete Anzahl an Nachweisen der Bakterienfamilie Enterobacteriacea pro Diagnose-Cluster

\begin{tabular}{llcccccc}
\hline & & \multicolumn{5}{c}{ Cluster } & \\
\cline { 3 - 6 } & & And. Dia. & F00-F03 & F10 & F20-F29 & F32-F33 & Gesamt \\
\hline k. N. für & Anzahl & 3.379 & 321 & 1.183 & 992 & 2.501 & 8.376 \\
Enterobacteriacea & Erw. Anzahl & $3.366,1$ & 335,2 & $1.176,3$ & 995,9 & $2.502,5$ & $8.376,0$ \\
& $\%$ & $40,3 \%$ & $3,8 \%$ & $14,1 \%$ & $11,8 \%$ & $29,9 \%$ & $100,0 \%$ \\
\hline Enterobacteriacea & Anzahl & 55 & 21 & 17 & 24 & 52 & 169 \\
positiv & Erw. Anzahl & 67,9 & 6,8 & 23,7 & 20,1 & 50,5 & 169,0 \\
& $\%$ & $32,5 \%$ & $12,4 \%$ & $10,1 \%$ & $14,2 \%$ & $30,8 \%$ & $100,0 \%$ \\
\hline Gesamt & Anzahl & 3.434 & 342 & 1.200 & 1.016 & 2.553 & 8.545 \\
& Erw. Anzahl & $3.434,0$ & 342,0 & $1.200,0$ & $1.016,0$ & $2.553,0$ & $8.545,0$ \\
& $\%$ & $40,2 \%$ & $4,0 \%$ & $14,0 \%$ & $11,9 \%$ & $29,9 \%$ & $100,0 \%$ \\
\hline
\end{tabular}

Anmerkung: k.N. = kein Nachweis; Erw. Anzahl = erwartete Anzahl

Tabelle 31. Ergebnis des Chi-Quadrat-Tests für die 5×2-Felder-Matrix der Enterobacteriacea

\begin{tabular}{lccc}
\hline & Wert & $d f$ & $\begin{array}{c}\text { Asymptotische } \\
\text { Signifikanz (2-seitig) }\end{array}$ \\
\hline Chi-Quadrat nach Pearson & 35,842 & 4 & 0,000 \\
Likelihood-Quotient & 25,338 & 4 & 0,000 \\
Zusammenhang linear-mit-linear & 0,703 & 1 & 0,402 \\
Anzahl der gültigen Fälle & 8.545 & & \\
\hline Anmerkung: $d f=$ Freiheitsorade &
\end{tabular}

Anmerkung: $d f=$ Freiheitsgrade

Tabelle 32. Erwartete Anzahl an Nachweisen der Bakterienfamilie Enterococcaceae pro Diagnose-Cluster

\begin{tabular}{llcccccc}
\hline & & \multicolumn{5}{c}{ Cluster } & \\
\cline { 3 - 6 } & & And. Dia. & F00-F03 & F10 & F20-F29 & F32-F33 & Gesamt \\
\hline k. N. für & Anzahl & 3.402 & 331 & 1.191 & 1.006 & 2.524 & 8.454 \\
Enterococcaceae & Erw. Anzahl & $3.397,4$ & 338,4 & $1.187,2$ & $1.005,2$ & $2.525,8$ & $8.454,0$ \\
& $\%$ & $40,2 \%$ & $3,9 \%$ & $14,1 \%$ & $11,9 \%$ & $29,9 \%$ & $100,0 \%$ \\
\hline Enterococcaceae & Anzahl & 32 & 11 & 9 & 10 & 29 & 91 \\
positiv & Erw. Anzahl & 36,6 & 3,6 & 12,8 & 10,8 & 27,2 & 91,0 \\
& $\%$ & $35,2 \%$ & $12,1 \%$ & $9,9 \%$ & $11,0 \%$ & $31,9 \%$ & $100,0 \%$ \\
\hline Gesamt & Anzahl & 3.434 & 342 & 1.200 & 1.016 & 2.553 & 8.545 \\
& Erw. Anzahl & $3.434,0$ & 342,0 & $1.200,0$ & $1.016,0$ & $2.553,0$ & $8.545,0$ \\
& $\%$ & $40,2 \%$ & $4,0 \%$ & $14,0 \%$ & $11,9 \%$ & $29,9 \%$ & $100,0 \%$ \\
\hline
\end{tabular}

Anmerkung: k.N. = kein Nachweis; Erw. Anzahl = erwartete Anzahl 
Tabelle 33. Ergebnis des Chi-Quadrat-Tests für die 5×2-Felder-Matrix der Enterococcaceae

\begin{tabular}{lccc}
\hline & Wert & $d f$ & $\begin{array}{c}\text { Asymptotische } \\
\text { Signifikanz (2-seitig) }\end{array}$ \\
\hline Chi-Quadrat nach Pearson & 16,916 & 4 & 0,161 \\
Likelihood-Quotient & 11,809 & 4 & 0,019 \\
Zusammenhang linear-mit-linear & 0,079 & 1 & 0,778 \\
Anzahl der gültigen Fälle & 8.545 & & \\
\hline Anm
\end{tabular}

Anmerkung: $d f=$ Freiheitsgrade

Tabelle 34. Erwartete Anzahl an Nachweisen der Bakterienfamilie Corynebacteriaceae pro Diagnose-Cluster

\begin{tabular}{llcccccc}
\hline & & \multicolumn{5}{c}{ Cluster } \\
\cline { 3 - 6 } & & And. Dia. & F00-F03 & F10 & F20-F29 & F32-F33 & Gesamt \\
\hline k. N. für & Anzahl & 3.422 & 336 & 1.194 & 1.006 & 2.541 & 8.499 \\
Corynebacteriaceae & Erw. Anzahl & $3.415,5$ & 340,2 & $1.193,5$ & $1.010,5$ & $2.539,3$ & $8.499,0$ \\
& $\%$ & $40,3 \%$ & $4,0 \%$ & $14,0 \%$ & $11,8 \%$ & $29,9 \%$ & $100,0 \%$ \\
\hline Corynebacteriaceae & Anzahl & 12 & 6 & 6 & 10 & 12 & 46 \\
positiv & Erw. Anzahl & 18,5 & 1,8 & 6,5 & 5,5 & 13,7 & 46,0 \\
& $\%$ & $26,1 \%$ & $13,0 \%$ & $13,0 \%$ & $21,7 \%$ & $26,1 \%$ & $100,0 \%$ \\
\hline Gesamt & Anzahl & 3.434 & 342 & 1.200 & 1.016 & 2.553 & 8.545 \\
& Erw. Anzahl & $3.434,0$ & 342,0 & $1.200,0$ & $1.016,0$ & $2.553,0$ & $8.545,0$ \\
& $\%$ & $40,2 \%$ & $4,0 \%$ & $14,0 \%$ & $11,9 \%$ & $29,9 \%$ & $100,0 \%$ \\
\hline
\end{tabular}

Anmerkung: k.N. = kein Nachweis; Erw. Anzahl = erwartete Anzahl

Tabelle 35. Ergebnis des Chi-Quadrat-Tests für die 5×2-Felder-Matrix der Corynebacteriaceae

\begin{tabular}{lccc}
\hline & Wert & df & $\begin{array}{c}\text { Asymptotische } \\
\text { Signifikanz (2-seitig) }\end{array}$ \\
\hline Chi-Quadrat nach Pearson & 15,762 & 4 & 0,272 \\
Likelihood-Quotient & 11,818 & 4 & 0,019 \\
Zusammenhang linear-mit-linear & 0,721 & 1 & 0,396 \\
Anzahl der gültigen Fälle & 8.545 & & \\
\hline
\end{tabular}

Anmerkung: $d f=$ Freiheitsgrade

Tabelle 36. Erwartete Anzahl an Nachweisen der Bakterienfamilie Staphylococcaceae pro Diagnose-Cluster

\begin{tabular}{llcccccc}
\hline & & \multicolumn{5}{c}{ Cluster } \\
\cline { 3 - 6 } & & And. Dia. & F00-F03 & F10 & F20-F29 & F32-F33 & Gesamt \\
\hline k. N. für & Anzahl & 3.387 & 326 & 1.190 & 989 & 2.504 & 8.396 \\
Staphylococcaceae & Erw. Anzahl & $3.374,1$ & 336,0 & $1.179,1$ & 998,3 & $2.508,5$ & $8.396,0$ \\
& $\%$ & $40,3 \%$ & $3,9 \%$ & $14,2 \%$ & $11,8 \%$ & $29,8 \%$ & $100,0 \%$ \\
\hline Staphylococcaceae & Anzahl & 47 & 16 & 10 & 27 & 49 & 149 \\
positiv & Erw. Anzahl & 59,9 & 6,0 & 20,9 & 17,7 & 44,5 & 149,0 \\
& $\%$ & $31,5 \%$ & $10,7 \%$ & $6,7 \%$ & $18,1 \%$ & $32,9 \%$ & $100,0 \%$ \\
\hline Gesamt & Anzahl & 3.434 & 342 & 1.200 & 1.016 & 2.553 & 8.545 \\
& Erw. Anzahl & $3.434,0$ & 342,0 & $1.200,0$ & $1.016,0$ & $2.553,0$ & $8.545,0$ \\
& $\%$ & $40,2 \%$ & $4,0 \%$ & $14,0 \%$ & $11,9 \%$ & $29,9 \%$ & $100,0 \%$ \\
\hline
\end{tabular}

Anmerkung: k.N. = kein Nachweis; Erw. Anzahl = erwartete Anzahl 
Tabelle 37. Ergebnis des Chi-Quadrat-Tests für die 5×2-Felder-Matrix der Staphylococcaceae

\begin{tabular}{lccc}
\hline & Wert & $d f$ & $\begin{array}{c}\text { Asymptotische } \\
\text { Signifikanz (2-seitig) }\end{array}$ \\
\hline Chi-Quadrat nach Pearson & 31,226 & 4 & 0,000 \\
Likelihood-Quotient & 26,755 & 4 & 0,000 \\
Zusammenhang linear-mit-linear & 2,676 & 1 & 0,102 \\
Anzahl der gültigen Fälle & 8.545 & & \\
\hline
\end{tabular}

Anmerkung: $d f=$ Freiheitsgrade 


\subsection{Quotenverhältnisse für die Diagnose-Cluster innerhalb der Bakterienfamilie (Hypothese 4)}

Um zu überprüfen, ob Bakterienfamilien bei einzelnen Clustern vermehrt oder vermindert nachgewiesen worden sind, also spezifische Assoziationen zwischen einzelnen Keimfamilien und Diagnose-Clustern existieren (H4), wurden für jeden Diagnose-Cluster innerhalb der einzelnen Bakterienfamilien die Quotenverhältnisse errechnet (s. Tabelle 38).

Tabelle 38. Anzahl der nachgewiesenen Anzahl an Bakterienfamilien und Quotenverhältnisse innerhalb der einzelnen Cluster pro Bakterienfamilie

\begin{tabular}{|c|c|c|c|c|}
\hline Cluster & $\sum$ & $\sum_{p o s .}$ & $\sum_{k, N}$ & Quot. \\
\hline \multicolumn{5}{|c|}{ Enterobacteriaceae } \\
\hline F00-F03 & 342 & $21(12,4 \%)$ & $321(3,8 \%)$ & $3,561^{*}$ \\
\hline F10 & 1200 & $17(10,1 \%)$ & $1183(14,1 \%)$ & 0,68 \\
\hline F20-F29 & 1016 & $24(14,2 \%)$ & $992(11,8 \%)$ & 1,232 \\
\hline F32-F33 & 2553 & $52(30,8 \%)$ & $2501(29,9 \%)$ & 1,044 \\
\hline Andere Diagnose & 3434 & $55(32,5 \%)$ & $3379(40,3 \%)$ & $0,713^{*}$ \\
\hline Alle Patienten & 8545 & 169 & 8376 & \\
\hline \multicolumn{5}{|c|}{ Enterococcaceae } \\
\hline F00-F03 & 342 & $11(12,1 \%)$ & $331(3,9 \%)$ & $3,374^{*}$ \\
\hline F10 & 1200 & $9(9,9 \%)$ & $1191(14,1 \%)$ & 0,669 \\
\hline F20-F29 & 1016 & $10(11,0 \%)$ & $1006(11,9 \%)$ & 0,914 \\
\hline F32-F33 & 2553 & $29(31,9 \%)$ & $2524(29,9 \%)$ & 1,099 \\
\hline Andere Diagnose & 3434 & $32(35,2 \%)$ & $3402(40,2 \%)$ & 0,805 \\
\hline Alle Patienten & 8545 & 91 & 8454 & \\
\hline \multicolumn{5}{|c|}{ Corynebacteriaceae } \\
\hline F00-F03 & 342 & $6(13,0 \%)$ & $336(4,0 \%)$ & $3,644^{*}$ \\
\hline F10 & 1200 & $6(13,0 \%)$ & $1194(14,0 \%)$ & 0,918 \\
\hline F20-F29 & 1016 & $10(21,7 \%)$ & $1006(11,8 \%)$ & $2,069^{*}$ \\
\hline F32-F33 & 2553 & $12(26,1 \%)$ & $2541(29,9 \%)$ & 0,828 \\
\hline Andere Diagnose & 3434 & $12(26,1 \%)$ & $3422(40,3 \%)$ & 0,524 \\
\hline Alle Patienten & 8545 & 46 & 8499 & \\
\hline \multicolumn{5}{|c|}{ Staphylococcaceae } \\
\hline F00-F03 & 342 & $16(10,7 \%)$ & $326(3,9 \%)$ & $2,978^{*}$ \\
\hline F10 & 1200 & $10(6,7 \%)$ & $1190(14,2 \%)$ & $0,436^{*}$ \\
\hline F20-F29 & 1016 & $27(18,1 \%)$ & $989(11,8 \%)$ & $1,657^{*}$ \\
\hline F32-F33 & 2553 & $49(32,9 \%)$ & $2504(29,8 \%)$ & 1,153 \\
\hline Andere Diagnose & 3434 & $47(31,5 \%)$ & $3387(40,3 \%)$ & $0,681^{*}$ \\
\hline Alle Patienten & 8545 & 149 & 8396 & \\
\hline
\end{tabular}

Anmerkung: $* \mathrm{p}<, 05 ; * * \mathrm{p}<, 01 ; * * * \mathrm{p}<, 001$. Diagnosen $=$ Aufschlüsselung nach Diagnose-Clustern; $\sum$ $=$ Anzahl Patienten; $\sum$ pos. $=$ Anzahl positiv getesteter Patienten $\left(\right.$ Keimfamilien A, B, C, D); $\sum$ k.N. = Anzahl Patienten ohne Nachweis der entsprechenden Keimfamilie; Quot. = Quotenverhältnis (Odds Ratio; * 95\%-CI $\neq 1)$ 
Bei den Quotenverhältnissen zeigen sich teils signifikant Abweichungen. Für den Cluster „F00-F03“ waren die Quotenverhältnisse für jede der vier Bakterienfamilien signifikant erhöht. Das Cluster „F10“ zeigte für alle vier Bakterienfamilien erniedrigte Quotenverhältnisse, im Fall Staphylococcaceae signifikant. Das Cluster „F20-F29“ zeigte ein erniedrigtes und drei erhöhte Quotenverhältnisse. Zwei der drei erhöhten Quotenverhältnisse erreichten die Signifikanz (Corynebacteriaceae, Staphylococcaceae). Für den Diagnose-Cluster „F32-F33“ waren die Quotenverhältnisse in drei Fällen erhöht, in einem Fall erniedrigt, jedoch ohne signifikante Abweichung. Für den Kontroll-Cluster „Andere Diagnosen“ zeigten sich für alle vier Bakterienfamilien durchgehend erniedrigte, ebenfalls nicht signifikante Quotenverhältnisse. Insgesamt kann die Hypothese, dass es Assoziationen zwischen Bakterienfamilien und den Diagnose-Clustern zu finden gibt (H4), angenommen werden.

\subsubsection{Einfluss von Lebensalter auf das Risiko einer bakteriellen Infektion bei Demenzpatienten}

Das Lebensalter der in dieser Studie untersuchten Patienten des Demenz-Clusters $(n=342$, $M=73,512, S D=10,196)$ lag, wie erwartet, deutlich über dem Durchschnitt der restlichen Cluster ( $n=8.203$ Patienten, $M=44,754, S D=16,801)$ (s. Tabelle 39 und Abbildung 9).

Tabelle 39. Gegenüberstellung des F00-F03-Clusters (inkl. G-Diagnosen) zu restlichen Diagnosen

\begin{tabular}{|c|c|c|c|c|}
\hline \multicolumn{5}{|c|}{ Alter } \\
\hline & \multicolumn{2}{|c|}{ Nicht F00-F03 } & \multicolumn{2}{|c|}{ F00-F03 } \\
\hline & & SE & & $S E$ \\
\hline$M$ & 44,75 & 0,186 & 73,51 & 0,551 \\
\hline $95 \%$ CI - Untergrenze & 44,39 & & 72,43 & \\
\hline $95 \%$ CI - Obergrenze & 45,12 & & 74,60 & \\
\hline $5 \%$ getrimmtes Mittel & 44,30 & & 73,95 & \\
\hline Median & 45,00 & & 74,00 & \\
\hline Varianz & 282,275 & & 103,951 & \\
\hline Standardabweichung & 16,801 & & 10,196 & \\
\hline Minimum & 7 & & 20 & \\
\hline Maximum & 98 & & 95 & \\
\hline Spannweite & 91 & & 75 & \\
\hline Interquartilbereich & 26 & & 13 & \\
\hline Schiefe & 0,257 & 0,027 & $-0,879$ & 0,132 \\
\hline Kurtosis & $-0,670$ & 0,054 & 2,265 & 0,263 \\
\hline
\end{tabular}

Anmerkung: $S E=$ Standardfehler; $M=$ Mittelwert; 95\% $C I=95 \%$ Konfidenzintervall 


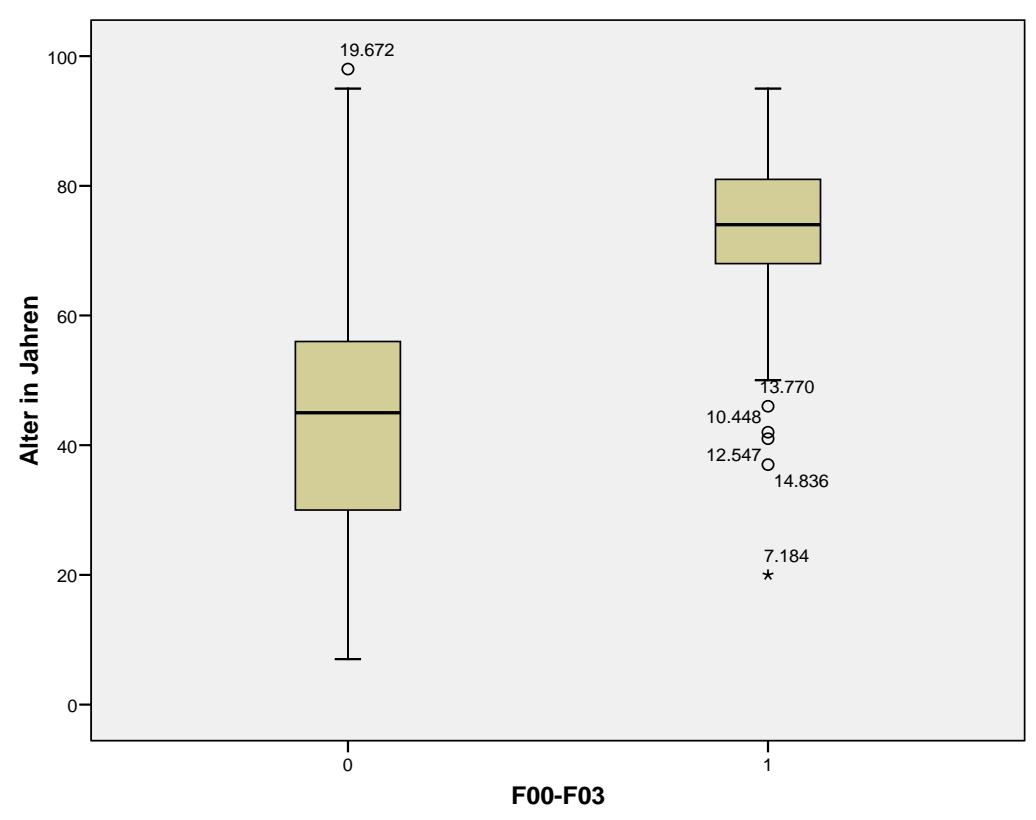

Anmerkung: $0=$ nicht F00-F03; 1 = F00-F03

Abbildung 9. Boxplot zu den Ergebnissen der Tabelle 39

Da die Quotenverhältnisse des „F00-F03“-Clusters für alle vier Bakterienfamilien signifikant erhöht waren und da Menschen mit erhöhtem Lebensalter anfälliger für Infektionen sind (s. H2), wurde durch weitere Analyse kontrolliert, ob die Demenz oder das erhöhte Lebensalter die mögliche Ursache für die erhöhte Anfälligkeit für bakterielle Infektionen ist.

Es wurde eine altersangepasste Vergleichsgruppe erstellt ( $n=1.037$ Patienten, $M=73,397$, $S D=6,132$ ), deren Mitglieder nicht die Hauptdiagnose Demenz hatten (s. Tabelle 40 und Abbildung 10). 
Tabelle 40. Gegenüberstellung des F00-F03-Clusters (inkl. G-Diagnosen) zur altersangepassten Vergleichsgruppe

\begin{tabular}{|c|c|c|c|c|}
\hline \multicolumn{5}{|c|}{ Alter } \\
\hline & \multicolumn{2}{|c|}{$\begin{array}{l}\text { Nicht F00-F03 } \\
\text { (altersangepasst) }\end{array}$} & \multicolumn{2}{|c|}{ F00-F03 } \\
\hline & & SE & & SE \\
\hline$M$ & 73,40 & 0,190 & 73,51 & 0,551 \\
\hline $95 \% C I$ - Untergrenze & 73,02 & & 72,43 & \\
\hline $95 \% C I$ - Obergrenze & 73,77 & & 74,60 & \\
\hline $5 \%$ getrimmtes Mittel & 72,94 & & 73,95 & \\
\hline Median & 72,00 & & 74,00 & \\
\hline Varianz & 37,606 & & 103,951 & \\
\hline Standardabweichung & 6,132 & & 10,196 & \\
\hline Minimum & 66 & & 20 & \\
\hline Maximum & 98 & & 95 & \\
\hline Spannweite & 32 & & 75 & \\
\hline Interquartilbereich & 9 & & 13 & \\
\hline Schiefe & 0,997 & 0,076 & $-0,879$ & 0,132 \\
\hline Kurtosis & 0,550 & 0,152 & 2,265 & 0,263 \\
\hline
\end{tabular}

Anmerkung: $S E=$ Standardfehler; $M=$ Mittelwert; 95\% CI =95\% Konfidenzintervall

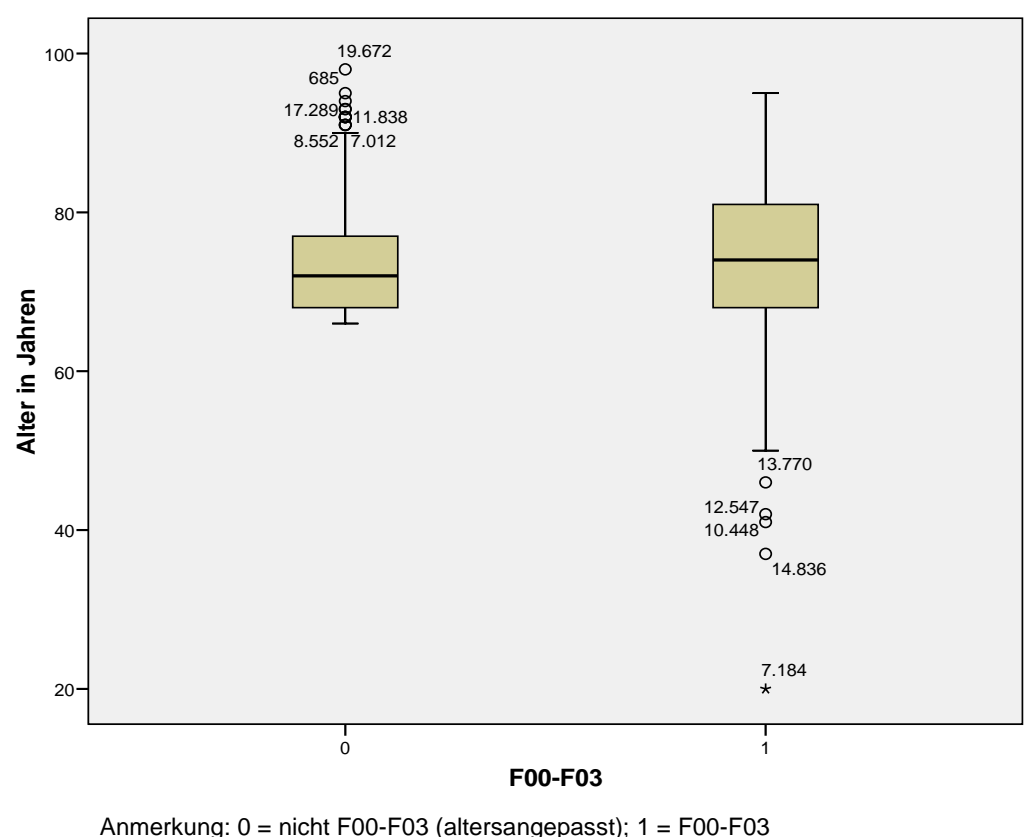

Abbildung 10. Boxplot zu den Ergebnissen der Tabelle 40

Zur Überprüfung, ob die Quotenverhältnisse auch im Vergleich mit der altersangepassten Stichprobe erhöht waren, wurden diese für alle vier Bakterienfamilien berechnet (s Tabelle 41). 
Tabelle 41. Ergebnisse der Quotenverhältnisse und Chi-Quadrat-Tests zwischen altersangepasster Vergleichsgruppe und F00-F03-Cluster

\begin{tabular}{|c|c|c|c|c|c|c|}
\hline Diagnosen & $\sum$ & $\sum_{p o s .}$ & $\sum_{k, N}$. & Quot. & $\chi^{2}(\mathrm{df}=1)$ & $p\left(\chi^{2}\right)$ \\
\hline \multicolumn{7}{|c|}{ Enterobacteriaceae } \\
\hline F00-F03 & 342 & 21 & 321 & \multirow{2}{*}{1,104} & \multirow{2}{*}{0,143} & \multirow{2}{*}{0,706} \\
\hline Nicht F00-F03 & 1037 & 58 & 979 & & & \\
\hline Alle Pat. & 1379 & 79 & 1300 & & & \\
\hline \multicolumn{7}{|c|}{ Enterococcaceae } \\
\hline F00-F03 & 342 & 11 & 331 & \multirow{2}{*}{0,898} & \multirow{2}{*}{0,095} & \multirow{2}{*}{0,758} \\
\hline Nicht F00-F03 & 1037 & 37 & 1000 & & & \\
\hline Alle Pat. & 1379 & 48 & 1331 & & & \\
\hline \multicolumn{7}{|c|}{ Corynebacteriaceae } \\
\hline F00-F03 & 342 & 6 & 336 & \multirow{2}{*}{1,834} & \multirow{2}{*}{1,4} & \multirow{2}{*}{0,237} \\
\hline Nicht F00-F03 & 1037 & 10 & 1027 & & & \\
\hline Alle Pat. & 1379 & 16 & 1363 & & & \\
\hline \multicolumn{7}{|c|}{ Staphylococcaceae } \\
\hline F00-F03 & 342 & 16 & 326 & \multirow{2}{*}{1,057} & \multirow{2}{*}{0,035} & \multirow{2}{*}{0,851} \\
\hline Nicht F00-F03 & 1037 & 46 & 991 & & & \\
\hline Alle Pat. & 1379 & 62 & 1317 & & & \\
\hline
\end{tabular}

Anmerkung: $\sum=$ Anzahl Patienten; $\sum$ pos. = Anzahl positiv getesteter Patienten; $\sum$ k. N. $=$ Anzahl Patienten ohne Nachweis der entsprechenden Keimfamilie; Quot. = Quotenverhältnis (Odds Ratio; * 95\%-CI $\neq 1$ ); $\chi 2$ : Empirisches Chi-Quadrat für die jeweilige $2 \times 2$-Felder-Matrix $(d f=1, N=1379) ; p(\chi 2)^{*}: p$-Wert für den Chi-Quadrat Test; "Nicht F00-03" steht in dieser Tabelle für die altersangepasste Stichprobe.

Es zeigte sich, dass die Quotenverhältnisse der vier Keimfamilien für Demenzpatienten bei altersangepasster Vergleichsgruppe nicht signifikant erhöht oder erniedrigt waren. Dies spricht dafür, dass für die erhöhte Prävalenz aller vier Bakterienfamilien im DemenzCluster „F00-F03“ eher das hohe Lebensalter als die Erkrankung an einer Demenz verantwortlich ist. 


\section{Diskussion}

In der vorliegenden Untersuchung wurde retrospektiv ein 12-Jahres-Datensatz untersucht, um Assoziationen zwischen Infektionen, Alter, Verweildauer und ausgewählten psychiatrischen Erkrankungen aufzudecken und diese mit der aktuellen wissenschaftlichen Datenlage in Beziehung zu setzen.

Es sollten mögliche Zusammenhänge zwischen bakteriellen Infektionen und der Länge der Verweildauer überprüft werden (H1). Zudem sollte untersucht werden, ob die Wahrscheinlichkeit, an einer Infektion zu erkranken, mit dem Alter psychiatrischer Patienten steigt (H2). Zusätzlich sollte überprüft werden, ob die in H1 und H2 gemachten Vorhersagen auch auf die vier relevanten Diagnose-Cluster „F00-F03“, „F10“, „F20-F29 und „F32-F33“ zutreffen (H3). Abschließend sollte untersucht werden, ob Über- oder Unterrepräsentationen ausgewählter Bakterienfamilien bei den Diagnose-Clustern vorhanden sind (H4).

\subsection{Mikrobiologische Untersuchung und Verweildauer (Hypothese 1)}

\subsubsection{Mikrobiologische Untersuchung und Verweildauer bei positiv, negativ und nicht getesteten Patienten}

In der vorliegenden Arbeit konnten die Ergebnisse zur Verweildauer vergleichender Arbeiten reproduziert werden. Die Mittelwerte der Verweildauer der nicht getesteten Patienten innerhalb der Diagnose-Cluster dieser Arbeit decken sich nahezu mit den Mittelwerten der gefundenen Daten. Die Ergebnisse dieser Arbeit sind als deckungsgleich zu betrachten, da in den Quellen der Recherche andere Cluster gebildet bzw. nur einzelne Krankheitsbilder dargestellt worden sind. Direkt übereinstimmende Cluster zum Vergleich der Verweildauer konnten nicht gefunden werden. Es zeigt sich dennoch, dass sich ein alkoholkranker Patient mit durchschnittlich 18,9 Tagen am kürzesten in Behandlung befindet, gefolgt von Demenz-Patienten ( $M=20,4$ Tage). Depressions- ( $M=36,5$ Tage) und Schizophrenie-Patienten $(M=34,5$ Tage) bleiben im Durchschnitt deutlich länger in Behandlung (s. Tabelle 42) (Bremer Krankenhausspiegel - Verweildauer je Erkrankung 2016; Bundespsychotherapeutenkammer - Studie zur stationären Versorgung psychisch kranker Menschen 2014; Gesundheitsberichterstattung des Bundes - Durchschnittliche Verweildauer ausgewählter Diagnosen 2017). 
Tabelle 42. Vergleich der Verweildauer der Cluster dieser Arbeit und der Verweildauer ähnlicher Krankheitsgruppierungen aus Internetquellen

\begin{tabular}{lccc}
\hline & \multicolumn{3}{c}{ Daten der } \\
& $M$ & Internetquellen & Daten des Bremer Krankenhausspiegels \\
\hline F00-F03 & 20,4 & $13,4(\mathrm{~F} 00-\mathrm{F} 03)$ & 13,8 (max. 23,8) (Demenz-Patienten) \\
F10 & 18,9 & $12,9(\mathrm{~F} 10)$ & 9,7 (max. 12,4) (Sucht-Patienten) \\
F20-F29 & 34,5 & $32,0($ Schizophrenie) & 27,0 (max. 31,6) (Schizophrene Erkr.) \\
F32-F33 & 36,5 & $35,3(F 30-F 39)$ & 28,4 (max. 37,3) (affektive Störung) \\
\hline
\end{tabular}

Anmerkung. Mittelwerte $(M)$ als Anzahl in Tagen; in Klammern: für Mittelwert genommene Patientengruppe

Die Verweildauer von Patienten im Krankenhaus kann sich durch eine Infektion stark verlängern. Auf internistischen, chirurgischen und Intensivstationen ist dieser Zusammenhang mehrfach untersucht worden (Gesundheitsberichterstattung des Bundes Themenheft 8 „Nosokomiale Infektionen“ 2002). Die Datenlage bezüglich Verweildauer bei Infektionen bei psychiatrischen Patienten ist hingegen äußerst spärlich. Eine Studie von Malyuk et al. weist darauf hin, dass Patienten, die bei Aufnahme in die Gerontopsychiatrie eine Infektion aufweisen, eine verlängerte Verweildauer haben, wenn diese unbehandelt bleibt (Malyuk et al. 2012).

Das Ergebnis dieser Arbeit zeigte, dass die negativ getesteten Patienten die längste Verweildauer aufwiesen ( $M=51,92$ Tage), gefolgt von den positiv getesteten Patienten ( $M$ $=46,92$ Tage). Der Unterschied zwischen diesen beiden Gruppen war nicht signifikant. Signifikant kürzer blieben nicht getestete Patienten ( $M=26,27$ Tage).

Patienten, deren Symptome einen Arzt dazu veranlasst haben, eine mikrobiologische Probe $\mathrm{zu}$ entnehmen (sowohl positiv als auch negativ getestete Patienten) und auswerten zu lassen, blieben demnach signifikant länger in der psychiatrischen Klinik als Patienten, die keinen Anlass dazu gaben.

Hypothese 1.1 besagt, dass Patienten mit einem positiven Bakteriennachweis länger in der psychiatrischen Behandlung verbleiben als negative und nicht getestete Patienten. Diese Hypothese muss verworfen werden: Negativ getestete Patienten hatten die längste Verweildauer, wenn auch nicht signifikant und im Mittelwert nur minimal länger als positiv getestete Patienten. Hypothese 1.2 besagt, dass nicht getestete Patienten die kürzeste Verweildauer aufweisen. Dies konnte in den Daten gefunden werden.

Eine mögliche Erklärung der gefundenen Ergebnisse ist, dass bei Patienten, die länger in der Psychiatrie bleiben, die Wahrscheinlichkeit steigt sich $\mathrm{zu}$ infizieren oder eine mikrobiologischen Testung zu durchlaufen. 
Es ist nicht davon auszugehen, dass die psychiatrischen Krankheitsbilder bei den positiv getesteten Patienten genauso schnell therapiert worden sind wie bei den Patienten ohne Keimnachweis und die positiv getesteten Patienten trotz erfolgreicher Behandlung des psychiatrischen Krankheitsbildes nur noch zur Behandlung der Infektion auf einer Station der Psychiatrie gelegen haben. Eher ist von einer notwendigen Verlängerung der Therapiemaßnahmen bezüglich der psychiatrischen Erkrankung auszugehen.

Eine Erklärung für die erhöhte Verweildauer der negativ getesteten Patienten könnten fehlerhafte klinische Prozesse sein. Es wurden Proben bei Patienten mit Symptomen entnommen. Wenn die Probe trotz Symptomen des Patienten negativ war, ist es möglich, dass der Patient dennoch eine Infektion hatte, diese jedoch nicht nachgewiesen werden konnte. Die Gründe dafür sind vielfältig: mangelnde Anzucht im mikrobiologischen Institut, falsche Fokussuche durch den behandelnden Arzt, falsche Entnahmeart, falscher Entnahmeort oder falscher Umgang mit der Probe.

Diese Annahme, dass zumindest manche der Proben als falsch-negativ zu werten sind, würde den Verdacht erhärten, dass Infektionen im Allgemeinen in Verbindung mit psychiatrischen Erkrankungen stehen. Subramaniapillai et al. beschreiben, dass viele Patienten mit Stimmungsstörungen (mood disorders) gleichzeitig ein Ungleichgewicht im Entzündungssystem aufweisen und vermuten, dass eine pharmakologische Behandlung der Entzündung eine neue Behandlungsstrategie in der Zukunft werden könnte. Sie beschreiben weiterhin, dass eine Entzündung nicht nur die Stimmung, sondern auch die Kognition negativ beeinflusst (Subramaniapillai et al. 2017).

Müller beschreibt, dass für die Depression und das frühe Stadium der Schizophrenie COX2-Inhibitoren (Cyclooxygenase-2-Inhibitoren, entzündungshemmende Pharmazeutika) den Krankheitsverlauf günstig beeinflussende Ergebnisse erzielt haben (Müller 2017). Andere Studien haben dazu positive Ergebnisse mit anderen entzündungshemmenden Verbindungen erzielt, z. B. einen Rückgang der Fatigue und von depressiven Symptomen bei Psoriasis-Patienten nach der Behandlung mit dem TNF-Blocker Etanercept. Dieser greift in das Immunsystem ein, indem er die Immunzytokine TNF- $\alpha$ und TNF- $\beta$ an sich bindet, sodass kein Entzündungsprozess mehr stattfinden kann (Tyring et al. 2006). Ebenso wurde ein besserer Krankheitsverlauf der Schizophrenie bei früher Gabe des Antibiotikums Minocycline festgestellt (Chaudhry et al. 2012).

Die Ergebnisse der vorliegenden Studie passen insofern zu den Ergebnissen bereits veröffentlichter Arbeiten, dass eine bakterielle Infektion und ihre Auswirkungen auf das 
Immunsystem einen Einfluss auf den Behandlungsverlauf psychiatrischer Erkrankungen und somit auch auf die Länge der Verweildauer haben.

Bakterielle Infektionen haben Auswirkungen auf die körperliche Verfassung und die Genesungszeit eines Patienten. Aber auch aus ökonomischer Sicht sind die Auswirkungen für das Gesundheitssystem als kritisch anzusehen. Das Ergebnis dieser Arbeit richtet einmal mehr den Fokus auf die notwendige Einhaltung der Hygienerichtlinien des RKI, um Infektionen möglichst zu unterbinden und im Fall einer Epidemie schnell einzudämmen.

\subsubsection{Mikrobiologische Untersuchung und Verweildauer innerhalb der Cluster - Vergleich der positiv, negativ und nicht getesteten Patienten (Hypothese 3)}

Hypothese 3 besagt, dass sich die Anzahl der Tage der Verweildauer der gesamten Stichprobe aller positiv, negativ und nicht getesteten Patienten auch in den Clustern widerspiegelt. Für die Gruppe der nicht getesteten Patienten traf dies zu. Alle nicht getesteten Patienten innerhalb der gebildeten Cluster blieben kürzer in Behandlung als die positiv und negativ getesteten Patienten. Im Cluster „F00-F03“ verblieben positiv getestete Patienten minimal länger als negativ getestete. Der Grund hierfür ist nicht bekannt und kann Gegenstand weiterer Untersuchungen werden. Die Datenlage zu diesem Thema ist äußerst spärlich. Insgesamt stützen die Daten teilweise die in Hypothese 3 gemachte Aussage.

\subsubsection{Mikrobiologische Untersuchung und Verweildauer innerhalb der Cluster - \\ Ergebnis des Post-Hoc-Tests}

Die Ergebnisse des Post-Hoc-Tests bezüglich der Verweildauer innerhalb der Cluster sind die logische Konsequenz der unterschiedlichen Behandlungszeiträume der einzelnen Erkrankungen. Die Ergebnisse zeigten, dass das Cluster „F32-F33“ die längste Verweildauer hatte, gefolgt von dem Cluster „F20-F29“, gefolgt von dem Cluster „F00F03“. Die kürzeste Verweildauer hatte das „F10“-Cluster. Die Cluster „F20-F29“ und „F32-F33“ verblieben in den korrigierten Paarvergleichen signifikant länger in Behandlung als die Cluster „F10“ und „F00-F03“. Die Behandlungsdauer zwischen den Clustern „F20F29“ und „F32-F33“ unterschied sich nicht signifikant. Diese Ergebnisse geben die deutlichen Unterschiede der benötigten Behandlungsdauer der unterschiedlichen psychiatrischen Erkrankungen wider. 


\subsection{Mikrobiologische Untersuchung und Alter (Hypothese 2)}

\subsubsection{Mikrobiologische Untersuchung und Alter bei positiv, negativ und nicht getesteten Patienten}

Die Immunoseneszenz (Weiskopf et al. 2009) und körperliche Veränderungen im Alter (Allgemeinarzt-online.de - Infektionen im Alter - Was macht sie so gefährlich? 2015) tragen dazu bei, dass der Mensch im Laufe seines Lebens anfälliger für Infektionen wird. Dies zeigt sich unter anderem durch höhere Infektionsraten mit steigendem Lebensalter bei Pneumonien (Ewig et al. 2009) und Clostridium-difficile-Infektionen (Murphy et al. 2012). Hypothese 2 besagt, dass der Altersdurchschnitt der positiv getesteten Patienten der Psychiatrie höher ist als der der negativ und der nicht getesteten Patienten - dies wurde für die hier untersuchte Stichprobe so gefunden: Die in der Psychiatrie positiv getesteten Patienten sind signifikant älter als die beiden Vergleichsgruppen. Vergleichsdaten zum Durchschnittsalter von an einem Infekt erkrankten Patienten innerhalb der Psychiatrie konnten nicht gefunden werden.

Zusätzlich gilt es zu beachten, dass Patienten mit höherem Lebensalter häufiger in Kontakt mit potentiellen Erregern kommen. Anhand der Risikofaktoren einer MRSA-Infektion des RKI lässt sich dieses ableiten. Ältere Patienten wohnen prozentual häufiger in Wohneinrichtungen mit hoher MRSA-Prävalenz, hatten einen stationären Krankenhausaufenthalt länger als drei Tage in den letzten 12 Monaten, haben häufig in ihrer Vorgeschichte eine bekannte MRSA-Anamnese und haben durch ihre Krankenhausgeschichte und Wohnungssituation im Pflegeheim eine höhere Wahrscheinlichkeit, Kontakt zu MRSA-Trägern gehabt zu haben. Häufig kommen dann noch mehrere der weiteren Risikofaktoren wie chronische Pflegebedürftigkeit, Antibiotikatherapie in den zurückliegenden sechs Monaten, liegende Katheter (z. B. Harnblasenkatheter, PEG-Sonde), Dialysepflicht, Hautulkus, Gangrän, chronische Wunden oder tiefe Weichteilinfektionen mit hinzu. Anhand dieser Risikofaktoren soll der behandelnde Arzt über die Notwendigkeit eines MRSA-Screenings entscheiden (Ruscher 2014).

Das Alter an sich ist somit aufgrund der Immunseneszenz schon ein Risikofaktor für Infektionen, aber auch die sich durch das Lebensalter ergebenden Lebensumstände tragen dazu bei. Vom RKI ist das Lebensalter nicht als Risikofaktor für Infektionen aufgeführt, der behandelnde Arzt sollte dieses dennoch als möglichen Prädiktor für weitere Risikofaktoren in Betracht ziehen und dementsprechend handeln. 
Wiederum in Bezug auf MRSA-Infektionen ist dann abhängig von den jeweiligen Hygienestandards des Krankenhauses über einen MRSA-Screening-Test zu entscheiden.

\subsubsection{Mikrobiologische Untersuchung und Alter innerhalb der Cluster - Vergleich der positiv, negativ und nicht getestete Patienten (Hypothese 3)}

Hypothese 3 besagt, dass sich das Ergebnis der Gesamtstichprobe bezüglich des Lebensalters auch in den Clustern widerspiegelt. Tendenziell konnte dies bestätigt werden: Lediglich bei dem Cluster „F00-F03“ waren nicht positiv, sondern negativ getestete Patienten (minimal) älter. Somit stützen die Ergebnisse die in Hypothese 3 gemachte Aussage weitgehend. Die leichten Abweichungen einzelner Cluster von der Verteilung der Gesamtstichprobe sollte Gegenstand weiterer Forschung werden. Anderweitige Daten zu diesem Thema konnten trotz umfangreicher Suche nicht gefunden werden.

\subsubsection{Mikrobiologische Untersuchung und Verweildauer innerhalb der Cluster - Ergebnis des Post-Hoc-Tests}

Die Ergebnisse des Post-Hoc-Tests bezüglich des Durchschnittsalters innerhalb der Cluster sind die logische Konsequenz der unterschiedlichen Altersprävalenzen der einzelnen Erkrankungen. Die Ergebnisse spiegeln wider, dass die Erkrankung der Demenz („F00-F03“; $M=73,51$ Jahre) gehäuft im höheren Lebensalter auftritt, die Erkrankungen der Depression („F32-F33“; $M=$ 48,64 Jahre), die Erkrankung der Alkoholsucht („F10“; $M=47,47$ Jahre) und die schizotopen Erkrankungen („F20-F29“; $M=40,12$ ) früher im Leben eine Rolle spielen.

Die Ergebnisse der vorliegenden Arbeit spiegeln die Statistik der Gesundheitsberichterstattung des Bundes (GBE) wider. Die gefundenen Zahlen beziehen sich auf Patientenzahlen in Deutschland pro 100.000 Einwohner im Jahr 2015. Von den an der vaskulären Demenz (F01) erkrankten Patienten waren 99\% 65 Jahre und älter. Patienten mit psychischen oder Verhaltensstörungen durch Alkohol (F10) waren zu 37\% zwischen 15 und 45 Jahren alt und zu 51\% zwischen 45 und 65 Jahren alt. Patienten mit Schizophrenie, schizotypen und wahnhaften Störungen (F20-F29) waren zu 44\% zwischen 15 und 45 Jahren alt und zu 40\% zwischen 45 und 65 Jahren alt. Patienten mit einer depressiven Episode (F32) waren zu 36\% zwischen 15 und 45 Jahren alt und zu 31\% zwischen 45 und 65 Jahren alt. 26\% der Patienten waren 65 Jahre und älter (Gesundheitsberichterstattung des Bundes - Diagnosedaten der Krankenhäuser 2017). 


\subsection{Diagnose-Cluster und Keimfamilien (Hypothese 4)}

Aufgrund der stetig anwachsenden Zahl von wissenschaftlichen Veröffentlichungen und des größer werdenden Verdachtes, dass Infektionen in Verbindung mit auftretenden psychiatrischen Erkrankungen stehen können, wurde die Hypothese formuliert, dass auch in dem Routine-Datensatz Assoziationen zwischen Bakterienfamilien und psychischen Erkrankungen zu finden sind (H4).

Die signifikanten Ergebnisse der Chi-Quadrat-Testungen zwischen den Diagnose-Clustern und Bakterienfamilien weisen darauf hin, dass es innerhalb jeder der vier Keimfamilien Unterschiede zwischen den Häufigkeiten des Auftretens der Diagnose-Clustern gab (s. Tabelle 43).

Tabelle 43. Zusammenfassung der Ergebnisse der Chi-Quadrat-Testungen und Signifikanzwerte zwischen Diagnose-Clustern und Bakterienfamilien

\begin{tabular}{lll}
\hline \multicolumn{1}{c}{ Keimfamilie } & $\chi^{2}(\mathrm{df}=4)$ & $p\left(\chi^{2}\right)$ \\
\hline Enterobacteriaceae & 35,842 & $<, 001$ \\
Enterococcaceae & 16,916 & $=, 016$ \\
Corynebacteriaceae & 15,762 & $=, 027$ \\
Staphylococcaceae & 31,226 & $<, 001$ \\
\hline
\end{tabular}

Anmerkung: $\chi^{2}$ : Empirisches Chi-Quadrat; $p\left(\chi^{2}\right): p$-Wert für den Chi-Quadrat-Test

Bezogen auf die jeweilige $5 \times 2$-Felder-Matrix zeigten sich signifikante Abweichungen zwischen den Diagnose-Clustern für alle vier Keimfamilien.

\subsubsection{Diagnose-Cluster F10}

Für das Diagnose-Cluster „F10“ waren die Quotenverhältnisse in allen Vergleichen mit der jeweiligen Bakterienfamilie erniedrigt, für die Bakterienfamilie Staphylococcaceae signifikant. Die wissenschaftliche Datenlage zu diesem Thema ist äußerst spärlich. Mutlu et al. schreiben, dass sich der Anteil der Bakterienfamilie Bacteroidaceae bei chronischem Alkoholkonsum innerhalb der Darmflora verringert, die Anzahl an Proteobacteriaceae erhöht (Mutlu et al. 2012). Die von den Autoren angeführte hypothetische Erklärung ist ein durch den chronischen Alkoholkonsum verursachter Rückgang der Konnektivität der Darmmukosa.

Außerdem verändert Alkoholabhängigkeit die Essgewohnheiten des Patienten, da Alkohol neben dem Sucht- auch ein Nahrungsmittel ist und dem Körper durch regelmäßigen Konsum viele Kalorien zugeführt werden und eine ausgewogene Ernährung nicht mehr 
stattfindet (Lewis 2011). Folglich ändert sich allein deshalb die Zusammensetzung der mikrobiellen Darmflora. Hinzu kommt, dass der chronische Konsum von Ethanol an sich ebenfalls die Zusammensetzung der Darmflora und die Permeabilität der Darmmukosa beeinflusst (Timary et al. 2015).

Es wurde herausgefunden, dass alkoholabhängige Patienten mit einer erhöhten Darmpermeabilität nach dreiwöchiger Abstinenz eine höhere Rate an Depressionen, Angstzuständen und Suchterscheinungen, also wichtigen Rückfallfaktoren, aufwiesen. Ebenfalls fand man eine veränderte Zusammensetzung und Aktivität der Darmmikrobiotika. Leclercq et al. kommen zu dem Schluss, dass es eine Darm-GehirnAchse in der Alkoholabhängigkeit zu geben scheint und dass das Darmmikrobiom ein neues Ziel zur Behandlung der Alkoholabhängigkeit werden könnte (Leclercq et al. 2014; Engen et al. 2015).

Die gefundenen Veröffentlichungen bezüglich der mikrobiellen Flora des Menschen und der Alkoholsucht beziehen sich größtenteils auf die Zusammensetzung der Darmflora. Eine generelle Untersuchung zu bakteriellen Infektionen in der Subgruppe der Alkoholabhängigen konnte nicht gefunden werden.

\subsubsection{Diagnose-Cluster F20-F29}

Für das Diagnose-Cluster „F20-F29“ waren die Quotenverhältnisse in den Vergleichen mit der jeweiligen Bakterienfamilie sowohl erhöht als auch erniedrigt. Für die Bakterienfamilien Corynebacteriaceae und Staphylococcaceae waren die Erhöhungen signifikant. Die wissenschaftliche Datenlage zu diesem Thema ist äußerst spärlich. Fellerhof und Wank fanden im präfrontalen Kortex verstorbener Schizophrenie-Patienten eine vierfach erhöhte Anzahl an Chlamydophila-DNA, dieses Bakterium gehört zur Familie der Chlamydiaceae (Fellerhoff und Wank 2011). Krause et al. schreiben, dass sie signifikant erhöhte Werte von Chlamydia trachomatis, ebenfalls ein Bakterium der Familie Chlamydiaceae, bei SchizophreniePatienten gefunden haben. Sie kommen jedoch zu dem Schluss, dass nicht das Bakterium an sich, sondern eher die daraus resultierende Immunantwort der Auslöser für eine Schizophrenie sein könnte (Krause et al. 2010). Cevizci et al. schreiben, dass sie in Schizophrenie-Patienten eine erhöhte Anzahl an Borrelien gefunden haben, diese gehören zur Familie der Spirochaetaceae. Sie geben jedoch zu bedenken, dass die gefundenen Ergebnisse auf die vernachlässigte körperliche Hygiene der untersuchten Patienten zurückzuführen sein könnte (Cevizci et al. 2015). 
Khandaker et. al fassen in ihrem Review mögliche Forschungsansätze über das Zusammenspiel von Infektionen, Entzündungen, des Immunsystems und der Entstehung der Schizophrenie zusammen und kommen zu dem Schluss, dass Infektionen an der Entstehung einer Schizophrenie beteiligt sein können (Khandaker et al. 2015).

In der vorliegenden Arbeit wurden die Diagnose-Cluster nicht nach denselben Erregern untersucht wie in den zitierten Arbeiten. Die gefundenen Ergebnisse erweitern dementsprechend den Kreis der assoziierten Bakterien für das Cluster „F20-F29“.

\subsubsection{Diagnose-Cluster F32-F33}

Für das Diagnose-Cluster „F32-F33“ waren die Quotenverhältnisse in drei Fällen erhöht, in einem Fall erniedrigt. Eine Signifikanz wurde in keinem Fall erreicht. Die von Wang et al. beschriebene Erhöhung der Bakterienfamilie Chlamydiaceae ist nicht untersucht worden und kann somit weder bestätigt noch widerlegt werden (Wang et al. 2014).

Das Ergebnis ist mit den Erkenntnissen von Dantzer et al. und Young et al. in Verbindung zu bringen, die beide zu dem Schluss kommen, dass die immunologischen Vorgänge im Abwehrsystem des Menschen während einer Infektion zu einer Depression führen oder aber diese verstärken können (Dantzer et al. 2008; Young et al. 2014). Eine Assoziation zwischen einer bestimmte Bakterienfamilie und dem Cluster „F32-F33“ konnte jedoch nicht gefunden werden.

\subsubsection{Diagnose-Cluster F00-F03}

Für das Diagnose-Cluster „F00-F03“ waren die Quotenverhältnisse in allen Vergleichen mit den Familien der Enterobacteriaceae, Enterococcaceae, Corynebacteriaceae und Staphylococcaceae erhöht. E. coli gehört zu der Familie der Enterobacteriacea. Ein erhöhtes Auftreten dieses Bakteriums in Gehirnen verstorbener Alzheimer-Patienten wurde von Zhan et al. beschrieben (Zhan et al. 2016). Eine erhöhte Prävalenz von Staphylococcus aureus bei Demenz-Patienten wurde von Lasseter et al. beschrieben (Lasseter et al. 2010). In wissenschaftlichen Veröffentlichungen wurden weiterhin Häufungen von Bakterien aus den Familien der Spirochaetaceae, Chlamydiaceae und Helicobacteracea beschrieben (Shima et al. 2010; Miklossy 2011; Maheshwari und Eslick 2015; Xu et al. 2016).

Wahrscheinlicher ist jedoch, dass nicht einzelne Bakterien, sondern Entzündungen generell eine Demenzerkrankung verursachen oder verstärken können. $\mathrm{Zu}$ diesem Ergebnis kommen mehrere Forschungsarbeiten (Wu et al. 2015; Popp et al. 2017). 


\subsubsection{Altersbasierte Vergleichsgruppe zu Diagnose-Cluster F00-F03}

Aufgrund der Feststellung, dass mit ansteigendem Lebensalter auch das Risiko für Infektionen steigt (Allgemeinarzt-online.de - Infektionen im Alter - Was macht sie so gefährlich? 2015) und den Ergebnissen der signifikanten Erhöhung aller vier Bakterienfamilien im Diagnose-Cluster „F00-F03“, wurde mittels altersangepasster Vergleichsstichprobe überprüft, ob die Demenzerkrankung oder das Lebensalter für das vermehrte Auftreten von Bakteriennachweisen ursächlich war. Die Ergebnisse zeigten, dass die Quotenverhältnisse für den Cluster „F00-F03“ im Vergleich zur nicht demenziellen, altersangepassten Vergleichsstichprobe weder signifikant erhöht noch signifikant verringert waren.

Eine mögliche Interpretation dieses Ergebnisses ist, dass das Lebensalter einen Mediator für den gesteigerten Nachweis der vier Bakterienfamilien bei Demenzerkrankten darstellt. Demnach kann eher das erhöhte Lebensalter und nicht die Demenzerkrankung an sich für erhöhte bakterielle Nachweise als ursächlich angesehen werden.

\subsubsection{Zusammenfassung zu Hypothese 4}

Assoziationen zwischen Bakterienfamilien und psychiatrischen Erkrankungen (H4), konnten in dem vorliegenden Datensatz gefunden werden. Für das Schizophrenie-Cluster „F20-F29“ war die nachgewiesene Anzahl der Familien Corynebacteriaceae und Staphylococcaceae signifikant erhöht, für das Cluster „F10“ war die Familie der Staphylococcaceae signifikant erniedrigt. Die signifikanten Werte aller vier Bakterienfamilien innerhalb des Demenz-Clusters „F00-F03“ sind eher auf das Alter der getesteten Patienten und nicht auf die Demenzerkrankung zurückzuführen. Es besteht demnach keine Assoziation zwischen dem Cluster „F00-F03“ und einer Bakterienfamilie.

Nachfolgende Forschungen sollten versuchen, das erhöhte und verminderte Auftreten bestimmter Bakterienfamilien bei psychiatrischen Erkrankungen zu erklären und weiter auszudifferenzieren.

\subsubsection{Spezielles Bakterium oder Infektion im Allgemeinen}

Vieles spricht dafür, dass Entzündungsvorgänge im Körper das Ausmaß verschiedener psychiatrischer Erkrankungen beeinflussen können. Dies wurde für die Schizophrenie (Khandaker et al. 2015), die Depression (Dantzer et al. 2008; Young et al. 2014) und die Demenz (Wu et al. 2015; Popp et al. 2017) beschrieben. 
Die signifikant erhöhten Anzahlen zweier Bakterienfamilien innerhalb des SchizophrenieClusters „F20-F29“ der vorliegenden Arbeit und die wissenschaftliche Datenlage zeigen, dass der Nachweis von Bakterienfamilien oder anderen Erregerarten bei den psychiatrischen Erkrankungen nicht homogen ist. Dies erlaubt die rein hypothetische Überlegung, dass nicht jeder Erreger die gleichen Auswirkungen auf Erkrankungen der Psyche hat.

Auch wenn noch nicht zweifelsfrei ein bestimmter Erreger als Auslöser einer psychiatrischen Erkrankung bestätigt werden konnte, sollte man Infektionen als Auslöser psychischer Erkrankungen in zukünftigen Forschungsarbeiten nicht außer Acht lassen, da sie unter Umständen den menschlichen Organismus nachhaltig beeinflussen können.

Würden weitere Forschungsergebnisse dies bestätigen, könnten neue Behandlungsansätze im Gebiet der psychiatrischen Erkrankungen durch antiinflammatorische und antibiotische Medikamente entstehen.

\subsubsection{Auswirkungen der Gut-Brain-Axis}

Ein weiteres Feld der Auswirkungen von Bakterien auf die Entstehung psychiatrischer Erkrankungen wird in Arbeiten zur sog. Gut-Brain-Axis (Darm-Gehirn-Verbindung), oder auch Microbiome-Gut-Brain-Axis, beschrieben (Cryan und Dinan 2012; Cenit et al. 2017; Clapp et al. 2017). Störungen der Darmflora und Entzündungen des Darms werden hierbei mit Krankheiten wie Schizophrenie, Depression, Alzheimer-Demenz und Parkinson in Verbindung gebracht.

Es wird angenommen, dass unter anderem eine gastrointestinale Barrierestörung und eine Entzündung des Darms zur Schizophrenieentwicklung beitragen können. Weiterhin wurde beschrieben, dass antimikrobielle Wirkstoffe und Probiotika bei Schizophreniepatienten ein therapeutisches Potential haben (Nemani et al. 2015; Caso et al. 2016).

Mehrere Reviews kommen zu dem Schluss, dass die Darmflora einen Einfluss auf die Stimmung hat. Eine gesunde Darmflora, die mittels Diät oder Probiotika gepflegt wird, kann helfen, eine Depression zu behandeln oder aber die Symptome zu lindern, da die Mikroorganismen im Darm dazu fähig sind, neuroaktive Substanzen wie Serotonin und Gamma-Aminobuttersäure auszuschütten. Ebenso wird erwähnt, dass Probiotika, also ein Nahrungszusatz aus lebensfähigen Mikroorganismen wie z. B. Milchsäurebakterien oder Hefen, antidepressive und anxiolytische Wirkungen haben (Evrensel und Ceylan 2015; Lima-Ojeda et al. 2017). 
Es wird beschrieben, dass eine durch Darmfloradysbiose entstandene erhöhte Darmmukosa- und Blut-Hirn-Schranken-Permeabilität die Erkrankung der AlzheimerDemenz vermitteln oder aber beeinflussen kann. Darmbakterien können große Mengen an Amyloiden und Lipopolysacchariden absondern, die zur Modulation von Signalwegen und der Produktion proinflammatorischer Zytokine beitragen können, die mit der Pathogenese der Alzheimer-Demenz in Verbindung stehen (Hu et al. 2016; Jiang et al. 2017).

Auch die Parkinson-Erkrankung wird in Zusammenhang mit gastrointestinaler Dysfunktion genannt, die mit erhöhter Durchgängigkeit der Darmbarriere einhergeht. Ebenfalls wurde eine veränderte Darmbakterienflora festgestellt. Als Konsequenz aus beiden Faktoren können Entzündungen der Darmmukosa das Gehirn erreichen und dort eine Neurodegeneration verursachen. Auch bei der Parkinson'schen Krankheit werden Pro- und Antibiotika als brauchbare therapeutische Strategie diskutiert (Perez-Pardo et al. 2017).

\subsection{Ausblick}

Die Bevölkerung Deutschlands wird in den nächsten Jahrzehnten ein immer höheres Lebensalter erreichen. Die Lebenserwartung ab Geburt wird bis zum Jahr 2060 bei Frauen um sieben Jahre auf 88,8 Lebensjahre und bei Männern um sechs Jahre auf 84,8 Jahre steigen (Statisches Bundesamt - Bevölkerung Deutschlands bis 2060 - 13. koordinierte Bevölkerungsvorrausberechnung 2015). Die Anzahl der über 60 Jährigen an der Gesamtbevölkerung in Deutschland betrug im Jahr 2012 27,1\% und wird im bis zum Jahr 2060 auf 38,2\% anstiegen. Der Altersdurchschnitt der Bevölkerung wird zunehmen (Bundeszentrale für politische Bildung - Bevölkerungsentwicklung und Altersstruktur).

Die Datenlage und das Ergebnis dieser Arbeit zeigen, dass mit höherem Lebensalter auch die Wahrscheinlichkeit für eine Infektionskrankheit steigt. Eine hypothetische Überlegung wäre somit, dass in den kommenden Jahren die Infektionsraten ebenfalls steigen und der Fokus noch stärker als bisher auf die Infektionsprävention gerichtet werden wird.

Wenn die Interaktionen und Auswirkungen der verschiedenen Komponenten der Entzündungsreaktionen und Infektionen auf psychiatrische Erkrankungen verstanden worden wären, würde sich vermutlich die medikamentöse Behandlung dieser Erkrankungen erweitern. Gerade im Bereich der Präbiotika, Probiotika, Antibiotika und entzündungshemmenden Medikamente könnte zukünftig ein großes Potential liegen (Chaudhry et al. 2012; Engen et al. 2015; Müller 2017). Die neuesten Veröffentlichungen deuten darauf hin. 
Von Interesse wäre es, weitere Bakteriensubsummierungen (andere Bakterienfamilien, ggf. Bakterienarten, oder nach grampositiv/gramnegativ sortiert) in Bezug zur Prävalenz in psychiatrischen Erkrankungen zu untersuchen. Ebenso in Bezug auf gemessene Entzündungsmediatorenspiegel im Blut des betroffenen Patienten. Wissenschaftlich wird diese Thematik immer intensiver beforscht, und es sind hier weitere intensive Studienarbeiten notwendig und zu erwarten.

\subsection{Limitationen}

Das Studiendesign der vorliegenden Arbeit als nicht-interventionelle Studie, die retrospektiv einen Standarddatensatz auswertet, bringt diverse Limitationen mit sich.

Patienten, die Erstkontakt zu der Klinik für Psychiatrie und Psychotherapie der UMG haben, könnten vorher schon in stationärer, psychiatrischer Behandlung gewesen sein. Zudem wurde nicht gezielt bei einem psychiatrischen Krankheitsbild nach einem speziellen Erreger gesucht, sondern nach den Krankheitssymptom-spezifischen Erregern.

Die Zusammenfassung der Bakterien nach biologischen Arten und die Bildung der Diagnose-Cluster sind der Stichprobengröße geschuldet. Für einen direkten Vergleich einer Bakterienart pro psychiatrische Diagnose wäre eine größere Stichprobe nötig. Ein differenzierteres Abbild möglicher Zusammenhänge von Bakterien und psychiatrischer Erkrankungen durch andere Subgruppen ließe sich mit einer größeren Stichprobe, im Idealfall durch multizentrische Datenauswertung, realisieren.

Viele der psychiatrischen Patienten haben mehr als eine psychiatrische Diagnose. Das führende Krankheitsbild wurde als Hauptdiagnose verschlüsselt, das vermutlich geringere Krankheitsbild als Nebendiagnose. Es war statistisch aufgrund der zu geringen Stichprobengröße nicht möglich, die Nebendiagnosen mit in die Auswertung zu nehmen.

Aufgrund des retrospektiven, nicht experimentellen Studiendesigns ist es nicht möglich, einen monokausalen Zusammenhang zwischen Verweildauer, Alter, Bakterienfamilie und psychiatrischem Cluster herzustellen. Assoziationen können beobachtet und beschrieben, Zusammenhänge hypothetisch interpretiert werden. 


\section{$5 \quad$ Zusammenfassung}

Ziel der vorliegenden Arbeit war es, mithilfe eines Routinedatensatzes retrospektiv Assoziationen zwischen bakteriellen Infektionen und Verweildauer, Lebensalter und psychischer Erkrankung von Patienten der Klinik für Psychiatrie und Psychosomatik der UMG zu identifizieren.

Zu diesem Zweck wurden vier übergeordnete Hypothesen formuliert, in Zusammenarbeit mit der Abteilung „Zentrales Datenmanagement“ der UMG und dem Institut der Medizinischen Mikrobiologie der UMG ein 12-Jahres-Datensatz erstellt, modifiziert und ausgewertet.

Zur Prüfung, ob das Lebensalter oder die Verweildauer Assoziationen mit bakteriellen Infektionen aufweisen, wurden ausgewählte Hauptdiagnosen nach klinischer Erscheinung und Behandlungsform sinngemäß zu den Clustern „F00-F03“, „F10“, „F20-F29“ und „F32-F33“ zusammengefasst. Zur Überprüfung, ob Assoziationen zwischen Bakterienfamilien und psychiatrischen Erkrankungen existieren, wurden die Bakterien ihrer hierarchischen Rangstufe „Familie“ zugeordnet und im Anschluss die jeweiligen Vergleichsgruppen statistisch analysiert.

Was die Verweildauer betrifft, konnte gezeigt werden, dass die Patienten, die nicht getestet worden sind, im Durchschnitt die kürzeste Verweildauer aufwiesen. Es wurde ebenfalls festgestellt, dass zwar Patienten mit positivem Keimnachweis signifikant länger in der Klinik blieben, sich diese jedoch nicht von Patienten mit negativem Keimnachweis unterschieden. Die Auswertung der Cluster ergab ein ähnliches Bild.

Es zeigte sich weiterhin, dass positiv getestete Patienten das höchste Lebensalter aufwiesen, gefolgt von negativ und nicht getesteten Patienten. Dies bestätigte vorangegangene, die Immunoseneszenz betreffende Arbeiten. Tendenziell bilden auch hier die Cluster das Ergebnis der Gesamtstichprobe ab.

Des Weiteren konnten Assoziationen zwischen Bakterienfamilien und Clustern gefunden werden. Für das Schizophrenie-Cluster „F20-F29“ war die nachgewiesene Anzahl der Familien Corynebacteriaceae und Staphylococcaceae signifikant erhöht, für das Cluster „F10“ war die Familie der Staphylococcaceae signifikant erniedrigt. Zwar konnten ebenfalls für das Cluster „F00-F03“ signifikant erhöhte Aufkommen aller vier Bakterienfamilien nachgewiesen werden, jedoch reduzierten sich diese erhöhten Aufkommen bei dem 
Einbeziehen einer altersangepassten Vergleichsgruppe auf ein nicht signifikantes Maß. Somit stellte das höhere Lebensalter mit höherer Wahrscheinlichkeit den Risikofaktor für ein verstärktes Auftreten von bakteriellen Infektionen als die demenzielle Erkrankung dar.

Die Erkenntnisse der vorliegenden Arbeit richten das Augenmerk auf die immer stärker werdende Notwendigkeit der Hygiene im Krankenhaus und auf das Alter als Risikofaktor für Infektionen. Die vorliegenden Ergebnisse helfen Assoziationen zwischen bakterieller Infektion und psychiatrischer Erkrankung besser zu verstehen. Die wachsende Anzahl von Veröffentlichungen und Erkenntnissen zu Interaktionen zwischen Krankheitserregern, den Stoffwechselprodukten von Bakterien, Entzündungen, immunologischen Reaktionen des Körpers, Botenstoffen, Entzündungsmediatoren und psychiatrischen Erkrankungen zeigt, dass es sich hierbei um äußerst relevante Fragestellungen aktueller medizinischer Forschung im Bereich der psychiatrischen Erkrankungen handelt. Diese äußerst komplexen und vielschichtigen, häufig sogar bidirektionalen Verbindungen gilt es weiterhin zu erforschen und zu verstehen, um in Zukunft unter Umständen sowohl prophylaktisch als auch medikamentös neue Wege einzuschlagen und Patienten mit einer psychiatrischen Erkrankung besser kurieren zu können. 


\section{$6 \quad$ Literaturverzeichnis}

\subsection{Literatur}

Abrahao AL, Focaccia R, Gattaz WF (2005): Childhood meningitis increases the risk for adult schizophrenia. World J Biol Psychiatry 6 Suppl 2, 44-48

Arefian H, Hagel S, Heublein S, Rissner F, Scherag A, Brunkhorst FM, Baldessarini RJ, Hartmann M (2016): Extra length of stay and costs because of health care-associated infections at a German university hospital. Am J Infect Control 44, 160-166

Barichello T, Generoso JS, Goularte JA, Collodel A, Pitcher MR, Simões LR, Quevedo J, DalPizzol F (2015): Does Infection-Induced Immune Activation Contribute to Dementia? Aging Dis $\underline{6}, 342-348$

Bibi F, Yasir M, Sohrab SS, Azhar EI, Al-Qahtani MH, Abuzenadah AM, Kamal MA, Naseer MI (2014): Link between chronic bacterial inflammation and Alzheimer disease. CNS Neurol Disord Drug Targets $\underline{13}, 1140-1147$

Bornand D, Toovey S, Jick SS, Meier CR (2016): The risk of new onset depression in association with influenza--A population-based observational study. Brain Behav Immun $\underline{53}$, 131-137

Caso JR, Balanzá-Martínez V, García-Bueno TP and B (2016): The Microbiota and Gut-Brain Axis: Contributions to the Immunopathogenesis of Schizophrenia. Curr Pharm Des 22, 61226133

Castle SC (2000): Clinical Relevance of Age-Related Immune Dysfunction. Clin Infect Dis $\underline{31}$, 578585

Cenit MC, Sanz Y, Codoñer-Franch P (2017): Influence of gut microbiota on neuropsychiatric disorders. World J Gastroenterol 23, 5486

Cevizci S, Celik M, Akcali A, Oyekcin DG, Sahin OO, Bakar C (2015): Seroprevalence of antiToxoplasma gondii and anti-Borrelia species antibodies in patients with schizophrenia: a case-control study from western Turkey. World J Biol Psychiatry 16, 230-236

Chaudhry IB, Hallak J, Husain N, Minhas F, Stirling J, Richardson P, Dursun S, Dunn G, Deakin B (2012): Minocycline benefits negative symptoms in early schizophrenia: a randomised double-blind placebo-controlled clinical trial in patients on standard treatment. J Psychopharmacol (Oxf) 26, 1185-1193

Chen M-H, Wei H-T, Su T-P, Li C-T, Lin W-C, Chang W-H, Chen T-J, Bai Y-M (2014): Risk of depressive disorder among patients with herpes zoster: a nationwide population-based prospective study. Psychosom Med 6ㅡ, 285-291

Chen Y, Yang F, Lu H, Wang B, Chen Y, Lei D, Wang Y, Zhu B, Li L (2011): Characterization of fecal microbial communities in patients with liver cirrhosis. Hepatology $\underline{54}, 562-572$

Chen Y-Y, Chou Y-C, Chou P (2005): Impact of nosocomial infection on cost of illness and length of stay in intensive care units. Infect Control Hosp Epidemiol 26, 281-287

Clapp M, Aurora N, Herrera L, Bhatia M, Wilen E, Wakefield S (2017): Gut microbiota's effect on mental health: The gut-brain axis. Clin Pract $\underline{7}, 987$ 
Cryan JF, Dinan TG (2012): Mind-altering microorganisms: the impact of the gut microbiota on brain and behaviour. Nat Rev Neurosci $\underline{13}, 701$

Dalman C, Allebeck P, Gunnell D, Harrison G, Kristensson K, Lewis G, Lofving S, Rasmussen F, Wicks S, Karlsson H (2008): Infections in the CNS during childhood and the risk of subsequent psychotic illness: a cohort study of more than one million Swedish subjects. Am J Psychiatry 165, 59-65

Dantzer R, O’Connor JC, Freund GG, Johnson RW, Kelley KW (2008): From inflammation to sickness and depression: when the immune system subjugates the brain. Nat Rev Neurosci $\underline{9}, 46-56$

Eckmann C, Wasserman M, Latif F, Roberts G, Beriot-Mathiot A (2013): Increased hospital length of stay attributable to Clostridium difficile infection in patients with four co-morbidities: an analysis of hospital episode statistics in four European countries. Eur J Health Econ $\underline{14}$, 835-846

Eikelenboom P, Hoozemans JJ, Veerhuis R, van Exel E, Rozemuller AJ, van Gool WA (2012): Whether, when and how chronic inflammation increases the risk of developing late-onset Alzheimer's disease. Alzheimers Res Ther $\underline{4}, 15$

Engen PA, Green SJ, Voigt RM, Forsyth CB, Keshavarzian A (2015): The Gastrointestinal Microbiome: Alcohol Effects on the Composition of Intestinal Microbiota. Alcohol Res Curr Rev $\underline{37}, 223$

Evrensel A, Ceylan ME (2015): The Gut-Brain Axis: The Missing Link in Depression. Clin Psychopharmacol Neurosci $\underline{13}, 239$

Ewig S, Birkner N, Strauss R, Schaefer E, Pauletzki J, Bischoff H, Schraeder P, Welte T, Hoeffken G (2009): New perspectives on community-acquired pneumonia in 388406 patients. Results from a nationwide mandatory performance measurement programme in healthcare quality. Thorax $\underline{64}, 1062$

Fellerhoff B, Wank R (2011): Increased prevalence of Chlamydophila DNA in post-mortem brain frontal cortex from patients with schizophrenia. Schizophr Res 129, 191-195

Fleßa S, Hübner C (2016): „Analyse der Kosten von multiresistenten Erregern in den verschiedenen Gesundheitseinrichtungen (Krankenhaus, Reha, Pflegeheim, Arztpraxis)“ Vortrag bei dem 13. Kongress für Krankenhaushygiene der Deutschen Gesellschaft für Krankenhaushygiene (DGKH) am 10.-13. April 2016 in Berlin.

Forster AJ, Taljaard M, Oake N, Wilson K, Roth V, van Walraven C (2012): The effect of hospitalacquired infection with Clostridium difficile on length of stay in hospital. CMAJ 184, 37-42

Ginaldi L, De Martinis M, D’Ostilio A, Marini L, Loreto MF, Quaglino D (1999): Immunological changes in the elderly. Aging Milano 11, 281-286

Graves N, Weinhold D, Tong E, Birrell F, Doidge S, Ramritu P, Halton K, Lairson D, Whitby M (2007): Effect of healthcare-acquired infection on length of hospital stay and cost. Infect Control Hosp Epidemiol 28, 280-292

Hsu P-C, Groer M, Beckie T (2014): New findings: depression, suicide, and Toxoplasma gondii infection. J Am Assoc Nurse Pract 26, 629-637

Hu X, Wang T, Jin F (2016): Alzheimer's disease and gut microbiota. Sci China Life Sci $\underline{59}, 1006$ 1023 
Jiang C, Li G, Huang P, Liu Z, Zhao B (2017): The Gut Microbiota and Alzheimer's Disease. J Alzheimers Dis $\underline{58}, 1-15$

Khandaker GM, Zimbron J, Dalman C, Lewis G, Jones PB (2012): Childhood infection and adult schizophrenia: a meta-analysis of population-based studies. Schizophr Res $\underline{139}, 161-168$

Khandaker GM, Zimbron J, Lewis G, Jones PB (2013): Prenatal maternal infection, neurodevelopment and adult schizophrenia: a systematic review of population-based studies. Psychol Med $\underline{43}, 239-257$

Khandaker GM, Pearson RM, Zammit S, Lewis G, Jones PB (2014a): Association of Serum Interleukin 6 and C-Reactive Protein in Childhood With Depression and Psychosis in Young Adult Life. JAMA Psychiatry $\underline{71}, 1121-1128$

Khandaker GM, Stochl J, Zammit S, Lewis G, Jones PB (2014b): Childhood Epstein-Barr Virus infection and subsequent risk of psychotic experiences in adolescence: a population-based prospective serological study. Schizophr Res 158, 19-24

Khandaker GM, Cousins L, Deakin J, Lennox BR, Yolken R, Jones PB (2015): Inflammation and immunity in schizophrenia: implications for pathophysiology and treatment. Lancet Psychiatry $\underline{2}, 258-270$

Koponen H, Rantakallio P, Veijola J, Jones P, Jokelainen J, Isohanni M (2004): Childhood central nervous system infections and risk for schizophrenia. Eur Arch Psychiatry Clin Neurosci $\underline{254}, 9-13$

Krause D, Matz J, Weidinger E, Wagner J, Wildenauer A, Obermeier M, Riedel M, Müller N (2010): The association of infectious agents and schizophrenia. World J Biol Psychiatry 11 , 739-743

Kudlow P, Cha DS, Carvalho AF, McIntyre RS (2016): Nitric Oxide and Major Depressive Disorder: Pathophysiology and Treatment Implications. Curr Mol Med 16, 206-215

Lasseter G, Charlett A, Lewis D, Donald I, Howell-Jones R, McNulty C (2010): Staphylococcus aureus carriage in care homes: identification of risk factors, including the role of dementia. Epidemiol Infect 138, 686

Leclercq S, Matamoros S, Cani PD, Neyrinck AM, Jamar F, Stärkel P, Windey K, Tremaroli V, Bäckhed F, Verbeke K, et al. (2014): Intestinal permeability, gut-bacterial dysbiosis, and behavioral markers of alcohol-dependence severity. Proc Natl Acad Sci U S A $\underline{111}$, E4485

Lewis MJ (2011): Alcohol and nutrient intake: Mechanisms of reinforcement and dependence. Physiol Behav 104, 138-142

Lima-Ojeda JM, Rupprecht R, Baghai TC (2017): "I Am I and My Bacterial Circumstances": Linking Gut Microbiome, Neurodevelopment, and Depression. Front Psychiatry $\underline{8}, 153$

Lövheim H, Gilthorpe J, Johansson A, Eriksson S, Hallmans G, Elgh F (2015): Herpes simplex infection and the risk of Alzheimer's disease: A nested case-control study. Alzheimers Dement $11,587-592$

Macedo-Viñas M, De Angelis G, Rohner P, Safran E, Stewardson A, Fankhauser C, Schrenzel J, Pittet D, Harbarth S (2013): Burden of meticillin-resistant Staphylococcus aureus infections at a Swiss University hospital: excess length of stay and costs. J Hosp Infect $\underline{84}, 132-137$

Maheshwari P, Eslick GD (2015): Bacterial infection and Alzheimer's disease: a meta-analysis. J Alzheimers Dis $\underline{43}$, 957-966 
Malyuk RE, Wong C, Buree B, Kang A, Kang N (2012): The interplay of infections, function and length of stay (LOS) in newly admitted geriatric psychiatry patients. Arch Gerontol Geriatr $\underline{54}, 251-255$

Miklossy J (2011): Alzheimer's disease - a neurospirochetosis. Analysis of the evidence following Koch's and Hill's criteria. J Neuroinflammation $\underline{8}, 90$

Monge D, Millán I, González-Escalada A, Asensio A (2013): The effect of Clostridium difficile infection on length of hospital stay. A cohort study. Enfermedades Infecc Microbiol Clínica $\underline{31}, 660-664$

Müller N (2017): Immunological aspects of the treatment of depression and schizophrenia. Dialogues Clin Neurosci 19, 55

Murphy CR, Avery TR, Dubberke ER, Huang SS (2012): Frequent Hospital Readmissions for Clostridium difficile Infection and the Impact on Estimates of Hospital-Associated C. difficile Burden. Infect Control Hosp Epidemiol Off J Soc Hosp Epidemiol Am $\underline{33}, 20$

Mutlu EA, Gillevet PM, Rangwala H, Sikaroodi M, Naqvi A, Engen PA, Kwasny M, Lau CK, Keshavarzian A (2012): Colonic microbiome is altered in alcoholism. Am J Physiol Gastrointest Liver Physiol $\underline{\text { 302, G966 }}$

Nanni MG, Caruso R, Mitchell AJ, Meggiolaro E, Grassi L (2015): Depression in HIV infected patients: a review. Curr Psychiatry Rep 17, 530

Nemani K, Hosseini Ghomi R, McCormick B, Fan X (2015): Schizophrenia and the gut-brain axis. Prog Neuropsychopharmacol Biol Psychiatry $\underline{56}, 155-160$

Olsen I, Singhrao SK (2015): Can oral infection be a risk factor for Alzheimer's disease? J Oral Microbiol ㄱ, 29143

Orsi GB, Di Stefano L, Noah N (2002): Hospital-acquired, laboratory-confirmed bloodstream infection: increased hospital stay and direct costs. Infect Control Hosp Epidemiol 23, 190197

Parte AC (2014): LPSN - list of prokaryotic names with standing in nomenclature. Nucleic Acids Res 42 , D613-D616

Perez-Pardo P, Hartog M, Garssen J, Kraneveld AD (2017): Microbes Tickling Your Tummy: the Importance of the Gut-Brain Axis in Parkinson's Disease. Curr Behav Neurosci Rep $\underline{4}$, $361-368$

Popp J, Oikonomidi A, Tautvydaite D, Dayon L, Bacher M, Migliavacca E, Henry H, Kirkland R, Severin I, Wojcik J, Bowman GL (2017): Markers of neuroinflammation associated with Alzheimer's disease pathology in older adults. Brain Behav Immun 62, 203-211

Rantakallio P, Jones P, Moring J, Von Wendt L (1997): Association between central nervous system infections during childhood and adult onset schizophrenia and other psychoses: a 28-year follow-up. Int J Epidemiol 26, 837-843

Rodrigues MA, Brady RR, Rodrigues J, Graham C, Gibb AP (2010): Clostridium difficile infection in general surgery patients; identification of high-risk populations. Int J Surg $\underline{8}, 368-372$

Rosenthal VD, Guzman S, Orellano PW (2003): Nosocomial infections in medical-surgical intensive care units in Argentina: Attributable mortality and length of stay. Am J Infect Control $\underline{31}, 291-295$ 
Ruscher C (2014): Empfehlungen zur Prävention und Kontrolle von Methicillin-resistenten Staphylococcus aureus-Stämmen (MRSA) in medizinischen und pflegerischen Einrichtungen: Empfehlung der Kommission für Krankenhaushygiene und Infektionsprävention (KRINKO) beim Robert Koch-Institut. Bundesgesundheitsblatt Gesundheitsforschung - Gesundheitsschutz 푸, 695-732

Salgado CD, Farr BM (2006): What Proportion of Hospital Patients Colonized With MethicillinResistant Staphylococcus aureus Are Identified by Clinical Microbiological Cultures? Infect Control Amp Hosp Epidemiol 27, 116-121

Sender-Janeczek A, Ziętek M (2016): The Distribution of Porphyromonas gingivalis, Tannerella forsythia, Treponema denticola and Aggregatibacter actinomycetemcomitans in Patients with Alcoholic Disease: A Pilot Study. Adv Clin Exp Med 25, 243-248

Serafini G, Montebovi F, Lamis DA, Erbuto D, Girardi P, Amore M, Pompili M (2015): Associations among depression, suicidal behavior, and quality of life in patients with human immunodeficiency virus. World J Virol $\underline{4}, 303-312$

Shen T-C, Wang C-Y, Lin C-L, Liao W-C, Chen C-H, Tu C-Y, Hsia T-C, Shih C-M, Hsu W-H, Chung C-J (2014): People with tuberculosis are associated with a subsequent risk of depression. Eur J Intern Med 25, 936-940

Shima K, Kuhlenbäumer G, Rupp J (2010): Chlamydia pneumoniae infection and Alzheimer's disease: a connection to remember? Med Microbiol Immunol (Berl) 199, 283-289

Steel AJ, Eslick GD (2015): Herpes Viruses Increase the Risk of Alzheimer's Disease: A MetaAnalysis. J Alzheimers Dis 47, 351-364

Subramaniapillai M, Carmona NE, Rong C, McIntyre RS (2017): Inflammation: opportunities for treatment stratification among individuals diagnosed with mood disorders. Dialogues Clin Neurosci $\underline{19}, 27$

Suvisaari J, Haukka J, Tanskanen A, Hovi T, Lönnqvist J (1999): Association Between Prenatal Exposure to Poliovirus Infection and Adult Schizophrenia. Am J Psychiatry 156, 11001102

Timary P de, Leclercq S, Stärkel P, Delzenne N (2015): A dysbiotic subpopulation of alcoholdependent subjects. Gut Microbes $\underline{6}, 388$

Torrey EF (1988): Stalking the Schizovirus. Schizophr Bull 14, 223-229

Torrey EF, Bartko JJ, Yolken RH (2012): Toxoplasma gondii and other risk factors for schizophrenia: an update. Schizophr Bull $\underline{38}, 642-647$

Tseng C-H, Huang W-S, Muo C-H, Chang Y-J, Kao C-H (2014): Increased depression risk among patients with chronic osteomyelitis. J Psychosom Res $\underline{77}$, 535-540

Tyring S, Gottlieb A, Papp K, Gordon K, Leonardi C, Wang A, Lalla D, Woolley M, Jahreis A, Zitnik R, et al. (2006): Etanercept and clinical outcomes, fatigue, and depression in psoriasis: double-blind placebo-controlled randomised phase III trial. Lancet 367, 29-35

Vonberg R-P, Reichardt C, Behnke M, Schwab F, Zindler S, Gastmeier P (2008): Costs of nosocomial Clostridium difficile-associated diarrhoea. J Hosp Infect $\underline{70}$, 15-20

Vos MC, Behrendt MD, Melles DC, Mollema FPN, Groot W de, Parlevliet G, Ott A, Horst-Kreft D, Belkum A van, Verbrugh HA (2009): 5 Years of Experience Implementing a Methicillin-Resistant Staphylococcus aureus Search and Destroy Policy at the Largest 
University Medical Center in the Netherlands. Infect Control Amp Hosp Epidemiol 30, 977-984

Vrijens F, Hulstaert F, Devriese S, van de Sande S (2012): Hospital-acquired infections in Belgian acute-care hospitals: an estimation of their global impact on mortality, length of stay and healthcare costs. Epidemiol Infect 140, 126-136

Wang X, Zhang L, Lei Y, Liu X, Zhou X, Liu Y, Wang M, Yang L, Zhang L, Fan S, Xie P (2014): Meta-analysis of infectious agents and depression. Sci Rep 4, 4530

Watson, Kucala T, Tilleskjor C, Jacobs L (1984): SChizophrenic birth seasonality in relation to the incidence of infectious diseases and temperature extremes. Arch Gen Psychiatry $\underline{41}, 85-90$

Weiskopf D, Weinberger B, Grubeck-Loebenstein B (2009): The aging of the immune system. Transpl Int 22, 1041-1050

Wu Y-Y, Hsu J-L, Wang H-C, Wu S-J, Hong C-J, Cheng IH-J (2015): Alterations of the Neuroinflammatory Markers IL-6 and TRAIL in Alzheimer's Disease. Dement Geriatr Cogn Disord Extra $\underline{5}, 424-434$

Xu Y, Wang Q, Liu Y, Cui R, Zhao Y (2016): Is Helicobacter pylori infection a critical risk factor for vascular dementia? Int J Neurosci 126, 899-903

Yolken RH, Torrey EF (2008): Are some cases of psychosis caused by microbial agents? A review of the evidence. Mol Psychiatry $\underline{13}$, 470-479

Yolken RH, Dickerson FB, Fuller Torrey E (2009): Toxoplasma and schizophrenia. Parasite Immunol $\underline{31}, 706-715$

Young JJ, Bruno D, Pomara N (2014): A review of the relationship between proinflammatory cytokines and major depressive disorder. J Affect Disord $\underline{169}, 15-20$

Zhan X, Stamova B, Jin L-W, DeCarli C, Phinney B, Sharp FR (2016): Gram-negative bacterial molecules associate with Alzheimer disease pathology. Neurology 구, 2324

\subsection{Internetquellen}

Aerzteblatt.de - Infektion und Psychose. https://www.aerzteblatt.de/archiv/60381/Infektion-undPsychose; Zugriff am 10.01.2018

Aerztezeitung.de - Hygiene: Wie Mikroben ein neues Krankenhaus besiedeln. https://www.aerztezeitung.de/praxis_wirtschaft/qualitaetsmanagement/article/936787/h ygiene-mikroben-neues-krankenhaus-besiedeln.html; Zugriff am 20.10.2017

Allgemeinarzt-online.de - Infektionen im Alter - Was macht sie so gefährlich? http://www.allgemeinarzt-online.de/a/was-macht-sie-so-gefaehrlich-1693953; Zugriff am 26.07.2017

Alzheimer-Europe.org - Prevalence of dementia in Europe. http://www.alzheimereurope.org/EN/Research/European-Collaboration-on-Dementia/Prevalence-ofdementia/Prevalence-of-dementia-in-Europe; Zugriff am 13.09.2017

Bremer Krankenhausspiegel - Verweildauer je Erkrankung 2016. https://www.bremerkrankenhausspiegel.de/qualitaetsergebnisse-a-z/psychiatrischebehandlungen/verweildauer-je-erkrankung/; Zugriff am 09.11.2017 
Bundespsychotherapeutenkammer - Schizophrenie - Ursachen, Symptome, Diagnostik, Therapie. http://www.bptk.de/patienten/psychische-krankheiten/schizophrenie.html; Zugriff am 10.01.2018

Bundespsychotherapeutenkammer - Studie zur stationären Versorgung psychisch kranker Menschen 2014. http://www.bptk.de/uploads/media/20140626_BPtK-

Studie_zur_stationaeren_Versorgung_psychisch_kranker_Menschen.pdf; Zugriff am 09.11.2017

Bundeszentrale für politische Bildung - Bevölkerungsentwicklung und Altersstruktur. http://www.bpb.de/nachschlagen/zahlen-und-fakten/soziale-situation-indeutschland/61541/altersstruktur; Zugriff am 07.12.2017

European Centre for Desease Prevention and Control - Annual epidemiological report on communicable diseases in Europe 2008.

https://ecdc.europa.eu/sites/portal/files/media/en/publications/Publications/0812_SUR _Annual_Epidemiological_Report_2008.pdf; Zugriff am 26.11.2017

Gesundheitsberichterstattung des Bundes - Diagnosedaten der Krankenhäuser. http:/ /www.gbebund.de/oowa921-install/servlet/oowa/aw92/WS0100/_XWD_FORMPROC; Zugriff am 21.12.2017

Gesundheitsberichterstattung des Bundes - Durchschnittliche Verweildauer ausgewählter Diagnosen 2017. http://www.gbe-bund.de/oowa921-

install/servlet/oowa/aw92/dboowasys921.xwdevkit/xwd_init?gbe.isgbetol/xs_start_neu/ \&p_aid=i\&p_aid $=8428113 \&$ nummer $=815 \&$ p_sprache $=$ D\&p_indsp $=-\& p \_a i d=42728310$; Zugriff am 09.11.2017

Gesundheitsberichterstattung des Bundes - Themenheft 8 „Nosokomiale Infektionen“. http://edoc.rki.de/docviews/abstract.php?id=183; Zugriff am 21.12.2017

ICD-10-GM-2017 - F00-F09 Organische, einschließlich symptomatischer psychischer Störungen. http://www.icd-code.de/icd/code/F00-F09.html; Zugriff am 27.11.2017

MRSA-net.nl - Was bedeutet search-and-destroy Politik? https://www.mrsanet.nl/de/oeffentlichkeit/mrsa-allgemein/definitionen/310-was-bedeutet-search-anddestroy-politik; Zugriff am 26.10.2017

Nationales Referenzzentrum - Abschlussbericht der Deutschen Nationalen Punkt-Prävalenzstudie zu nosokomialen Infektionen und Antibiotika-Anwendung 2017. http://www.nrzhygiene.de/fileadmin/nrz/download/pps2016/PPS_2016_Abschlussbericht_20.07.2017.p df; Zugriff am 24.10.2017

Neurologen-und-Psychiater-im-Netz.org - Schizophrenie: Ursachen. https://www.neurologen-undpsychiater-im-netz.org/psychiatrie-psychosomatik-psychotherapie/stoerungenerkrankungen/schizophrenie-und-schizophrene-psychosen/ursachen/; Zugriff am 10.01.2018

Psychiatrie-Entgelt.de - PEPP-System. http://www.psychiatrie-entgelt.de/pepp-system/; Zugriff am 15.01.2018

Robert Koch-Institut - Antibiotikaresistenz und Nosokomiale Infektionen (FAQ). https://www.rki.de/DE/Content/Infekt/Antibiotikaresistenz/FAQ/FAQ_node.html; Zugriff am 15.01.2018

Robert Koch-Institut - Empfehlungen der Kommission für Krankenhaushygiene und Infektionsprävention. 
http://www.rki.de/DE/Content/Infekt/Krankenhaushygiene/Kommission/kommission _node.html; Zugriff am 26.10.2017

Robert Koch-Institut - Medizinische Wirksamkeit und Kosten-Effektivität von Präventions- und Kontrollmaßnahmen gegen Methicillin-resistente Staphylococcus aureus (MRSA)Infektionen im Krankenhaus.

https://www.rki.de/DE/Content/Infekt/Krankenhaushygiene/Erreger_ausgewaehlt/MR SA/MRSA_HTABericht.pdf?_blob=publicationFile; Zugriff am 20.10.2017

Spitzenverband Bund der Krankenkassen - PEPP. https://www.gkvspitzenverband.de/krankenversicherung/krankenhaeuser/psychiatrie/pepp_entgeltsystem _2016/pepp_entgeltsystem_4.jsp; Zugriff am 21.04.2016

Statisches Bundesamt - Bevölkerung Deutschlands bis 2060 - 13. koordinierte Bevölkerungsvorrausberechnung. https://www.destatis.de/DE/PresseService/Presse/Pressekonferenzen/2015/bevoelkeru ng/Pressebroschuere_Bevoelk2060.pdf?__blob=publicationFile; Zugriff am 07.12.2017

Statistisches Bundesamt - Die 10 häufigsten psychischen und Verhaltensstörungen. https://www.destatis.de/DE/ZahlenFakten/GesellschaftStaat/Gesundheit/Krankenhaeu ser/Tabellen/PsychischeVerhaltensstoerungen.html; Zugriff am 14.09.2017

Uni-Muenster.de - Niederlande als Vorbild im Kampf gegen Krankenhauskeime. https://www.unimuenster.de/NiederlandeNet/aktuelles/archiv/2015/maerz/0324krankenhauskeime.html; Zugriff am 26.10.2017 


\section{Danksagung}

Ich möchte mich bei den Personen bedanken, die maßgeblich am Gelingen der Dissertation beteiligt gewesen sind.

Zuerst möchte ich Herrn PD Dr. Claus Wolff-Menzler danken. Die kontinuierliche Unterstützung, die regelmäßigen Telefonate, die konstruktive Kritik und der freundschaftliche Umgangston waren die Stützpfeiler dieser Dissertation.

Ein ganz besonderer Dank geht an Herrn Dr. Michael Belz. Mit seinen unzähligen Ratschlägen, fachkundigen Hinweisen, unfassbaren Statistikkenntnissen, SPSS-Fähigkeiten und klugen Kommentaren hat er mich ein ums andere Mal wieder in die Spur gebracht. Vielen Dank für die zahllosen Telefonate und Gespräche zu den teilweise unmöglichsten Uhrzeiten.

Mein Dank gilt ebenfalls Herrn Prof. Dr. Jens Wiltfang für meine Annahme als Promovend und Herrn PD Dr. Bernhard Kis für die zeitweilige Übernahme der Betreuung. Mein Dank gilt auch Herrn Christian Fritsch von der Abteilung des Zentralen Datenmanagements der UMG und Herrn Dr. Oliver Bader vom Institut für Medizinische Mikrobiologie der UMG für die freundliche Unterstützung bei der Erstellung der Datenbank. 